\title{
VII. Anhang
}

\section{Die Führungselite der CSU}

Die Mitglieder des geschäftsführenden Landesvorstands der CSU 1946-1955

\begin{tabular}{|c|c|c|}
\hline Name & Funktion & Zeitraum \\
\hline Brunner, Josef & Generalsekretär & $1952-1954$ \\
\hline Eberhard, Rudolf & stellv. Landesvorsitzender & 1954-1964 \\
\hline \multirow[t]{3}{*}{ Ehard, Hans } & Landesvorsitzender & $1949-1955$ \\
\hline & weiteres Mitglied & $1955-1963$ \\
\hline & kooptiertes Mitglied & $1963-1965$ \\
\hline Elsen, Franz & Landesschatzmeister & 1949-1952 \\
\hline \multirow[t]{5}{*}{ Feury, Freiherr Otto von } & 1. Landesschriftführer & $1952-1961$ \\
\hline & & $1963-1968$ \\
\hline & & seit 1970 \\
\hline & 2. Landesschriftführer & $1961-1963$ \\
\hline & & $1968-1970$ \\
\hline Geiger, Hugo & 1. Landesschatzmeister & $1952-1959$ \\
\hline Grasmann, Max & Landesschatzmeister & $1946-1948$ \\
\hline \multirow[t]{2}{*}{ Haußleiter, August } & weiteres Mitglied & $1946-1948$ \\
\hline & stellv. Landesvorsitzender & $1948 / 1949$ \\
\hline \multirow[t]{4}{*}{ Horlacher, Michael } & weiteres Mitglied & $1946-1948$ \\
\hline & & 1952-1955 \\
\hline & stellv. Landesvorsitzender & $1948-1952$ \\
\hline & kooptiertes Mitglied & $1955-1957$ \\
\hline \multirow[t]{2}{*}{ Hundhammer, Alois } & weiteres Mitglied & $1952-1955$ \\
\hline & kooptiertes Mitglied & $1955-1960$ \\
\hline Kreble, Heinrich & weiteres Mitglied & $1952-1955$ \\
\hline Kreußel, Alfons & weiteres Mitglied & $1952-1963$ \\
\hline Lechmann, Heinz & $\begin{array}{l}\text { Landesgeschäftsführer } \\
\text { bzw. Generalsekretär }\end{array}$ & 1954 \\
\hline \multirow[t]{2}{*}{ Liedig, Franz } & weiteres Mitglied & $1947-1949$ \\
\hline & Landesschatzmeister & 1948 \\
\hline \multirow[t]{2}{*}{ Mayr, Karl Sigmund } & stellv. Landesvorsitzender & $1950-1953$ \\
\hline & 2. Landesschatzmeister & $1955-1957$ \\
\hline Meixner, Georg & weiteres Mitglied & $1951-1958$ \\
\hline Meyer-Spreckels, Elisabeth & weiteres Mitglied & $1946-1949$ \\
\hline \multirow[t]{2}{*}{ Müller, Josef } & Landesvorsitzender & $1946-1949$ \\
\hline & kooptiertes Mitglied & $1963-1965$ \\
\hline Mubler, Emil & weiteres Mitglied & $1946-1963$ \\
\hline \multirow[t]{3}{*}{ Schachtner, Richard } & Landesschatzmeister & 1949 \\
\hline & 2. Landesschatzmeister & 1959-1961 \\
\hline & 1. Landesschriftführer & 1961 \\
\hline Schleip, Eva & weiteres Mitglied & 1949-1951 \\
\hline Schmidt, Wilhelm A. & weiteres Mitglied & $1952-1955$ \\
\hline Sedlmayr, Lorenz & weiteres Mitglied & $1946-1950$ \\
\hline
\end{tabular}


Strauß, Franz Josef

weiteres Mitglied

1946-1948

Generalsekretär

1948-1952

stellv. Landesvorsitzender

1952-1961

Landesvorsitzender

1961-1988

Die Vorsitzenden der Bezirksverbände der CSU 1946-1955

\begin{tabular}{|c|c|c|}
\hline Name & Bezirksverband & Zeitraum \\
\hline $\begin{array}{l}\text { Hundhammer, Alois } \\
\text { Schäffer, Fritz }\end{array}$ & Oberbayern & $\begin{array}{l}1946-1948 \\
1948-1970 \\
1948\end{array}$ \\
\hline $\begin{array}{l}\text { Schäffer, Fritz } \\
\text { Kreble, Heinrich } \\
\text { Geiger, Hugo } \\
\text { Heubl, Franz } \\
\text { Müller, Josef }\end{array}$ & München & $\begin{array}{l}1946 \\
1946-1949 \\
1949 / 1950 \\
1950 / 1951 \\
1951-1960\end{array}$ \\
\hline $\begin{array}{l}\text { Kübler, Konrad } \\
\text { Haniel-Niethammer, Fritz von }\end{array}$ & Niederbayern & $\begin{array}{l}1946-1949 \\
1949-1965\end{array}$ \\
\hline $\begin{array}{l}\text { Ortloph, Klement } \\
\text { Rucker, Eugen } \\
\text { Gamperl, Georg } \\
\text { Dengler, Fritz } \\
\text { Herrmann, Hans }\end{array}$ & Oberpfalz & $\begin{array}{l}1946 \\
1946 / 1947 \\
1947-1949 \\
1949 / 1950 \\
1950-1955\end{array}$ \\
\hline $\begin{array}{l}\text { Rindt, Eugen } \\
\text { Fischer, Josef } \\
\text { Kaifer, Albert } \\
\text { Höhenberger, Fritz }\end{array}$ & Schwaben & $\begin{array}{l}1946 / 1947 \\
1947-1949 \\
1949-1952 \\
1952-1955\end{array}$ \\
\hline $\begin{array}{l}\text { Rindt, Eugen } \\
\text { Fischer, Josef }\end{array}$ & Augsburg & $\begin{array}{l}1946 / 1947 \\
1947-1965\end{array}$ \\
\hline $\begin{array}{l}\text { Mayr, Karl Sigmund } \\
\text { Küßwetter, Hans }\end{array}$ & Mittelfranken & $\begin{array}{l}1946-1952 \\
1952-1965\end{array}$ \\
\hline $\begin{array}{l}\text { Deggendorfer, Emanuel } \\
\text { Euerl, Alfred } \\
\text { Hassel, Hans } \\
\text { Schäfer, Karl }\end{array}$ & Nürnberg-Fürth & $\begin{array}{l}1946 \\
1946-1952 \\
1952 \\
1952-1977\end{array}$ \\
\hline Barth, Georg & Oberfranken & $\begin{array}{l}1946 \\
1947-1949\end{array}$ \\
\hline $\begin{array}{l}\text { Kroll, Gerbard } \\
\text { Hergenröder, Anton }\end{array}$ & & $\begin{array}{l}1946 / 1947 \\
1949-1976\end{array}$ \\
\hline $\begin{array}{l}\text { Dürr, Kaspar } \\
\text { Sauer, Franz Ludwig } \\
\text { Greib, Karl }\end{array}$ & Unterfranken & $\begin{array}{l}1946 \\
1946-1949 \\
1949-1957\end{array}$ \\
\hline
\end{tabular}

Die Mitglieder des Vorstands der Landtagsfraktion der CSU 1946-1954

\begin{tabular}{lll}
\hline Name & Funktion & Zeitraum \\
\hline Bachmann, Georg & Mitglied des Fraktionsvorstands & $1949-1958$ \\
Donsberger, Josef & Mitglied des Fraktionsvorstands & $1946-1950$ \\
Eberhard, Rudolf & stellvertretender Fraktionsvorsitzender & $1951-1957$ \\
Gröber, Franziska & Mitglied des Fraktionsvorstands & 1950 \\
Haußleiter, August & Mitglied des Fraktionsvorstands & $1946 / 1947$ \\
& & $1948 / 1949$
\end{tabular}


Hundhammer, Alois

Junker, Heinrich

Kurz, Andreas

Lang, Andreas

Meixner, Georg

Michel, Franz

Prittwitz und Gaffron,

Friedrich Wilhelm von

Probst, Maria

Rindt, Eugen

Schmid, Karl

Sübler, Adam

Weigel, Wenzel

Zebner, Zita

Zillibiller, Max
Fraktionsvorsitzender

Mitglied des Fraktionsvorstands

Mitglied des Fraktionsvorstands

Mitglied des Fraktionsvorstands

Fraktionsvorsitzender

Mitglied des Fraktionsvorstands

stellvertretender Fraktionsvorsitzender

Mitglied des Fraktionsvorstands stellvertretender Fraktionsvorsitzender Mitglied des Fraktionsvorstands Mitglied des Fraktionsvorstands Mitglied des Fraktionsvorstands Mitglied des Fraktionsvorstands Mitglied des Fraktionsvorstands
1946-1951

1950-1954

1950-1958

1946-1948

1951-1958

$1948-1950$

$1950 / 1951$

1946-1949

1946-1950

1946-1950

1946-1949

1950-1954

1950-1958

1950-1958

Die Mitglieder der Landtagsfraktion der CSU 1946-1954

\begin{tabular}{|c|c|c|}
\hline Name & Zeitraum & Wahlkreis \\
\hline Allwein, Max & $\begin{array}{l}1946-1949 \\
1949 / 1950 \text { (frktls.) }\end{array}$ & Obb. \\
\hline Ammann, Erwin & $1946-1950$ & Ufr. \\
\hline Anetseder, Josef & $\begin{array}{l}1946-1948 \\
(† 12.12 .1948)\end{array}$ & Ndb./Opf. \\
\hline Ankermüller, Willi & $1946-1966$ & Ufr. \\
\hline Bachmann, Georg & $1946-1962$ & $\begin{array}{l}\text { 1946-1950 Ofr./Mfr., } \\
\text { seit } 1950 \mathrm{Mfr} .\end{array}$ \\
\hline Bachmann, Wilhelm & $1950-1966$ & Mfr. \\
\hline Baumeister, Leonhard & $1946-1954$ & Schw. \\
\hline \multirow[t]{2}{*}{ Baumgartner, Joseph } & 1946-1948 & Schw. \\
\hline & $\begin{array}{l}1948-1950 \text { (frktls.) } \\
1950-1962 \text { (BP) }\end{array}$ & $\begin{array}{l}\text { 1950-1954 Obb. } \\
\text { 1954-1962 Ndb. }\end{array}$ \\
\hline Baur, Leonhard & $1950-1954$ & Schw. \\
\hline Berger, Ludwig & $1946-1950$ & Ndb./Opf. \\
\hline Berger, Rupert & $\begin{array}{l}1946-1950 \\
1954-1958 \\
(† 9.2 .1958)\end{array}$ & Obb. \\
\hline Bickleder, Karl & $\begin{array}{l}1946-1950 \\
1954-1958 \\
(† 4.2 .1958)\end{array}$ & $\begin{array}{l}\text { Ndb./Opf. } \\
\text { Ndb. }\end{array}$ \\
\hline Brandner, Johann & $1946-1950$ & Ndb./Opf. \\
\hline Braun, Josef & $\begin{array}{l}1946-1950 \\
1954-1966\end{array}$ & $\begin{array}{l}\text { Ndb./Opf. } \\
\text { Ndb. }\end{array}$ \\
\hline Brumberger, Josef & $\begin{array}{l}1950 \\
\text { (1. 1. } 1950 \text { Nachr. f. A. Sühler) }\end{array}$ & Ofr./Mfr. \\
\hline Bübner, Eustach & $\begin{array}{l}1946-1949 \\
(† 28.6 .1949)\end{array}$ & Ufr. \\
\hline Centmayer, Hans & $1946-1950$ & Ofr./Mfr. \\
\hline Deku, Maria & $\begin{array}{l}\text { 1946-1948 } \\
\text { (Verz. 29. 2. 1948) }\end{array}$ & Ndb./Opf. \\
\hline Demmelmeier, Hans & $\begin{array}{l}\text { 1950-1953 } \\
\text { (Verz. 23.10.1953) }\end{array}$ & Obb. \\
\hline Dietlein, Johann & $1946-1950$ & Ufr. \\
\hline
\end{tabular}




$\begin{array}{ll}\text { Donsberger, Josef } & 1946-1958 \\ \text { Eberhard, Rudolf } & 1950-1974 \\ \text { Eder, Hans } & 1946-1954 \\ & \\ \text { Egger, Alois } & 1946-1950 \\ \text { Ehard, Hans } & 1946-1966 \\ & \\ \text { Eichelbrönner, Gottfried } & 1946-1962 \\ \text { Elsen, Franz } & 1950-1966 \\ \text { Emmert, Heinrich } & 1946-1950 \\ \text { Englert, Rudolf } & 1949 / 1950 \\ & (5.7 .1949 \text { Nachr. f. A. Zeisslein) } \\ \text { Euerl, Alfred } & 1946-1966 \\ & \\ \text { Faltermeier, Josef } & 1946-1950 \\ \text { Feury, Freiherr Otto von } & 1950-1978 \\ \text { Fischer, Josef } & 1946-1950 \\ \text { Fischer, Karl } & 1950-1954 \\ & 1958-1962 \\ \text { Franckenstein, Freiherr } & 1950-1965 \\ \text { Georg von und zu } & (\dagger 27.3 .1965) \\ \text { Freundl, Otto } & 1946-1970 \\ & \\ \text { Gaßner, Wilhelm } & 1952-1959\end{array}$

(30.11. 1952 Nachw. f. G. Gromer; + 14.6. 1959)
Gehring, Georg

Geiger, Hugo

Göttler, Wilhelm

Greib, Karl

Gröber, Franziska

Gromer, Georg

Haaf, Karl

Hagn, Hans

Haisch, Andreas

1946-1950

1950-1953

(Verz. 27. 10. 1953)

1950-1953

(† 22. 2. 1953)

1950-1962

1946-1950

1946-1952

(† 23. 10. 1952)

$1949 / 1950$

(18. 9. 1949 Nachr. f. M. Probst)

1946-1949

$(† 7.10 .1949)$

1951-1969

(17. 6. 1951 Nachw. f. G. Stang;

+ 4. 9. 1969)

Haniel-Niethammer, Fritz von 1950-1954

Hauck, Georg

Hangg, Pius

Haußleiter, August

Heigl, Ludwig

Held, Walter

Helmerich, Michael
1946-1950

1946-1950

1950 (frktls.)

1946-1949

1949/1950 (frktls.)

1950-1954 (BHE/DG)

1986/1987 (Die Grünen)

(Verz. 25.6. 1987)

1950-1954

1946-1950

1950-1966

(9. 2. 1950 Nachr. f. M. Horlacher)
1946-1950 Ofr./Mfr., seit $1950 \mathrm{Mfr}$.

Ofr.

1946-1950 Ndb./Opf., seit 1950 Opf.

$\mathrm{Ndb}$./Opf.

1946-1950 Ofr./Mfr., seit 1950 Ofr.

Ufr.

Ufr.

Ofr./Mfr.

Ufr.

1946-1950 Ofr./Mfr., seit $1950 \mathrm{Mfr}$.

$\mathrm{Ndb}$.Opf.

Obb.

Schw.

Opf.

Mfr.

1946-1950 Ndb./Opf., seit 1950 Opf.

Schw.

Ufr.

$\mathrm{Ndb}$.

Schw.

Ufr.

Schw.

Schw.

Ufr.

Obb.

Schw.

Ndb.

Ufr.

Schw.

Ofr./Mfr.

Ofr.

Obb.

$\mathrm{Ndb}$.

Ndb./Opf.

1950 Ndb./Opf., seit $1950 \mathrm{Ndb}$. 


\begin{tabular}{|c|c|c|}
\hline Hettrich, Philipp & $1950-1966$ & Ufr. \\
\hline Heubl, Franz & 1953-1990 & 1953-1958 Obb., \\
\hline & (27. 10. 1953 Nachr. f. H. Demmelmeier) & seit 1958 Schw. \\
\hline $\begin{array}{l}\text { Hirschenauer, Benedikt } \\
\text { Hofmann, Engelbert }\end{array}$ & $\begin{array}{l}1946-1950 \\
1950-1966\end{array}$ & $\begin{array}{l}\text { Ndb./Opt. } \\
\text { Ufr. }\end{array}$ \\
\hline Horlacher, Michael & $\begin{array}{l}1946-1950 \\
\text { (Verz. 8.2.1950) }\end{array}$ & Ndb./Opf. \\
\hline Huber, Sebastian & $1946-1970$ & Obb. \\
\hline Hundhammer, Alois & $1946-1970$ & Obb. \\
\hline Huth, Friedrich & $1946-1950$ & Ufr. \\
\hline Jüngling, Max Josef & $\begin{array}{l}\text { 1951-1963 } \\
\text { (23.9. } 1951 \text { Nachw. f. J. Wittmann; } \\
\text { † 14. 2. 1963) }\end{array}$ & Ofr. \\
\hline Junker, Heinrich & $1950-1970$ & Obb. \\
\hline Kaifer, Albert & $1946-1954$ & Schw. \\
\hline Karl, Hans & $1950-1958$ & Ndb. \\
\hline Kerber, Ferdinand & $\begin{array}{l}1950-1954 \\
1954 \mathrm{BP}\end{array}$ & Schw. \\
\hline Kraus, Engelbert & $1946-1962$ & Ufr. \\
\hline Krehle, Heinrich & $\begin{array}{l}\text { 1948-1958 } \\
\text { (10. 12. } 1948 \text { Nachr. f. A. Lang) }\end{array}$ & Obb. \\
\hline Krempl, Josef & $1946-1950$ & Ndb./Opf. \\
\hline Kroll, Gerhard & $1946-1950$ & Mfr./Ofr. \\
\hline Kroth, Karl August & $\begin{array}{l}\text { 1949/1950 } \\
\text { (30.11. } 1949 \text { Nachr. f. W. Laforet) }\end{array}$ & Ufr. \\
\hline Kübler, Konrad & $1946-1950$ & Ndb./Opf. \\
\hline Kurz, Andreas & $1946-1958$ & Obb. \\
\hline Lacherbauer, Carljörg & $\begin{array}{l}1946-1953 \\
1953 / 1954(\mathrm{BP}) \\
1954-1958(\mathrm{BP})\end{array}$ & Obb. \\
\hline Laforet, Wilhelm & $\begin{array}{l}\text { 1946-1949 } \\
(\text { Verz. 16.11.1949) }\end{array}$ & Ufr. \\
\hline Lang, Andreas & $\begin{array}{l}1946-1948 \\
(† 28.11 .1948)\end{array}$ & Obb. \\
\hline Lau, Johannes & $1946-1950$ & Schw. \\
\hline Lehmer, Max & $1946-1950$ & Obb. \\
\hline Lenz, Karl & $1950-1954$ & Schw. \\
\hline Lutz, Hermann & $\begin{array}{l}\text { 1949-1958 } \\
\text { (30. 12. } 1949 \text { Nachr. f. F. Ziegler) }\end{array}$ & Schw. \\
\hline Mack, Georg & 1946-1970 & $\begin{array}{l}1946-1950 \text { Ofr./Mfr., } \\
\text { seit } 1950 \mathrm{Mfr} .\end{array}$ \\
\hline Maderer, Andreas & $1946-1950$ & Ndb./Opf. \\
\hline Maier, Anton & $\begin{array}{l}\text { 1948-1950 } \\
\text { (21. 12. } 1948 \text { Nachr. f. J. Anetseder) }\end{array}$ & Ndb./Opf. \\
\hline Mayer, Gabriel & $1946-1950$ & Obb. \\
\hline Meixner, Georg & $1946-1958$ & Ofr. \\
\hline Melchner, August & $\begin{array}{l}\text { 1949/1950 } \\
\text { (17. 10. } 1949 \text { Nachr. f. H. Hagn) }\end{array}$ & Obb. \\
\hline Michel, Franz & $\begin{array}{l}1946-1956 \\
1956-1958 \text { (frktls.) }\end{array}$ & Obb. \\
\hline Müller, Josef & $1946-1962$ & $\begin{array}{l}\text { 1946-1950 Ofr./Mfr., } \\
\text { seit } 1950 \text { Obb. }\end{array}$ \\
\hline Nagengast, Wilhelm & $1946-1962$ & $\begin{array}{l}\text { 1946-1950 Ofr./Mfr., } \\
\text { seit } 1950 \mathrm{Mfr} \text {. }\end{array}$ \\
\hline $\begin{array}{l}\text { Neumann, Ferdinand } \\
\text { Nirschl, Josef }\end{array}$ & $\begin{array}{l}1946-1950 \\
1946-1950\end{array}$ & $\begin{array}{l}\text { Ndb./Opf. } \\
\text { Ndb./Opf. }\end{array}$ \\
\hline
\end{tabular}




\begin{tabular}{|c|c|c|}
\hline Nüssel, Adam & $1946-1950$ & Ofr./Mfr. \\
\hline Ortloph, Klement & $1946-1958$ & $\begin{array}{l}\text { 1946-1950 Ndb./Opf., } \\
\text { seit } 1950 \text { Opf. }\end{array}$ \\
\hline Papstmann, Hans & $1946-1950$ & Ofr./Mfr. \\
\hline Pfeiffer, Anton & $1946-1950$ & Obb. \\
\hline Piechl, Josef & $\begin{array}{l}1946-1961 \\
(† 18.8 .1961)\end{array}$ & $\begin{array}{l}\text { 1946-1950 Ndb./Opf., } \\
\text { seit } 1950 \mathrm{Ndb} \text {. }\end{array}$ \\
\hline Pösl, Johann & $\begin{array}{l}\text { 1948-1954 } \\
\text { (8. 3. } 1948 \text { Nachr. f. M. Deku) }\end{array}$ & $\begin{array}{l}1948-1950 \mathrm{Ndb} . / O p f ., \\
\text { seit } 1950 \mathrm{Opf} .\end{array}$ \\
\hline Prechtl, Wolfgang & $1946-1950$ & Ndb./Opf. \\
\hline $\begin{array}{l}\text { Prittwitz und Gaffron, } \\
\text { Friedrich von }\end{array}$ & $1946-1954$ & Ufr. \\
\hline Probst, Maria & $\begin{array}{l}\text { 1946-1949 } \\
\text { (Verz. 1.9. 1949) }\end{array}$ & Ufr. \\
\hline Prüschenk, Josef & $1946-1950$ & Ndb./Opf. \\
\hline Ramelsberger, Ludwig & $\begin{array}{l}\text { 1953-1965 } \\
(28.10 .1953 \text { Nachr. f. H. Geiger; } \\
\dagger 22.1 .1965)\end{array}$ & $\mathrm{Ndb}$. \\
\hline Rindt, Eugen & $1946-1950$ & Schw. \\
\hline Riß, Josef & $1946-1950$ & Obb. \\
\hline Sauer, Franz Ludwig & $\begin{array}{l}1946-1950 \\
(† 28.3 .1950)\end{array}$ & Ufr. \\
\hline Schäfer, Franz & $\begin{array}{l}1946-1950 \\
1958-1962\end{array}$ & Obb. \\
\hline Scharf, Josef & $\begin{array}{l}1946-1949 \\
1949 / 1950 \text { (frktls.) }\end{array}$ & Ndb./Opf. \\
\hline Schedl, Otto & $1950-1974$ & Opf. \\
\hline Schefbeck, Otto & $1946-1950$ & Obb. \\
\hline Schlögl, Alois & $\begin{array}{l}1946-1957 \\
(† 27.9 .1957)\end{array}$ & Schw. \\
\hline Schmid, Andreas & $1946-1950$ & Ofr./Mfr. \\
\hline Schmid, Karl & $1946-1954$ & Obb. \\
\hline Schmidramsl, Hanns Martin & $1950-1974$ & Mfr. \\
\hline Schöner, Franz & $\begin{array}{l}\text { 1949/1950 } \\
\text { (21. 3. } 1949 \text { Nachr. f. W. Stegerwald) }\end{array}$ & Ndb./Opf. \\
\hline Schraml, Josef & $1946-1950$ & Ndb./Opf. \\
\hline Schubert, Karl & $\begin{array}{l}1950-1954 \\
1958-1966\end{array}$ & $\mathrm{Ndb}$. \\
\hline Schuster, Georg & $1950-1970$ & Ndb. \\
\hline Schwägerl, Hans & $\begin{array}{l}1950 \\
\text { (11. 4. } 1950 \text { Nachr. f. F. L. Sauer) }\end{array}$ & Ufr. \\
\hline Schwalber, Josef & $1946-1950$ & Obb. \\
\hline Schwingenstein, August & $\begin{array}{l}\text { 1946-1948 } \\
\text { (Verz. 18.9.1948) }\end{array}$ & Schw. \\
\hline Seidel, Hanns & $\begin{array}{l}1946-1961 \\
(† 5.8 .1961)\end{array}$ & Ufr. \\
\hline Stang, Georg & $\begin{array}{l}1946-1951 \\
(\dagger 10.5 .1951)\end{array}$ & Schw. \\
\hline Stegerer, Wilhelm & $\begin{array}{l}1950-1954 \\
1954 \mathrm{BP}\end{array}$ & Opf. \\
\hline Stegerwald, Wilhem & $\begin{array}{l}\text { 1946-1949 } \\
\text { (Verz. 12.3.1949) }\end{array}$ & Ndb./Opf. \\
\hline Sterzer, Michael & $1950-1954$ & Obb. \\
\hline Stinglwagner, Alois & $1946-1950$ & Obb. \\
\hline Strathmann, Hermann & $1946-1950$ & Mfr. \\
\hline Strenkert, Paul & $1950-1966$ & Schw. \\
\hline
\end{tabular}




$\begin{array}{lll}\text { Strobel, Fritz } & 1946-1950 & \text { Ofr./Mfr. } \\ \text { Stücklen, Georg } & 1946-1950 & \text { Ofr./Mfr. } \\ \text { Stürmann, Josef } & 1948-1950 & \text { Obb. } \\ \text { Sübler, Adam } & (12.3 .1948 \text { Nachr. f. M. Zwicknagl) } & \\ & 1946-1949 & \text { Ofr./Mfr. } \\ \text { Thaler, Rupert } & (\text { Verz. } 31.12 .1949) & \\ \text { Thanbichler, Jobann } & 1946-1950 & \text { Ndb./Opf. } \\ \text { Trepte, Hans } & 1950-1958 & \text { Obb. } \\ \text { Trettenbach, Martin } & 1946-1950 & \text { Ndb./Opf. } \\ \text { Vidal, Konstantin } & 1946-1950 & \text { Obb. } \\ \text { Weigel, Wenzel } & 1946-1950 & \text { Schw. } \\ \text { Weiglein, Otto } & 1950-1954 & \text { Opf. } \\ \text { Weinkamm, Otto } & 1946-1950 & \text { Ufr. } \\ & 1953-1957 & \text { Schw. } \\ \text { Weinzierl, Alois } & (16.3 .1953 \text { Nachr. f. W. Göttler; } & \\ \text { Weinzierl, Georg } & \text { Verz. } 11.10 .1957) & \\ \text { Winkler, Martin } & 1946-1950 & \text { Ndb./Opf. } \\ \text { Wittmann, Julian } & 1946-1950 & \text { Ofr./Mfr. } \\ & 1946-1950 & \text { Ndb./Opf. } \\ \text { Witzlinger, Michael } & 1946-1951 & 1946-1950 \text { Ofr./Mfr., } \\ \text { Wölfel, Gustav } & (\dagger 17.8 .1951) & \text { seit 1950 Ofr. } \\ & 1946-1950 & \text { Ndb./Opf. } \\ \text { Wutzlbofer, Hans } & 1949-1970 & \text { Ufr. } \\ \text { Zebner, Zita } & (8.7 .1949 \text { Nachr. f. E. Bühner) } & \\ \text { Zeisslein, Anton } & 1946-1950 & \text { Ufr. } \\ & 1946-1970 & \text { Obb. } \\ \text { Ziegler, Franz } & 1946-1949 & \text { Ufr. } \\ & (\dagger 10.6 .1949) & \\ \text { Zillibiller, Max } & 1948 / 1949 & \text { Schw. } \\ \text { Zitzler, Georg } & (30.9 .1948 \text { Nachr. f. A. Schwingenstein) } & \\ \text { Zwicknagl, Max } & 1949(\text { frktls.) } & \\ & (\dagger 27.12 .1949) & \text { Schw. } \\ & 1946-1966 & \text { Ndb./Opf. } \\ & 1946-1950 & \text { Obb. } \\ & 1946-1948 & \\ & (\text { Verz. 5.3.1948) } & \\ & & \\ & & \\ & & \end{array}$

Die Mitglieder des Vorstands der CSU-Landesgruppe im Deutschen Bundestag 1949-1957

\begin{tabular}{lll}
\hline Name & Funktion & Zeitraum \\
\hline Dollinger, Werner & weiteres Mitglied & $1953-1957$ \\
& & $1963-1969$ \\
& seit 1976 \\
& stellvertretender Landesgruppen- & $1957-1961$ \\
& vorsitzender & $1969-1976$ \\
& Landesgruppenvorsitzender & $1961 / 1962$ \\
Funk, Friedrich J. & stellvertretender & $1953-1957$ \\
& Landesgruppenvorsitzender & \\
Höcherl, Hermann & weiteres Mitglied & $1955-1957$ \\
& Landesgruppenvorsitzender & $1957-1961$ \\
Horlacher, Michael & weiteres Mitglied & $1949-1957$
\end{tabular}


Jaeger, Richard

Schäffer, Fritz

Schütz, Hans

Solleder, Maximilian

Strauß, Franz Josef

Stücklen, Richard

Wacher, Gerhard stellvertretender

1953-1955

Landesgruppenvorsitzender

weiteres Mitglied

Landesgruppenvorsitzender

weiteres Mitglied

weiteres Mitglied

stellvertretender

Landesgruppenvorsitzender

stellvertretender

Landesgruppenvorsitzender

geschäftsführender

Landesgruppenvorsitzender

Landesgruppenvorsitzender

weiteres Mitglied

parlamentarischer Geschäftsführer

stellvertretender

Landesgruppenvorsitzender

weiteres Mitglied

Landesgruppenvorsitzender

parlamentarischer Geschäftsführer
1955-1976

1949-1961

1949-1957

1957-1962

1950-1953

1949-1957

1963-1966

1957-1962

1966-1978

1953-1955

1955-1957

1957-1966

seit 1976

1966-1976

1956-1962

Die Mitglieder der CSU-Landesgruppe im Deutschen Bundestag 1949-1957

\begin{tabular}{lll}
\hline Name & Zeitraum & Wahlkreis/Landesliste \\
\hline Bauer, Josef & $1953-1969$ & Altötting \\
Bauereisen, Friedrich & $1949-1961$ & Ansbach \\
Bodensteiner, Hans & $1949-1953$ & Tirschenreuth \\
Demmelmeier, Hans & $1953-1961$ & Ingolstadt \\
Dittrich, Stefan & $1953-1972$ & Deggendorf \\
Dollinger, Werner & $1953-1990$ & $1953-1965$ Erlangen \\
& & $1965-1972$ Fürth \\
& & $1972-1976$ LL \\
Donbauser, Anton & $1953-1957$ & $1976-1990$ Fürth \\
& $1949-1953$ (BP) & Amberg \\
Franz, Ludwig & $1953-1976$ & \\
Fuchs, Gustav & $1949-1961$ & Rosenheim \\
Fugger von Glött, & $1949-1953$ & Bad Kissingen \\
Fürst Josef Ernst & & Memmingen \\
Funk, Friedrich J. & $1949-1963$ & \\
& $(\dagger 5.8 .1963)$ & Schweinfurt \\
Geiger, Hugo & $1953-1961$ & \\
Geisendörfer, Ingeborg & $1953-1972$ & Tirschenreuth \\
Gleissner, Franz & $1953-1972$ & LL \\
Graf, Benno & $1953-1957$ & Miesbach \\
Gumrum, Otto & $($ Wahlabkommen mit BP) & München-West \\
Henckel von Donnersmarck,, $1953-1957$ & \\
Graf Georg & $1953-1957$ & München-Nord \\
& $(5.9 .1959$ Nachr. f. J. Oesterle) & \\
& $($ Wahlabkomm mit BP) & LL \\
& & \\
& &
\end{tabular}




\begin{tabular}{|c|c|c|}
\hline Höcherl, Hermann & $1953-1976$ & Regensburg \\
\hline Horlacher, Michael & 1949-1957 & Forchheim \\
\hline Jaeger, Richard & $1949-1980$ & Fürstenfeldbruck \\
\hline Kabn, Karl & $1949-1957$ & Burglengenfeld \\
\hline Karpf, Hugo & $1949-1957$ & Aschaffenburg \\
\hline Kemmer, Emil & $\begin{array}{l}\text { 1949-1964 } \\
\text { (Verz. 7.10.1964) }\end{array}$ & Bamberg \\
\hline Kihn, Karl Alfred & 1953-1957 & Würzburg \\
\hline Klausner, Wolfgang & $\begin{array}{l}1953-1958 \\
(† 17.4 .1958)\end{array}$ & Traunstein \\
\hline Kleindinst, Josef $F$. & $1949-1957$ & Augsburg-Stadt \\
\hline Kramel, Angelo & $1953-1961$ & $\begin{array}{l}\text { 1953-1957 München-Ost } \\
\text { 1957-1961 LL }\end{array}$ \\
\hline Kuchtner, Edeltraud & 1953-1972 & LL \\
\hline Laforet, Wilhelm & $1949-1953$ & Würzburg \\
\hline Lang, Georg & $\begin{array}{l}1953-1965 \\
(† 1.6 .1965)\end{array}$ & $\begin{array}{l}\text { 1953-1957 LL } \\
\text { 1957-1961 München-Ost } \\
\text { 1961-1965 LL }\end{array}$ \\
\hline Lermer, Josef & $\begin{array}{l}1953-1964 \\
(† 15.7 .1964)\end{array}$ & Straubing \\
\hline Leukert, Edmund & $\begin{array}{l}\text { 1953-1957 } \\
1958-1961 \\
\text { (21.4. } 1958 \text { Nachr. f. W. Klausner) } \\
\text { 1962-1965 } \\
\text { (27.6. } 1962 \text { Nachr. f. } \\
\text { G. von Manteuffel-Szoege) }\end{array}$ & LL \\
\hline & 1965-1969 & LL \\
\hline Loibl, Martin & $\begin{array}{l}1949-1951 \\
(† 17.4 .1951)\end{array}$ & Donauwörth \\
\hline Lücker, Hans August & $1953-1980$ & $\begin{array}{l}\text { 1953-1965 Memmingen } \\
\text { 1965-1976 Kaufbeuren } \\
\text { 1976-1980 Unterallgäu }\end{array}$ \\
\hline $\begin{array}{l}\text { Manteuffel-Szoege, } \\
\text { Baron Georg von }\end{array}$ & $\begin{array}{l}1953-1962 \\
(† 8.6 .1962)\end{array}$ & Schwabach \\
\hline Meyer, Philipp & $\begin{array}{l}1953-1962 \\
(† 29.1 .1962)\end{array}$ & Donauwörth \\
\hline Miller, Anton & $1953-1957$ & LL \\
\hline Nickl, Christof & $1949-1953$ & Cham \\
\hline Niederalt, Alois & 1953-1969 & $\begin{array}{l}\text { 1953-1965 Cham } \\
\text { 1965-1969 Burglengen- } \\
\text { feld }\end{array}$ \\
\hline Niklas, Wilhelm & $\begin{array}{l}\text { 1951-1953 } \\
\text { (Nachw. 27. 5. } 1951 \text { in Donauwörth) }\end{array}$ & \\
\hline Oesterle, Josef & $\begin{array}{l}1949-1959 \\
(† 31.8 .1959)\end{array}$ & Augsburg-Land \\
\hline Probst, Maria & $\begin{array}{l}1949-1967 \\
(\dagger 1.5 .1967)\end{array}$ & Karlstadt \\
\hline $\begin{array}{l}\text { Riederer von Paar zu } \\
\text { Schönau, Freiberr Max }\end{array}$ & $1953-1957$ & Pfarrkirchen \\
\hline Rinke, Walter & $1953-1957$ & LL \\
\hline Schäffer, Fritz & $1949-1961$ & Passau \\
\hline Schatz, Josef & $1949-1953$ & Amberg \\
\hline Schuberth, Hans & $1953-1957$ & Landshut \\
\hline Schütz, Hans & $\begin{array}{l}\text { 1949-1963 } \\
\text { (Verz. 5. 2. 1963) }\end{array}$ & Dillingen \\
\hline Seidl, Franz & $1953-1965$ & München-Land \\
\hline
\end{tabular}


Semler, Johannes

Solleder, Maximilian

Spies, Josef

Spörl, Max

Spreti, Graf Karl von

Stiller, Georg

Strauß, Franz Josef

Stücklen, Richard

Unertl, Franz Xaver

Wacher, Gerhard

Wieninger, Karl

Winter, Friedrich

Wittmann, Franz
1950-1953

(Nachw. 14. 5. 1950 in Kulmbach)

1949-1953

1949-1965

1969

(4. 8. 1969 Nachr. f. K. von Bayern)

1953-1957

1949-1956

(Verz. 5. 3. 1956)

1953-1969

1949-1978

(Verz. 29. 11. 1978)

1949-1990

1953-1970

$(† 31.12 .1970)$

1953-1963

(Verz. 26. 3. 1963)

1953-1969

$1956 / 1957$

(6. 3. 1956 Nachr. f. K. von Spreti)

1957-1961

1962-1965

(2. 2. 1962 Nachr. f. Ph. Meyer)

1953-1961

$1964 / 1965$

(26. 10. 1964 Nachr. f. E. Kemmer)
Regensburg

Kaufbeuren

Kulmbach

Kempten

1953-1957 LL

1957-1961 Nürnberg

1961-1969 LL

Weilheim

1949-1976 Weißenburg

1976-1990 Roth

1953-1965 Vilshofen

1965-1970 Passau

1953-1957 LL

1957-1961 Hof

1961-1963 LL

1953-1965 München-Süd

1965-1969 LL

Nürnberg-Fürth

LL 


\section{Geschichte und Struktur der CSU - Forschungsstand und Quellenlage}

\section{a) Schwerpunkte und Probleme der Forschung ${ }^{l}$}

„Die Erforschung der Geschichte der CSU“, so bilanzierte Rudolf Morsey vor einigen Jahren, „ist wie die keiner anderen seit 1949 im Bundestag vertretenen Partei Domäne eines Autors, A[lf] Mintzel, geblieben. “2 Obwohl Mintzels grundlegende Studien nun schon vor zwei Jahrzehnten erschienen sind, müssen sie noch immer als die Standardwerke zur Entwicklung und Struktur der CSU angesehen werden, die nach wie vor den Ausgangspunkt für weitere Forschungen über diese Partei bilden. Bis dahin war die Erforschung der autonomen bayerischen Landespartei mit ihren bundespolitischen Ambitionen und Einflußmöglichkeiten weitgehend ein Desiderat der zeithistorischen und sozialwissenschaftlichen Forschung gewesen; die wissenschaftlichen Untersuchungen über die CSU ließen sich beinahe an einer Hand abzählen. Das lag zum einen daran, daß die Forschung den ambivalenten Charakter der CSU als Landes- und Bundespartei fast ausnahmslos unberücksichtigt gelassen hatte. Entgegen ihrem Selbstverständnis und entgegen der politischen Wirklichkeit wurde die CSU als Teil einer imaginären Gesamtunion betrachtet und gleichsam als ein - wenn auch besonders eigenständiger - Landesverband der CDU in die Analyse einbezogen ${ }^{3}$. Zum anderen war die schlechte Quellenlage ein Hindernis, an dem noch Ende der sechziger Jahre Mintzels Projekt fast gescheitert wäre. Denn ganz im Gegensatz zu ihrem Bekenntnis zur Tradition und Geschichte Bayerns vernachlässigte die CSU die Pflege ihrer eigenen Geschichte geradezu sträflich. Ein zentrales Parteiarchiv wurde in der Landesgeschäftsstelle erst 1965 eingerichtet. Die CSU selbst gab weder Geschäftsberichte noch Parteitagsprotokolle heraus, lediglich die Reden prominenter Politiker der Partei wurden als Druckschriften verbreitet; nur 1954 veröffentlichte die Landes-

\footnotetext{
1 Einen sehr guten Zugriff auf die vorhandene Forschungsliteratur über Geschichte, Entwicklung und Programmatik der CSU bieten: Bibliographie zur Geschichte der CDU und CSU 1945-1980, bearb. von Gerhard Hahn, Stuttgart 1982, und Bibliographie zur Geschichte der CDU und CSU 1981-1986. Mit Nachträgen 1945-1980, bearb. von Brigitte Krahe und Michaela Seibel, Düsseldorf 1990, sowie Bibliographie zur Geschichte der CDU und CSU 1987-1990, bearb. von Thomas Saarschmidt und Hildegard Krengel, Düsseldorf 1994. Die drei Bibliographien umfassen ca. 25.000 Titel, die durch ein Personenregister, ein Sach- und Institutionenregister sowie durch ein Regionenregister dreifach erschlossen sind. Die Bearbeiter haben nicht nur Forschungsarbeiten aufgenommen, sondern auch das Schriftum der Parteien selbst und Veröffentlichungen aus dem Bereich der politischen Publizistik.

2 Rudolf Morsey, Die Bundesrepublik Deutschland. Entstehung und Entwicklung bis 1969, München 1987, S. 177; der neueste Forschungsstand wird kurz referiert in der 1995 erschienenen 3., überarbeiteten und erweiterten Auflage dieses Werks (S. 179f.), und bei Adolf M. Birke, Die Bundesrepublik Deutschland. Verfassung, Parlament und Parteien, München 1997, S. 8 f. und S. $100 \mathrm{f}$.

${ }^{3}$ Geradezu typisch dafür ist der Sammelband von Lange u. a., Parteien in der Bundesrepublik, aus dem Jahre 1955, der keinen eigenen Beitrag zur CSU enthält. Auch im umfangreichen Kapitel über die CDU fehlen Ausführungen zur bayerischen Unionspartei. Ähnlich auch die bereits 1954 im Manuskript abgeschlossene, aber erst 26 Jahre später veröffentlichte Studie von Gurland, CDU/ CSU, die die CSU nur am Rande in die Untersuchung einbezieht. Intensiver mit der Geschichte der CSU setzte sich Ernst Deuerlein, Historiker und Ministerialbeamter in der bayerischen Staatskanzlei, auseinander; vgl. Ernst Deuerlein, CDU/CSU 1945-1957. Beiträge zur Zeitgeschichte, Köln 1957.
} 
leitung ein Politisches Jahrbuch, das allerdings noch heute von hohem Quellenwert ist ${ }^{4}$. Eine Ausnahme war auch die kurze Überblicksdarstellung zur Geschichte der CSU, die der Landesvorstand anläßlich der Feiern zum 10 jährigen Bestehen der Partei bei Walter Berberich in Auftrag gegeben hatte ${ }^{5}$. Berberich, zwischen 1950 und 1958 Geschäftsführer des CSU-Bezirksverbands Unterfranken, konnte zu diesem Zweck neben Materialien aus der eigenen Geschäftsstelle die Akten der Landesleitung sowie die Unterlagen im Privatarchiv von Josef Müller einsehen und baute seine Studien später zu einer Dissertation aus ${ }^{6}$ - ein Vorhaben, das dem Parteivorstand übrigens bekannt war ${ }^{7}$. Berberich konzentrierte sich auf die historisch-genetische Darstellung der Gründung und Entwicklung der CSU in den ersten vier Jahren ihres Bestehens, wobei er die Flügel- und Führungskämpfe sowie die Herausbildung des spannungsreichen Verhältnisses zwischen CDU und CSU besonders berücksichtigte. $\mathrm{Zu}$ dem lieferte seine Studie erstmals detailliertere Informationen über die Wähler- und Mitgliederstruktur der Partei. Berberichs Dissertation löste jedoch nur geringes Echo aus, und die CSU war auch in den folgenden Jahren für die Wissenschaft kaum von Interesse ${ }^{8}$.

Dies änderte sich erst mit Beginn der siebziger Jahre, als Vorgeschichte und Geschichte der Bundesrepublik zunehmend als Forschungsfeld entdeckt wurden. Auch die spätestens seit den Landtagswahlen von 1970 augenfällige politische Hegemonialisierung Bayerns durch die CSU und die wachsenden Spannungen zwischen den Unionsparteien während der sozial-liberalen Koalition, die die Sonderrolle der CSU deutlich werden ließen, mögen zu verstärktem Nachdenken über diese Partei angeregt haben'. 1973 war es Karl Möckl, der in einem ausführlichen Aufsatz nicht nur den bisherigen Forschungsstand zusammenfaßte, sondern auf der Basis bisher unbekannten Quellenmaterials die Führungs- und Flügelkämpfe der frühen Jahre neu interpretierte. Er bezog stärker als Berberich die besatzungspolitischen und historischen Rahmenbedingungen in seine Studien ein und versuchte, die Entwicklung der CSU von ihrer Gründung bis zur Ablösung des ersten Parteivorsitzenden Josef Müller auch begrifflich zu fassen ${ }^{10}$.

${ }^{4}$ Vgl. Mintzel, Anatomie, S. 77-80.

${ }^{5}$ ACSP, CSU-LL, Protokoll der Sitzung des geschäftsführenden Landesvorstands am 13. 9. 1955. Vgl. Walter Berberich, Die CSU als neue interkonfessionell-christliche und föderalistische Mehrheitspartei. Ein Beitrag zur Geschichte der Christlich Sozialen Union in Bayern, in: Politisches Jahrbuch der CSU 1954, S. 33-53, und Walter Berberich, 10 Jahre Christlich-Soziale Union in Bayern. Arbeit, Kampf, Verantwortung und Erfolge, in: 10 Jahre CSU, S. 5-36.

${ }^{6}$ Vgl. Berberich, Historische Entwicklung; die Nähe Berberichs zur CSU erfordert ohne Zweifel eine besonders kritische Lektüre seiner Studie.

7 ACSP, CSU-LL, Protokoll der Sitzung des geschäftsführenden Landesvorstands am 13. 9. 1955.

${ }^{8}$ Alf Mintzel, Die CSU in Bayern als Forschungsobjekt - Entwicklung, Stand, Defizite und Perspektiven der CSU-Forschung, in: Oskar Niedermayer, Richard Stöss (Hrsg.), Stand und Perspektiven der Parteienforschung in Deutschland, Opladen 1993, S. 81-118, hier S. 83, hat Berberichs Dissertation mit einiger Berechtigung als bescheidenen "Erstling" bezeichnet. Etwa zur selben Zeit entstand auch die unveröffentlichte Zulassungsarbeit von Hilde Schrepfer, Beiträge zur Frühgeschichte der CSU in Bayern, Bamberg 1965, die vor allem viele interessante Details aus der unmittelbaren Gründungszeit enthält.

9 So Otto Stammer in seinem Vorwort zu Mintzel, Anatomie, S. 15, der vor allem auf den spektakulären Wahlerfolg der CSU bei den Landtagswahlen von 1974 abhebt, und Mintzel, CSU in Bayern, in: Niedermayer/Stöss (Hrsg.), Stand und Perspektiven, S. 83.

${ }^{10}$ Der Autor wertete erstmals den Nachlaß des 1967 verstorbenen Fritz Schäffer aus, der sich damals noch in Privatbesitz befand. Möckl hat von einer Auseinandersetzung zwischen "Weltanschauung“ 
1975 legte dann Alf Mintzel seine bahnbrechende Studie „Die CSU. Anatomie einer konservativen Partei“ vor. Das Erkenntnisziel des Soziologen war es, „eine landes- und sozialgeschichtlich fundierte und zeitlich tief abgestützte Struktur- und Entwicklungsgeschichte der CSU im Rahmen der gesellschaftlich-politischen Entwicklung Bayerns und der Bundesrepublik" zu erarbeiten ${ }^{11}$. Mintzels Interesse galt dabei vor allem den weitgehend unbekannten organisationspolitischen Wandlungsprozessen konservativer Parteien in modernen Industriegesellschaften, denen er sich am Beispiel des Aufbaus, des Strukturwandels und der Organisationspolitik der CSU im Kontext der soziopolitischen Rahmenbedingungen zu nähern gedachte. In diesem Zusammenhang richtete er sein besonderes Augenmerk auf die Auswirkungen der ökonomischen Entwicklung des Freistaates ${ }^{12}$ und auf innerbayerische Regionalismen und Spannungslinien ${ }^{13}$ sowie deren Rückwirkungen auf die Organisation der CSU. Dementsprechend liegen die Schwerpunkte dieser Studie, die sich vom theoretischen Ansatz her als „empirisch-deskriptive Analyse“ versteht ${ }^{14}$, auf der organisationssoziologischen Ebene und auf der Analyse der Binnenstruktur der CSU ${ }^{15}$.

Mintzels Untersuchung zerfällt in zwei große Teile: Im ersten Hauptteil thematisiert er die Gründung der CSU als christlich-interkonfessionelle Sammlungsbewegung, das weitgehende Scheitern dieser Konzeption und die Degeneration der CSU zu einer Honoratiorenpartei in der ersten Hälfte der fünfziger Jahre. Im zweiten Hauptteil, der den Zeitraum von 1955 bis 1972 behandelt, wird die Entwicklung der CSU zu einer „Massen- und Apparat-Partei modernen Typs “ ${ }^{16}$ untersucht. Diesen Begriff, den Mintzel in Anlehnung an die Typologie Sigmund Neumanns geprägt hat, stellte er den $\mathrm{Be}$ griffen „Volkspartei“, „Allerweltspartei“ oder „soziale Querschnittspartei“ entgegen,

und "politische[m] Pragmatismus" gesprochen, wobei er den Exponenten des konservativen Flügels die Rolle der Ideologen, Müller und seinen Mitstreitern diejenige der Pragmatiker zugewiesen hat, sowie von einer Auseinandersetzung zwischen den "Formprinzipien“ „Volkspartei“ oder "Honoratiorenpartei“. Einiges ist dabei sicherlich richtig erkannt, vor allem der Dauerkonflikt um den Aufbau der Partei, aber die Vertreter des Müller-Flügels in toto als Pragmatiker zu bezeichnen, hieße, die Ideologisierung des Konflikts auf beiden Seiten und auch die daraus resultierende Konsensunfähigkeit zu verkennen. Vgl. Möckl, Struktur, S. 736 f. und S. 746 f.

11 Mintzel, Anatomie, S. 35.

12 Zur Bedeutung, die Mintzel der ökonomischen Entwicklung Bayerns hinsichtlich seiner Fragestellungen beimaß, vgl. ebenda, S. 47-55.

${ }^{13}$ Mintzel führte diese Spannungslinien und Regionalismen auf die historische Entwicklung der „drei großen bayerischen Traditionszonen ", nämlich der altbayerischen, der schwäbischen und der fränkischen, zurück. Vgl. ebenda, S. 58-67, Zitat S. 58. Dieses Modell, das sich als durchaus brauchbares heuristisches Instrument erwiesen hat, führte Mintzel jedoch insbesondere bei der Analyse der Führungs- und Flügelkämpfe in der CSU zu überspitzten strukturalistischen Interpretationen. Mintzel hat auch in seinen letzten Arbeiten an diesem Modell festgehalten, seine Überlegungen allerdings differenziert und durch empirisches Material abgestützt; vgl. Mintzel, Regionale politische Traditionen, in: Oberndörfer/Schmitt (Hrsg.), Parteien und regionale Traditionen. Eine Einteilung in politische Regionen, die er nach sozialistischen, katholischen und bürgerlich-protestantischen "Subkulturen" klassifizierte, nahm auch Thränhardt vor, wobei er Bayern nach seiner territorialen Entwicklung in das "protestantische Franken", das "katholische Franken und Schwaben“ und in "Altbayern" untergliederte. Vgl. Thränhardt, Wahlen und politische Strukturen, S. 152-180.

14 Vgl. Mintzel, Anatomie, S. 43-47. Otto Stammer spricht dagegen in seinem Vorwort von einer über Mintzels eigene Ansprüche hinausgehenden "soziologisch-politische[n] Verlaufsanalyse, der [...] die theoretisch-methodologisch abgesicherte Konzeption der Entwicklung des Realtypus einer konservativen Partei unter den besonderen gesellschaftlich-ökonomischen Voraussetzungen der, politischen Kultur' Bayerns" zugrundeliege. Ebenda, S. 18.

15 Für die Schwesterpartei vgl. Schönbohm, Volkspartei.

${ }^{16} \mathrm{Zu}$ diesem Begriff vgl. Mintzel, Anatomie, S. 67-71, Zitat S. 67; das folgende nach ebenda. 
die er für ideologisch belastet und zu wenig trennscharf hielt ${ }^{17}$. Mintzels Begrifflichkeit konnte sich jedoch in der Forschung nicht durchsetzen ${ }^{18}$.

Was die Untersuchungen des Soziologen so interessant machte, war nicht zuletzt das Quellenmaterial, das ihm zur Verfügung stand. Es gelang Mintzel im Laufe seiner Recherchen nicht nur, die Unterlagen verschiedener CSU-Politiker und die mehr oder weniger ergiebigen Bestände der Bezirksgeschäftsstellen auszuwerten, sondern auch Einsicht in die Akten der Parteileitung zu nehmen, die zu dieser Zeit noch in der Registratur der Landesgeschäftsstelle lagerten. 1967 und 1968 konnte Mintzel diese Materialien mehrere Wochen lang weitgehend unbehindert auswerten und Kopien der wichtigsten Unterlagen anfertigen. Diese geheimnisumwitterte Sammlung bildete im wesentlichen die Quellenbasis der großen Studien Mintzels sowie seiner späteren Arbeiten, die seine Forschungsergebnisse zur Geschichte der CSU um einzelne Aspekte ergänzten und aktualisierten. Als die bayerische Unionspartei dazu überging, ihr Schriftgut wieder stärker unter Verschluß zu halten, kam dem Privatarchiv Mintzels die Funktion eines Schlupflochs zu, dessen sich Historiker und Politologen für Forschungen zur Parteiengeschichte und zur Geschichte Bayerns immer wieder gerne bedienten ${ }^{19}$.

Bei näherer Betrachtung der Sammlung Mintzel werden auch einige Desiderate und Forschungslücken verständlich, die sich wie ein roter Faden durch die Studien des Soziologen ziehen. Das Fehlen von Aktenmaterial zur Entwicklung, Struktur und Politik von Landtagsfraktion und Landesgruppe der CSU ließ die parlamentarische Repräsen$\tan z$ der bayerischen Unionspartei merkwürdig blaß erscheinen und führte dazu, daß die Machtverteilung und die Konflikte zwischen den verschiedenen Entscheidungszentren weitgehend im dunkeln blieben. Zudem sind die Akten der Landesleitung nicht für alle Phasen der Geschichte der CSU von gleicher Qualität und Dichte, so daß Mintzels Studien immer wieder Lücken aufweisen oder empirisch nur schwach abgestützt sind. Dies gilt für die Entwicklung der CSU unter der Führung Hans Ehards und für den Zerfall des Parteiapparats nach 1948 ebenso wie für die Finanzierung der CSU vor 1957 und für die Organisation und Tätigkeit der Arbeitsgemeinschaften der CSU.

Nicht nur durch die Quellenlage, sondern vor allem auch durch die Konzentration auf die organisationspolitische Dimension war Mintzel gezwungen, andere wichtige Themenbereiche entweder weitgehend auszublenden oder nur kursorisch zu behandeln, beispielsweise die Entwicklung der politischen Programmatik, das nicht immer spannungsfreie Verhältnis zur CDU, die politische Arbeit der Partei in München und Bonn oder aber das Verhältnis der christlichen Partei zur evangelischen und katholischen Kirche. Zwar hatte Mintzel angekündigt, einen Teil dieser Desiderate in einer

${ }^{17}$ Grundlage der Auseinandersetzung waren die Termini „Volkspartei“ und „Allerweltspartei“, wie sie von Otto Kirchheimer entwickelt worden sind, sowie der Terminus "soziale Querschnittspartei“ von Wolf-Dieter Narr. Zu Otto Kirchheimers Begrifflichkeit vgl. Richard Stöss, Struktur und Entwicklung des Parteiensystems in der Bundesrepublik. Eine Theorie, in: ders. (Hrsg.), Parteien-Handbuch, Bd. 1, S. $137 \mathrm{f}$.

18 Vgl. Morsey, Bundesrepublik Deutschland (3. Auflage), S. 179.

19 Die Sammlung Alf Mintzels befindet sich seit März 1991 unter der Signatur ED 720 im Archiv des Instituts für Zeitgeschichte. Vgl. dazu Mintzel, Anatomie, S. 76-80, sowie den maschinenschriftlichen, cum ira et studio geschriebenen Erinnerungsbericht Mintzels „Mein Abschlußbericht: Die Geschichte hinter der Geschichte" vom Dezember 1993; Herr Mintzel hat mir freundlicherweise eine Kopie überlassen. 
zweiten Studie zu beseitigen ${ }^{20}$, löste dieses Versprechen jedoch nicht ein. Auch die 1977 erschienene Überblicksdarstellung „Geschichte der CSU“21 konnte die Lücken nur teilweise schließen. Sie führte jedoch insbesondere im Bereich der ideologisch-programmatischen Entwicklung der Partei über die erste Studie hinaus ${ }^{22}$ und untersuchte zudem wichtige Elemente ihrer politischen Praxis an ausgewählten Fallbeispielen aus Bundes- und Landespolitik.

Nach Alf Mintzel hat sich niemand mehr an eine umfassende Darstellung der Geschichte der CSU gewagt. Seine Ergebnisse und Interpretationen sind jedoch vor allem für die Jahre der Besatzung erweitert, vertieft und zum Teil relativiert worden. So ergänzten Klaus-Dietmar Henke und Hans Woller mit ihrer 1984 erschienenen Edition vertraulicher Berichte an die amerikanische Militärregierung in Bayern das bisherige Bild der Führungs- und Flügelkämpfe in der CSU durch bislang unbekannte Einzelheiten über Interna aus den Führungszirkeln der Partei. Diese gelungene Edition enthält die Gedächtnisprotokolle eines Vertrauensmannes der Besatzungsbehörden über die Sitzungen des „Ochsen-Clubs“ und des „Dienstag-Clubs“ aus den Jahren 19461948, wo sich CSU-Politiker regelmäßig zu Diskussionen trafen ${ }^{23}$. Drei Jahre später legte Winfried Becker eine Überblicksdarstellung zur Gründung und Entwicklung der Unionsparteien auf regionaler Ebene vor, die zwar nicht wesentlich über das bereits Bekannte zur frühen Geschichte der CSU hinausführt, aber doch die Möglichkeit bietet, die Entwicklung der CSU mit derjenigen der einzelnen CDU-Landesverbände zwischen 1945 und 1950 zu vergleichen ${ }^{24}$. Zuletzt hat sich Barbara Fait mit den Anfängen der CSU bis zur Rebellion des Bezirksverbands Oberbayern im Februar 1948 beschäftigt ${ }^{25}$. Bei ihrem Versuch, die Frühgeschichte der bayerischen Unionspartei mit der politischen Geschichte Bayerns zu verknüpfen und so die Wechselwirkungen zwischen innerparteilichen Auseinandersetzungen und politischen Grundsatzentscheidungen herauszuarbeiten, bleiben aber zentrale Aspekte der organisatorischen und programmatischen Entwicklung der CSU nahezu vollständig unberücksichtigt.

Ansonsten war es vor allem die bundespolitische Rolle der CSU, die das Forschungsinteresse auf sich zog. Gegenstand umfangreicherer Untersuchungen wurden ihre außen- und europapolitischen Konzeptionen, wobei Vorstellungen und Einfluß des damaligen Vorsitzenden Franz Josef Strauß besondere Berücksichtigung fanden ${ }^{26}$.

20 Vgl. Mintzel, Anatomie, S. 25.

${ }^{21} \mathrm{Daß}$ diese Überblicksdarstellung explizit nicht mit der 1975 angekündigten Studie identisch ist, betonte Mintzel selbst; vgl. Mintzel, Geschichte der CSU, S. 19.

22 Eine gründliche Untersuchung der Programmatik der bayerischen Unionspartei fehlt ebenfalls. Vgl. dazu die Beiträge von Muhler, Ideologische Grundlagen; Kirchmann, Bedeutung christlicher Werte, und Repgen, Anfänge, in: Kraus (Hrsg.), Land und Reich, Bd. 3.

23 Der Informant der Militärregierung war Kurt Heinrich Heizmann, Mitglied der Organisation TURICUM, der sowohl an den Sitzungen des "Dienstag-Clubs“ als auch an denen des „Ochsen-Clubs“ teilnahm. Im „Ochsen-Club“ trafen sich regelmäßig die Mitstreiter Josef Müllers, der „DienstagClub" war ein Diskussionszirkel von jüngeren CSU-Politikern, der eng mit der katholischen Vereinsbewegung verknüpft war. Vgl. Lehrjahre, S. 21-32.

${ }^{24} \mathrm{Vgl}$. Becker, CDU und CSU; nützlich ist der umfangreiche Quellenanhang (S. 353-448) zu Beckers Studie.

${ }^{25}$ Vgl. Fait, Anfänge; diese Studie basiert zu einem großen Teil auf der von Fait verfaßten Einleitung zu: Protokolle und Materialien, S. III-XCVI.

${ }^{26}$ Vgl. Detlef Bischoff, Franz Josef Strauß, die CSU und die Außenpolitik. Konzeptionen und Realität am Beispiel der Großen Koalition, Meisenheim am Glan 1973, und Erich Eisner, Das europäische Konzept von Franz Josef Strauß. Die gesamteuropäischen Ordnungsvorstellungen der CSU, Meisenheim am Glan 1975, sowie Christian Hacke, Die Ost- und Deutschlandpolitik der CDU/CSU. Wege 
Über diese Arbeiten hinaus ist die bundespolitische Rolle der CSU allerdings weitgehend unbeachtet geblieben. So weiß man nur wenig darüber, welchen Einfluß die bayerische Unionspartei auf die Formulierung der Politik hatte, als sie in der Bundesregierung vertreten $\mathrm{war}^{27}$, und wie sich die CSU später in der Opposition zurechtfand $^{28}$. In diesem Kontext wären vor allem drei Themenkomplexe zu untersuchen: erstens das Verhältnis und die Koordination zwischen Bundes- und Landespolitik innerhalb der CSU, zweitens die Struktur und die Arbeitsweise der CSU-Landesgruppe in Bonn $^{29}$ sowie drittens die Politik der CSU im Bundesrat, wobei die ambivalente Funktion dieses Verfassungsorgans als Kanal zur Durchsetzung landespolitischer Interessen und als Werkzeug für parteipolitische Strategien berücksichtigt werden müßte ${ }^{30}$.

Was die Frage nach dem Verhältnis von CDU und CSU betrifft, so ist generell zu sagen, daß hier für die Forschung ein erheblicher Nachholbedarf besteht. Neben den Arbeiten Günter Müchlers ${ }^{31}$ sind vor allem die Protokolle der Arbeitsgemeinschaft der CDU/CSU und der Konferenzen der Landesvorsitzenden der Unionsparteien zu nennen. Diese Quellenedition gibt nicht nur Einblick in verschiedene Bereiche deutscher Nachkriegspolitik, sondern läßt auch die vergleichende Betrachtung von CDU und CSU in den vier Besatzungszonen und in einzelnen deutschen Ländern zu. Eine

und Irrwege der Opposition seit 1969, Köln 1975. Die Quellenbasis dieser Untersuchungen ist jedoch sehr schmal, den Autoren standen hauptsächlich veröffentlichte Reden und Schriften führender CSUPolitiker, Druckschriften der Partei sowie die politische Publizistik zur Verfügung. Vgl. zum Themenkomplex Außenpolitik auch Hans-Jürgen Grabbe, Unionsparteien, Sozialdemokratie und Vereinigte Staaten von Amerika 1945-1966, Düsseldorf 1983, und Clay Clemens, The CSU and West German Foreign Policy. The Strauß Era and beyond, in: Politics and Society in Germany, Austria and Switzerland 2 (1990), S. 16-38.

27 Vgl. den Überblick von Heinrich Oberreuter, Konkurrierende Kooperation - Die CSU in der Bundespolitik, in: Geschichte einer Volkspartei, S. 319-332; Grosser, Fritz Schäffer als Finanzminister, in: Mückl (Hrsg.), Föderalismus und Finanzpolitik; Mintzel, Geschichte der CSU, S. 363-377 und S. 381-393; Wolfgang F. Dexheimer, Koalitionsverhandlungen in Bonn 1961, 1965, 1969. Zur Willensbildung in Parteien und Fraktionen, Konstanz 1973; Daniel Koerfer, Schwierige Geburten: Regierungsbildungen 1961, 1962, 1963 und 1965, in: Wolfgang Mischnick (Hrsg.), Verantwortung für die Freiheit. 40 Jahre F. D. P., Stuttgart 1989, S. 156-162; Domes, Mehrheitsfraktion und Bundesregierung.

${ }^{28}$ Vgl. dazu das entsprechende Kapitel bei Mintzel, Geschichte der CSU, S. 394-415, sowie auch Geoffrey Pridham, Christian Democracy in Western Germany. The CDU/CSU in Government and Opposition 1945-1976, London 1977.

${ }^{29}$ Vgl. erste Informationen bei Wolfgang F. Dexheimer, Die CSU-Landesgruppe. Ihre organisatorische Stellung in der CDU/CSU-Fraktion, in: ZfParl 3 (1972), S. 307-313, und bei Mintzel, Franz Josef Strauß und die CSU-Landesgruppe, in: Zimmermann (Hrsg.), Anspruch und Leistung; vgl. auch Alf Mintzel, Die Rolle der CSU-Landesgruppe im politischen Kräftespiel der Bundesrepublik Deutschland, in: Politische Studien Sonderheft 1/1989, S. 113-134, und Theo Waigel, Die Rolle der CSU-Landesgruppe im Spannungsfeld von Partei, Regierung und Fraktion, in: Politische Studien Sonderheft 1/1989, S. 106-112, sowie den Überblick bei Mintzel, Geschichte der CSU, S. 345-363.

30 Vgl. Rainer Roth, Zentralgewalt und Eigenstaatlichkeit. Das Ringen um die Mitgestaltung der Bundespolitik, in: Rainer A. Roth (Hrsg.), Freistaat Bayern. Die politische Wirklichkeit eines Landes der Bundesrepublik Deutschland, München 3., überarbeitete Auflage 1982, S. 143-160.

${ }^{31}$ Vgl. Müchler, Zum frühen Verhältnis, und Müchler, CDU/CSU. Müchler, der das Verhältnis der Unionsparteien bis in die siebziger Jahre untersucht hat, konnte neben dem Archiv der CSU-Landesleitung auch Bestände im Archiv der Bonner Landesgruppe auswerten; beachtenswert die konstruktive Kritik von Mintzel, CSU in Bayern, in: Niedermayer/Stöss (Hrsg.), Stand und Perspektiven, S. 104-108. Für die siebziger Jahre vgl. auch Wolfgang Pauly, Christliche Demokraten und Christlich-Soziale. Untersuchungen zum innerparteilichen Bündnisverhalten von CDU und CSU 1969-1979, Diss., Trier 1981. 
solche Perspektive könnte es ermöglichen, die Geschichte der CSU in den ersten Jahren nach ihrer Gründung aus ihrer vielleicht nur scheinbaren Singularität herauszulösen und sowohl Besonderheiten als auch Parallelen der Entwicklung durch den historischen Vergleich mit den einzelnen Landesverbänden der Bundes-CDU in statu nascendi besser faßbar zu machen ${ }^{32}$.

Von den Problemkomplexen, deren Ursprung vor 1949 liegt, war es vor allem das bis in die sechziger Jahre überaus spannungsreiche Verhältnis zwischen CSU und Bayernpartei, das die Aufmerksamkeit von Historikern und Politologen erregt hat. Die Entwicklung der Bayernpartei zu einem „Krisenfaktor der CSU“33, die damit verbundene Spaltung des politischen Katholizismus insbesondere in Altbayern sowie die jahrelangen Auseinandersetzungen zwischen diesen beiden verwandten Parteien waren neben der Geschichte und Struktur der Bayernpartei selbst Gegenstand umfangreicherer Untersuchungen ${ }^{34}$. Die sogenannte Spielbankenaffäre als Höhepunkt der „Aufreibung und Aufsaugung “ ${ }^{35}$ dieser Konkurrenzpartei durch die CSU war dabei von besonderem Interesse, da sie weithin sichtbar den Niedergang der Bayernpartei markier$\mathrm{te}^{36}$. Bisher unzugängliche Quellenbestände - Nachlässe und Akten der Führungsgremien der bayerischen Unionspartei - lassen jedoch eine erneute Beschäftigung mit dem „Bruderkampf“37 zwischen CSU und BP dringend geboten erscheinen. Daß die Auseinandersetzungen zwischen diesen beiden Parteien noch verworrener und facettenreicher waren, als man das bisher angenommen hat, zeigt beispielsweise die noch unveröffentlichte biographische Studie von Regina Vossen über den Bayernpartei-Vorsitzenden Joseph Baumgartner ${ }^{38}$.

Über die Föderalismusthematik, die auf die CSU äußerst polarisierend wirkte, sind wir für die Zeit zwischen 1945 und 1949 hauptsächlich durch die Studien von Peter Jakob Kock unterrichtet ${ }^{39}$. Eine wichtige Ergänzung stellen in diesem Zusammenhang die von Rainer Salzmann edierten Protokolle der CDU/CSU-Fraktionen im Frankfurter Wirtschaftsrat und im Parlamentarischen Rat dar ${ }^{40}$. Sie geben nicht nur Einblick in

${ }^{32}$ Vgl. Unionsparteien. Ansätze dazu bei Werner Burger, Die CDU in Baden-Württemberg und die CSU in Bayern. Eine vergleichende Analyse, Freiburg 1984, und bei Rainer Nick, Schwesterparteien. CDU, CSU und Österreichische Volkspartei. Ein Vergleich, Innsbruck 1984.

${ }^{33}$ Mintzel, CSU, in: Stöss (Hrsg.), Parteien-Handbuch, Bd. 2, S. 687.

${ }^{34}$ Vgl. Wolf, CSU und BP; Mintzel, Bayernpartei, in: Stöss (Hrsg.), Parteien-Handbuch, Bd. 1, S. 395-489; Unger, Bayernpartei.

${ }^{35}$ Wolf, CSU und BP, S. 179.

${ }^{36}$ Vgl. Volkmar Gabert, Die Bedeutung der Viererkoalition und des Spielbankenuntersuchungsausschusses für die Entwicklung der politischen Verhältnisse in Bayern, in: Hans Jochen Vogel, Helmut Simon, Adalbert Podlech (Hrsg.), Die Freiheit des Anderen. Festschrift für Martin Hirsch, BadenBaden 1981, S. 187-206, und Heinrich Senfft, Glück ist machbar. Der bayerische Spielbankenprozeß, die CSU und der unaufhaltsame Aufstieg des Doktor Friedrich Zimmermann. Ein politisches Lehrstück, Köln 1988. Senfft behandelt das Thema in der ihm eigenen polemischen Art.

37 ACSP, NL Seidel 35 c, Rundfunkrede Alois Hundhammers am 22. 6. 1949.

38 Vgl. Vossen, Joseph Baumgartner.

39 Vgl. Kock, Bayerns Weg, und Peter Jakob Kock, Bayern und Deutschland. Föderalismus als Anspruch und Wirklichkeit, in: Benz (Hrsg.), Neuanfang in Bayern, S. 183-204; vgl. auch Stelzle, Föderalismus und Eigenstaatlichkeit. Zur Positionsbestimmung innerhalb der CDU/CSU vgl. Richard Ley, Föderalismusdiskussion innerhalb der CDU/CSU von der Parteigründung bis zur Verabschiedung des Grundgesetzes, Mainz 1978, und Wolfgang Benz, Föderalistische Politik in der CDU/ CSU. Die Verfassungsdiskussion im „Ellwanger Kreis“ 1947/48, in: VfZ 25 (1977), S. 776-820. Vgl. auch die Untersuchung von D. R. Dorondo, Bavaria and German Federalism. Reich to Republic, 1918-33, 1945-49, New York 1992.

$40 \mathrm{Vgl}$. CDU/CSU im Parlamentarischen Rat, und CDU/CSU im Frankfurter Wirtschaftsrat. 
die Politik der Unionsparteien im Vorfeld der Weststaatsgründung, sondern lassen auch Rückschlüsse auf abweichende Standpunkte der CSU und auf Kontroversen unter ihren Mandatsträgern zu. Die Entwicklung des Verhältnisses zwischen Bayern und der Bundesrepublik seit 1949 im allgemeinen und die föderalistische Politik der CSU in den fünfziger und sechziger Jahren im besonderen war dagegen bis vor kurzem ein weißer Fleck in der Nachkriegsgeschichte Bayerns. Die vorzügliche Dissertation von Karl-Ulrich Gelberg schließt diese Lücke zumindest teilweise ${ }^{41}$.

Vergeblich sucht man eine systematische Untersuchung der bayerischen Kulturpolitik seit 1945. Neben dem Föderalismusproblem gehörte dieser Politikbereich bis zum Ende der fünfziger Jahre zu den umstrittensten Themen überhaupt und löste nicht nur zwischen Parteien, Kirchen und Verbänden heftige Diskussionen aus, sondern führte auch in der CSU zu schwerwiegenden Auseinandersetzungen. Insbesondere die kulturpolitischen Konzeptionen des katholisch-konservativen Flügels der CSU, allen voran diejenigen Alois Hundhammers und Georg Meixners, erwiesen sich als permanente innere Belastung und trugen nicht unwesentlich zum Machtwechsel nach der Landtagswahl im November 1954 bei $^{42}$. Bisher liegen jedoch lediglich zur bayerischen Schulpolitik mehrere Studien vor, wobei vor allem der Wiederaufbau des Schulwesens nach 1945 und das lange Jahre strukturell unlösbare Problem der Lehrerbildung die Aufmerksamkeit der Forschung gefunden haben ${ }^{43}$.

Grundsätzlich ist festzustellen, daß die Regierungspolitik der CSU bislang kaum größeres Interesse gefunden hat. Die Grundprobleme sind zwar in den bekannten Überblicksdarstellungen skizziert ${ }^{44}$, Spezialstudien zu wichtigen Bereichen fehlen jedoch. Dies gilt auch für die wirtschaftspolitischen Konzeptionen der $\mathrm{CSU}^{45}$. Die „späte Vollindustrialisierung" Bayerns, deren politische Steuerung nach Alf Mintzel die „sozialökonomische Hauptaufgabe der CSU“ war, ist für die Sozial- und Wirtschafts-

${ }^{41}$ Vgl. Gelberg, Hans Ehard.

${ }^{42}$ Vgl. dazu Bretschneider, Viererkoalition.

${ }^{43}$ Vgl. Isa Huelsz, Schulpolitik in Bayern zwischen Demokratisierung und Restauration in den Jahren 1945-1950, Hamburg 1970; Sonnenberger, Rekonfessionalisierung; Buchinger, Volksschule und Lehrerbildung; Müller, Schulpolitik; Richter, Schule für Bayern. Zum Gesamtzusammenhang vgl. Georg Knauss, Kulturhoheit der Länder - Chance oder Hypothek?, in: Roth (Hrsg.), Freistaat Bayern, S. 161-174.

${ }^{44}$ Vgl. Baer, Ministerpräsidenten; Gruner, Fritz Schäffer und der Neubeginn, in: Mückl (Hrsg.), Föderalismus und Finanzpolitik, S. 37-66; Ernst Deuerlein, Wolf D. Gruner, Die politische Entwicklung Bayerns 1945-1972, in: Spindler (Hrsg.), Handbuch der bayerischen Geschichte, Bd. IV/1, S. 538-644; Zorn, Bayerns Geschichte, Kap. V und VI; als Einführung nützlich Hartmann, Bayerns Weg, S. 530-599; die neueste Darstellung bei Maximilian Lanzinner, Zwischen Sternenbanner und Bundesadler. Bayern im Wiederaufbau 1945-1958, Regensburg 1996; einiges auch bei Mintzel, Geschichte der CSU, S. 298-344. Zum Selbstverständnis der bayerischen Unionspartei vgl. Hans Ehard, Die CSU als Regierungspartei, in: Politisches Jahrbuch der CSU 1954, S. 55-80.

${ }^{45}$ Zur wirtschaftlichen Entwicklung Bayerns allgemein vgl. Schreyer, Industriestaat, sowie Erker, Keine Sehnsucht nach der Ruhr, und Paul Erker, Der lange Abschied vom Agrarland. Zur Sozialgeschichte der Bauern im Industrialisierungsprozeß, in: Matthias Frese, Michael Prinz (Hrsg.), Politische Zäsuren und gesellschaftlicher Wandel im 20. Jahrhundert. Regionale und vergleichende Perspektiven, $\mathrm{Pa}$ derborn 1996, S. 327-360; Andreas Eichmüller, Landwirtschaft und bäuerliche Bevölkerung in Bayern. Ökonomischer und sozialer Wandel 1945-1970. Eine vergleichende Untersuchung der Landkreise Erding, Kötzting und Obernburg, München 1997. Interessante Überlegungen über die Wirkung gesellschaftspolitischer Konzeptionen finden sich in dem Beitrag von Detlev Ipsen, Thomas Fuchs, Die Modernisierung des Raumes - Blockierung und Öffnung. Raumbilder als historische Bedingung regionaler Entwicklung in Nordhessen und Oberbayern, in: 19996 (1991) H. 1, S. 13-33. Zur diesbezüglichen Programmatik und Politik der CSU vgl. Mintzel, Geschichte der CSU, S. 235-271; die folgenden Zitate finden sich ebenda, S. 35 und S. 49. 
geschichte Bayerns nach dem Zweiten Weltkrieg von kaum zu überschätzender Bedeutung. Um so wichtiger wäre es, die strukturpolitischen Grundentscheidungen der Nachkriegszeit, ihre politische Durchsetzung und ihren Erfolg oder Mißerfolg zu erforschen ${ }^{46}$. Damit verbunden ist auch die Frage, wie die Modernisierungsimpulse, denen die bayerische Gesellschaft nach 1945 ausgesetzt war, auf die politische Kultur wirkten und inwieweit sie die politische Mentalität der Bevölkerung prägten ${ }^{47}$. Vergleichende Regional- und Lokalstudien, die eine erfolgversprechende Annäherung an den bisher lediglich konstatierten „innerbayerischen politisch-kulturellen Homogenisierungsprozeß ${ }^{\text {“48 }}$ erlauben und die Rolle, die die CSU dabei spielte, erhellen würden, sind jedoch noch nicht durchgeführt worden ${ }^{49}$. Auch fehlt bislang eine Untersuchung über die Landtagsfraktion der CSU, die nicht nur zu den wichtigsten innerparteilichen Entscheidungszentren zählte, sondern auch die Politik der CSU-geführten Kabinette wesentlich mitgestaltet und durchgesetzt hat ${ }^{50}$.

$\mathrm{Zu}$ den Desideraten der Forschung gehört ferner das Verhältnis der CSU zu großen gesellschaftlichen Gruppen oder einflußreichen Interessenverbänden. Dabei ist die Analyse dieser wechselseitigen Beziehungen zum Verständnis von Politik und Herrschaftspraxis politischer Parteien gerade in einem politischen System überaus wichtig, das so sehr von der Dominanz einer Partei geprägt ist wie das Bayerns. Aufschlußreich wäre sicherlich, wie sich das Verhältnis zwischen der CSU und dem Bayerischen Bauernverband sowie zwischen der CSU und den Repräsentanten der Wirtschaft auf der einen und den Gewerkschaften ${ }^{51}$ auf der anderen Seite gestaltet hat. Von besonderem Interesse wären dabei genauere Kenntnisse über den 1948 gegründeten Wirtschaftsbeirat der Union ${ }^{52}$, einer nominell unabhängigen Vereinigung, die nicht nur bei der Finanzierung der CSU eine wichtige Rolle spielte und in der ersten Hälfte der fünfziger Jahre auch großen Einfluß auf die programmatische Entwicklung der Partei hatte, sondern sich an der Nahtstelle zwischen Partei, Staat und Wirtschaft zunehmend zu einer

46 Vgl. Gerhard Kleinhenz, Wirtschafts- und Sozialpolitik - Die Verwirklichung einer Sozialen Marktwirtschaft durch die Landespolitik der CSU, in: Geschichte einer Volkspartei, S. 253-289.

47 Vgl. erste Überlegungen dazu bei Alf Mintzel, Besonderheiten der politischen Kultur Bayerns. Facetten und Etappen einer politisch-kulturellen Homogenisierung, in: Dirk Berg-Schlosser, Jakob Schissler (Hrsg.), Politische Kultur in Deutschland. Bilanz und Perspektiven der Forschung, Opladen 1987, S. 295-308; Alf Mintzel, Political and Socio-Economic Developments in the Post-War Era: The Case of Bavaria 1945-1989, in: Karl Rohe (Hrsg.), Elections, Parties and Political Traditions, New York u. a. 1990, S. 145-178. Vgl. auch die Kontroverse zwischen Alf Mintzel und Jürgen Falter: Jürgen W. Falter, Bayerns Uhren gehen wirklich anders. Politische Verhaltens- und Einstellungsunterschiede zwischen Bayern und dem Rest der Bundesrepublik, in: ZfParl 13 (1982), S. 504-521; Alf Mintzel, Gehen in Bayern die Uhren wirklich anders?, in: ZfParl 18 (1987), S. 145-178; Jürgen W. Falter, Wie gehen sie nun wirklich, die bayerischen Uhren?, in: ZfParl 19 (1988), S. $113 \mathrm{f}$.

${ }^{48}$ Mintzel, CSU, in: ders./Oberreuter (Hrsg.), Parteien in der BRD, S. 227.

${ }^{49}$ Im Gefolge der Pionierstudie von Woller, Gesellschaft und Politik, sind für die Besatzungszeit inzwischen mehrere Arbeiten erschienen; vgl. z. B. Dietmar Grypa, Studien zu Kriegsende und Neuanfang im Landkreis Altötting, Burghausen 1991. Für die Jahre 1945-1949 existiert auch eine Vielzahl von Diplom-, Magister- und Zulassungsarbeiten, die sich mit der Gründung und Entwicklung der CSU bis 1949 befassen und von denen einige im Literaturverzeichnis der vorliegenden Arbeit aufgeführt sind.

so Vgl. die Festschriften 30 Jahre Landtagsfraktion der CSU; Gerold Tandler (Hrsg.), 40 Jahre Landtagsfraktion der CSU, Würzburg 1986; In Verantwortung für Bayern.

${ }^{51}$ Vgl. Karl Jörg Wohlhüter, Die CSU. Der linke Flügel lahmt, in: Peter Josef Bock (Hrsg.), Im Prinzip sozial. Die großen Parteien und die Arbeitnehmer, Hannover 1976, S. 87-105.

52 Vgl. Franz Elsen, Der Wirtschaftsbeirat, in: Politisches Jahrbuch der CSU 1954, S. 126 f., und Georg Haindl, Der Wirtschaftsbeirat der CSU. Mittler zwischen Politik und Wirtschaft, in: Gesellschaftspolitische Kommentare 14 (1967), S. 236-238. Haindl war lange Jahre Vorsitzender des Wirtschaftsbeirats. 
„Schaltstelle des Interessenausgleichs" ${ }^{43}$ entwickelte. Weiterhin müßte das Verhältnis der bayerischen Unionspartei zu den christlichen Kirchen genauer als bisher analysiert werden ${ }^{54}$. Vordringlich ist in diesem Zusammenhang zum einen die Erforschung der selten spannungsfreien Beziehungen der CSU zur Evangelisch-Lutherischen Kirche Bayerns und der parteiinternen Bewältigung konfessioneller Konflikte als Voraussetzung für die Gewinnung des protestantischen Bevölkerungsteils in Ober- und Mittelfranken ${ }^{55}$. Zum anderen gilt es, das Verhältnis der CSU zur katholischen Kirche im Kontext der sozialen und politischen Veränderungen, denen die westdeutsche Gesellschaft seit den fünfziger Jahren ausgesetzt war, zu untersuchen. Alf Mintzel hat noch vor wenigen Jahren davon gesprochen, daß die Beziehung von CSU und katholischer Kirche "traditionsgemäß geradezu symbiotisch" geblieben sei ${ }^{56}$. Ob dieser Befund jedoch tatsächlich tragfähig ist oder ob er - trotz der Einschränkung, daß sich die CSU durch ihre Metamorphose zu einer wirklich christlich-interkonfessionellen Partei „vom Odium [...] , klerikaler Abhängigkeit“" befreit habe - nicht den Blick auf zentrale Probleme verstellt, wird sich erst erweisen, wenn quellengesättigte Studien zu den diesbezüglichen Fragen vorliegen.

Nicht ganz so negativ fällt die Bestandsaufnahme im Hinblick auf die lange vernachlässigte Biographieforschung aus, wo sich gerade in jüngster Zeit einiges getan hat. Sprach Hans-Ulrich Wehler 1971 noch von einer „Krise der politischen Biographie“57, so erlebt diese Form der Historiographie in den letzten Jahren unzweifelhaft eine Renaissance. Dieser Trend wirkt sich auch positiv auf die Erforschung der bayerischen Nachkriegsgeschichte im allgemeinen und auf die Erforschung der Geschichte der CSU im besonderen aus. Bis in die zweite Hälfte der achtziger Jahre hinein waren biographische Studien über führende CSU-Politiker Mangelware. Es existierten in den meisten Fällen nur skizzenhafte Darstellungen und mehr oder weniger tendenziöse Lebensbilder $^{58}$. Erst in den letzten Jahren wurde über einige prominente Vertreter der

53 So - wenn auch in anderem Zusammenhang - Möckl, Struktur, S. 751.

54 Zum Urkonflikt der CSU zwischen Katholiken und Protestanten vgl. Kühnel, Fränkischer Protestantismus; Renner, Nachkriegsprotestantismus; Hermann Ehlers. Präsident des Deutschen Bundestages. Ausgewählte Reden, Aufsätze und Briefe 1950-1954, bearb. von Rüdiger Wenzel, hrsg. und eingel. von Karl Dietrich Erdmann, Boppard am Rhein 1991; Frederic Spotts, Kirchen und Politik in Deutschland, Stuttgart 1976; Trippen, Interkonfessionelle Irritationen, in: Bracher u. a. (Hrsg.), Staat und Parteien. Zum Verhältnis der CDU bzw. CSU zur katholischen Kirche vgl. Rudolf Morsey, Katholizismus und Unionsparteien in der Ära Adenauer, in: Albrecht Langner (Hrsg.), Katholizismus im politischen System der Bundesrepublik 1949-1963, Paderborn 1978, S. 33-59; Thomas M. Gauly, Katholiken. Machtanspruch und Machtverlust, Bonn 1991; Thomas Grossmann, Zwischen Kirche und Gesellschaft. Das Zentralkomitee der deutschen Katholiken 1945-1970, Mainz 1991; Bernhard Lehmann, Katholische Kirche und Besatzungsmacht in Bayern 1945-1949 im Spiegel der OMGUSAkten, München 1994.

55 Welche Rolle dabei der Evangelische Arbeitskreis der CSU spielen konnte, wäre genauer zu analysieren. Vgl. dazu Egen, Entstehung; Roman Herzog, Die geistigen Grundlagen der freiheitlichen Gesellschaftsordnung. Zugleich: zu den Aufgaben des Evangelischen Arbeitskreises der CDU/CSU in Politik und Kirche, in: Hermann Kunst, Helmut Kohl, Peter Egen (Hrsg.), Dem Staate verpflichtet. Festgabe für Gerhard Schröder, Stuttgart, Berlin 1980, S. 157-169, und Besier, Christliche Parteipolitik.

56 Mintzel, CSU in Bayern, in: Niedermayer/Stöss (Hrsg.), Stand und Perspektiven, S. 100; das folgende Zitat ebenda.

57 Hans-Ulrich Wehler, Zum Verhältnis von Geschichtswissenschaft und Psychoanalyse, in: ders. (Hrsg.), Geschichte und Psychoanalyse, Köln 1971, S. 9-30, hier S. 9 f.; vgl. auch Hagen Schulze, Die Biographie in der „Krise der Geschichtswissenschaft“, in: GWU 29 (1978), S. 508-518.

$58 \mathrm{Vgl}$. z. B. Josef H. Mauerer, Aus dem Leben und politischen Wirken des Dr. Josef Müller (Ochsensepp) 1945-1965, München 1967. 
bayerischen Unionspartei eine politische Biographie verfaßt. Den Anfang machte 1987 Christiane Reuter mit ihrer Studie über Anton Pfeiffer, den Stabschef Hans Ehards, der als ehemaliger Generalsekretär der BVP nach 1945 in den Führungs- und Flügelkämpfen auf der Seite Fritz Schäffers und Alois Hundhammers stand ${ }^{59} .1991$ erschien Friedrich Hermann Hettlers Biographie über Josef Müller, eine der schillernden Figuren, an denen die bayerische Politik nicht eben arm ist ${ }^{60}$. Eine Studie über den Ochsensepp war auch unter dem Gesichtspunkt der Parteigeschichte seit langem wünschenswert. Da Hettler jedoch nicht auf den materialreichen Nachlaß Josef Müllers zurückgreifen konnte, bleibt seine Studie zumindest für die Zeit nach 1945 blaß und liefert nur an wenigen Stellen neue Erkenntnisse ${ }^{61}$.

Von Müllers Gegnern hat vor allem Fritz Schäffer in jüngster Zeit die Aufmerksamkeit der historischen Forschung gefunden. Aus Anlaß seines 100. Geburtstages fand 1988 an der Universität Passau ein Symposion statt, dessen Beiträge zwei Jahre später als „Gedenkschrift für Fritz Schäffer" veröffentlicht wurden ${ }^{62}$. Mittlerweile sind auch zwei Dissertationen über den BVP-Vorsitzenden und späteren Bundesfinanzminister fertiggestellt worden, in denen die politische Biographie Schäffers detailliert aufgearbeitet ist ${ }^{63}$. Dagegen fehlt noch immer eine wissenschaftliche Studie über Alois Hundhammer, die aber angesichts der Quellenlage - der Nachlaß gilt als verschollen - nicht $\mathrm{zu}$ erwarten ist ${ }^{64}$. Dasselbe gilt für den Bamberger Domkapitular und Päpstlichen Hausprälaten Georg Meixner, dessen Nachlaß ebenfalls verloren ist ${ }^{65}$. Auch Hans Ehard stand bis Anfang der achtziger Jahre im Abseits der Forschung. Es war dann vor allem Rudolf Morsey, der sich in mehreren Aufsätzen mit Ehard beschäftigte, wobei für ihn vor allem die politische Rolle des bayerischen Ministerpräsidenten im Prozeß der Gründung eines deutschen Weststaates von Interesse war ${ }^{66}$. Die erste umfangreiche Studie über Hans Ehard, aus der Feder von Karl-Ulrich Gelberg, hebt ebenfalls

59 Vgl. Reuter, Anton Pfeiffer. Die Autorin betont in ihrer Studie die Autonomie der politischen Vorstellungen Pfeiffers gegenüber denjenigen Hundhammers und Schäffers; ebenda, S. $128 \mathrm{f}$.

${ }^{60} \mathrm{Vgl}$. Hettler, Josef Müller. Zur Verwicklung Müllers in die „Arisierung“ jüdischen Eigentums vgl. das cum ira et studio verfaßte Kapitel ${ }_{n}$ Kratzen an einer Legende: Die Eidenschink-Konsorten und der ,Ochsensepp'“ in dem Buch von Ludwig, Boykott, Enteignung, Mord, S. 87-103.

${ }^{61}$ So zur Ausschaltung Müllers bei der ersten parlamentarischen Regierungsbildung in Bayern nach Kriegsende (S. 274-310) und zur gleitenden Entmachtung des CSU-Vorsitzenden 1948/1949 (S. 390-409). Eine intensivere Auswertung der vorhandenen Quellen und der Literatur wäre ebenso wünschenswert gewesen wie ein kritischerer Umgang mit Müllers Memoiren.

$62 \mathrm{Vgl}$. Mückl (Hrsg.), Föderalismus und Finanzpolitik. Hervorzuheben ist vor allem der Beitrag Grossers über Fritz Schäffer als Bundesfinanzminister.

${ }^{63} \mathrm{Vgl}$. Henzler, Fritz Schäffer. Henzlers umfangreiche Arbeit ist vor allem für die Frühgeschichte der CSU von Bedeutung, während sie Schäffers Rolle in der CSU nach 1949 nur am Rande berührt. Zur politischen Biographie Schäffers vor 1945 vgl. Altendorfer, Fritz Schäffer, und Otto Altendorfer, Fritz Schäffer. Politik in schwierigen Zeiten. Eine Studie zum 100. Geburtstag (1888-1988), in: Politische Studien 39 (1988), S. 305-322, sowie Hartmann/Altendorfer (Hrsg.), 100 Jahre Fritz Schäffer.

${ }^{64}$ Zu Hundhammer vgl. Zittel, Alois Hundhammer, in: Aretz/Morsey/Rauscher (Hrsg.), Zeitgeschichte in Lebensbildern, Bd. 5, und Paul Hussarek, Hundhammer. Weg des Menschen und Staatsmannes, München 1951. Im ACSP wird lediglich ein unergiebiger Nachlaßsplitter verwahrt.

${ }^{65} \mathrm{Vgl}$. jetzt Blessing, Georg Meixner.

${ }^{66} \mathrm{Vgl}$. Rudolf Morsey, Föderalismus im Bundesstaat. Die Rolle des bayerischen Ministerpräsidenten Hans Ehard in der Vor- und Frühgeschichte der Bundesrepublik Deutschland, in: HJb 108 (1988), S. 430-447; Rudolf Morsey, Hans Ehard (1887-1980), in: GiW 2 (1987), S. 71-89; Rudolf Morsey, Zwischen Bayern und der Bundesrepublik. Die politische Rolle des bayerischen Ministerpräsidenten Hans Ehard 1946-1949, in: Juristenzeitung 36 (1981), S. 361-370; Vgl. auch Dieter Albrecht, Hans Ehard (1887-1980), in: Aretz/Morsey/Rauscher (Hrsg.), Zeitgeschichte in Lebensbildern, Bd. 5, S. 266-280. 
primär auf die staatspolitische Ebene ab. Gelberg analysiert die föderalistische Politik und die dahinterstehenden Konzeptionen des bayerischen Ministerpräsidenten zwischen 1946 und 1954, während ihn Ehards Rolle als Landesvorsitzender der CSU erst in zweiter Linie interessiert ${ }^{67}$. Eine biographische Untersuchung zu Hanns Seidel hat Hans Ferdinand Groß 1992 vorgelegt ${ }^{68}$. Diese Studie leidet allerdings unter dem Manko, daß sie den Einfluß Seidels auf die Reorganisation der CSU nach seiner Wahl zum Parteivorsitzenden im Januar 1955 ebensowenig aufzeigt wie seinen Einfluß auf die bayerische Politik während seiner Zeit als Wirtschaftsminister und vor allem als Ministerpräsident. Eine wissenschaftliche Aufarbeitung der politischen Biographie von Franz Josef Strauß steht dagegen noch aus. Neben einer Vielzahl von publizistischpolemischen Beiträgen existieren einige knappe Überblicksdarstellungen, die zum Teil erst vor kurzem erschienen sind ${ }^{69}$. Eine aus dem umfangreichen Nachlaß gearbeitete biographische Studie über den CSU-Vorsitzenden und Ministerpräsidenten darf mit Spannung erwartet werden.

Man betritt also bei der Erforschung von Geschichte, Struktur und Politik der CSU kein Neuland mehr, allerdings bleibt noch viel zu tun. Die Rahmenbedingungen für diesbezügliche Arbeiten sind jedoch günstiger als je zuvor, da die CSU ihrer eigenen Geschichte in den letzten Jahren offensichtlich mehr Aufmerksamkeit geschenkt und in diesem Sinne auch wissenschaftliche Untersuchungen gefördert hat. 1986 wurde das Archiv für Christlich-Soziale Politik als neues und eigenständiges Referat in die Akademie für Politik und Zeitgeschehen der Hanns-Seidel-Stiftung eingegliedert und mit der Sammlung und archivalischen Erschließung von parteiinternem Schriftgut sowie von Nachlässen betraut ${ }^{70}$. Mittlerweile ist auch eine eigene Schriftenreihe ins Leben gerufen worden, deren erster Band 1992 erschienen ist. Die Öffnung der CSU für ihre eigene Geschichte setzte sich mit den Feierlichkeiten zum 50 jährigen Gründungsjubiläum der Partei im Herbst 1995 fort. Die Parteiführung veranstaltete nicht nur ein medienwirksames Spektakel in der Münchner Olympiahalle, das einmal mehr der Selbstdarstellung der CSU als der einzig legitimen Vertreterin Bayerns galt. Ein mehr als 800 Seiten dickes Sammelwerk sollte überdies die Entwicklung der CSU dokumentieren. Mit dem Sammelband "Geschichte einer Volkspartei. 50 Jahre CSU“ liegt tatsächlich so etwas wie eine Bestandsaufnahme des gegenwärtigen Forschungsstandes vor. Elf Aufsätze zu zentralen Aspekten der Parteigeschichte werden ergänzt durch ausgewählte Quellentexte, Erinnerungsinterviews mit so wichtigen Entscheidungsträgern wie Werner Dollinger, Franz Heubl oder Friedrich Zimmermann und einen Anhang, der biographische Daten, eine Zeittafel, Mitgliederzahlen und Wahlergebnisse enthält.

\footnotetext{
${ }^{67}$ Zu Gelbergs Ehard-Biographie vgl. Rudolf Morsey, Das föderalistische Konzept Hans Ehards. Ansprache anläßlich der Präsentation des Buches von Karl-Ulrich Gelberg über den bayerischen Ministerpräsidenten, in: ZfBLG 56 (1993), S. 769-775.

68 Vgl. Groß, Hanns Seidel.

${ }^{69}$ Vgl. Alf Mintzel, Franz Josef Strauß, in: Walther L. Bernecker, Volker Dotterweich (Hrsg.), Persönlichkeit und Politik in der Bundesrepublik Deutschland. Politische Porträts, Bd. 2, Göttingen 1982, S. 196-208; Horst Möller, Franz Josef Strauß 1915-1988, in: Lothar Gall (Hrsg.), Die großen Deutschen unserer Epoche, Berlin 1995, S. 535-553; Krieger, Franz Josef Strauß. Von der Vielzahl der publizistisch-polemischen Darstellungen sei lediglich genannt Erich Kuby u. a., Franz Josef Strauß. Ein Typus unserer Zeit, Wien u. a. 1963.

70 Vgl. die Broschüre „ACSP-Informationen“ von 1989, S. 1.
} 
Ein großes Forschungsprojekt zur Geschichte Bayerns und der CSU auf der Basis „der arbeitsteiligen Annäherung und interdisziplinären Zusammenarbeit von Geschichtswissenschaft und Sozialwissenschaft, von Landesgeschichte, politischer Zeitgeschichte und sozialwissenschaftlicher Struktur- und Prozeßanalyse“, wie es Alf Mintzel vor einigen Jahren gefordert hat ${ }^{71}$, ist jedoch derzeit nicht in Sicht.

\section{b) Quellenlage}

Gedruckte Quellen zur Geschichte der CSU stehen nach wie vor nur in sehr begrenztem Umfang zur Verfügung. Lediglich für die Phase der „Lehrjahre der CSU“ bis 1949 sind wichtige Materialien publiziert worden. An erster Stelle ist hier die schon angesprochene Edition von Klaus-Dietmar Henke und Hans Woller zu nennen, wobei quellenkritisch anzumerken ist, daß hier keine internen Dokumente aus den Gremien der CSU veröffentlicht wurden, sondern die Aufzeichnungen eines gut unterrichteten Gewährsmannes der amerikanischen Militärregierung, die die Konflikte und Gegensätze in der Partei mehrfach gebrochen widerspiegeln. Ebenfalls bereits Erwähnung fand die Edition der Protokolle der Arbeitsgemeinschaft der CDU/CSU und der Konferenzen der Landesvorsitzenden, die vor allem Einblick geben in die Phase der Formierung der CDU und der Sonderentwicklung der CSU zur autonomen Landespartei, aber auch über wichtige Fragen der staatlichen Entwicklung Deutschlands vor und nach der Gründung der Bundesrepublik informieren. Primär waren die Fraktionen von CDU und CSU im Frankfurter Wirtschaftsrat und im Parlamentarischen Rat mit diesen Problemen beschäftigt, deren Sitzungsprotokolle ebenfalls ediert vorliegen.

Mit der 1993 im Auftrag des Instituts für Zeitgeschichte veröffentlichten Dokumentation „Die CSU 1945-1948“ konnte die Forschung zur stürmischen Geschichte der bayerischen Unionspartei in den ersten Jahren der Ära Müller auf eine neue Grundlage gestellt werden ${ }^{72}$. Diese bisher einzige geschlossene Sammlung parteiinterner Quellen zur Geschichte der CSU enthält auf fast 1700 Seiten die bislang nur schwer oder überhaupt nicht zugänglichen Protokolle der vorläufigen Gründungs- und Führungsgremien der CSU, der Landesausschußsitzungen und der Landesversammlungen von September 1945 bis Februar 1948; lediglich die Protokolle des Landesvorstands fehlen. Diese 32 Dokumente, teils Ergebnis-, teils Verlaufs-, überwiegend jedoch Wortprotokolle, ermöglichen eine intensive Auseinandersetzung mit den politischen Grundproblemen der CSU und den parteiinternen Führungs- und Flügelkämpfen. In einem umfangreichen Anhang finden sich zudem neben wichtigen Materialien zur organisatorischen und programmatischen Entwicklung der bayerischen Unionspartei mehr als 570 Kurzbiographien, die sich fast ausschließlich auf Gründungsmitglieder der CSU vom Landesvorstand bis zu den Kreis- und Ortsvorsitzenden beziehen. Ob und in welcher Form diese Dokumentation zu einer Neuinterpretation der frühen CSU-Geschichte beitragen wird, bleibt abzuwarten. Möglicherweise wird man - wie schon 1946 der Historiker Hermann Mau nach Gesprächen mit Josef Müller und Friedrich

\footnotetext{
7 Mintzel, CSU in Bayern, in: Niedermayer/Stöss (Hrsg.), Stand und Perspektiven, S. 118.

72 Die hier veröffentlichten Dokumente finden sich zum Teil auch abgedruckt im Quellenteil von Geschichte einer Volkspartei, S. 424-475, der für die Jahre 1945 bis 1949 darüber hinaus noch einige interessante Ergänzungen liefert.
} 
Wilhelm von Prittwitz-Gaffron - die innovativen Potentiale dieser Partei stärker gewichten müssen als die restaurativen ${ }^{73}$.

Für die fünfziger und frühen sechziger Jahre gibt es dagegen so gut wie keine publizierten Quellenmaterialien. Einiges findet sich in der neunbändigen Edition Ossip K. Flechtheims, die in der Hauptsache Satzungen, programmatische Dokumente oder Presseveröffentlichungen, aber auch so wichtige interne Materialien wie Auszüge aus den vertraulichen Rechenschaftsberichten der CSU-Generalsekretäre enthält ${ }^{74}$. Ansonsten ist vor allem der Rückgriff auf die bis 1961 ediert vorliegenden Protokolle des Bundesvorstands der großen Schwesterpartei CDU hilfreich ${ }^{75}$. In diesem Gremium wurde nicht nur immer wieder aus bundespolitischem Blickwinkel über innerbayerische Entwicklungen oder die CSU betreffende Fragen gesprochen, oft genug kamen die Exponenten der bayerischen Union auch selbst zu Wort.

Diese publizierten Dokumente wurden für die vorliegende Studie ebenso ausgewertet wie verschiedene Periodika der CSU, wobei für die Jahre zwischen 1946 und 1948 vor allem die Mitteilungen der Christlich-Sozialen Union und die Halbmonatsschrift Bayerische Rundschau zu nennen sind. Während das Mitteilungsblatt vorwiegend über aktuelle politische Fragen informierte, war die Bayerische Rundschau mehr programmatisch orientiert. Im Herbst 1948 wurden diese beiden Blätter zugunsten der Wochenzeitung Der Gerade Weg eingestellt, die als offizielles Publikationsorgan der CSU diente, bis sie im Mai 1949 aus Geldmangel ebenfalls aufgegeben werden mußte. Als langlebiger erwiesen sich der erstmals 1950 erschienene Bayern-Kurier und die von der Landtagsfraktion herausgegebene CSU-Correspondenz, in der sich unter anderem die Konflikte zwischen Parteiführung und Fraktion sowie zwischen der Landtagsfraktion und der CSU-Landesgruppe in Bonn widerspiegeln.

Konsultiert wurden selbstverständlich auch die wenigen Memoiren und Autobiographien von führenden Politikern der CSU. 1975, vier Jahre vor seinem Tod, veröffentlichte Josef Müller seine Erinnerungen, deren Hang zur Selbststilisierung nicht zu übersehen ist ${ }^{76}$. Der erste Landesvorsitzende der CSU legte den Schwerpunkt seiner Memoiren auf seine Aktivitäten im Widerstand gegen das NS-Regime und beschäftigte sich lediglich im letzten Abschnitt mit seiner politischen Karriere bis 1949. Von Müllers Widersachern hat lediglich Fritz Schäffer fragmentarische Erinnerungen niedergeschrieben $^{77}$, von Alois Hundhammer existieren nur wenige Seiten über seinen „Beitrag zur bayerischen Politik ${ }^{\alpha 78}$, und auch Hans Ehard hat nur ein kurzes Manuskript hin-

${ }^{73}$ Vgl. Hermann Graml, Zur Frage der Demokratiebereitschaft des deutschen Bürgertums nach dem Ende der NS-Herrschaft. Hermann Maus Bericht über eine Reise nach München im März 1946, in: Wolfgang Benz (Hrsg.), Miscellanea. Festschrift für Helmut Krausnick zum 75. Geburtstag, Stuttgart 1980, S. 149-168, hier S. 161.

74 Vgl. das neunbändige Quellenwerk Dokumente zur parteipolitischen Entwicklung, das zwischen 1962 und 1971 in Berlin erschienen ist.

75 Vgl. Adenauer: „Es mußte alles neu gemacht werden.“ Die Protokolle des CDU-Bundesvorstands 1950-1953, bearb. von Günter Buchstab, Stuttgart 1986; CDU-Bundesvorstandsprotokolle 1953-1957; Adenauer: „... um den Frieden zu gewinnen.“ Die Protokolle des CDU-Bundesvorstands 1957-1961, bearb. von Günter Buchstab, Düsseldorf 1994.

$76 \mathrm{Vgl}$. Müller, Konsequenz.

77 Vgl. Fritz Schäffer, Die Zeit der ersten Ministerpräsidentschaft in Bayern nach dem Zusammenbruch im Jahre 1945, München 1963, sowie Fritz Schäffer, Die Bayerische Volkspartei (BVP), in: Politische Studien 14 (1963), S. 46-63.

78 Vgl. Alois Hundhammer, Mein Beitrag zur bayerischen Politik 1945-1965, München 1965. 
terlassen ${ }^{79}$. Ein Jahr nach dem Tod von Franz Josef Strauß erschienen die Fragment gebliebenen Memoiren des langjährigen CSU-Vorsitzenden. Die Entwicklung der CSU und der Aufstieg Strauß' in der Partei nehmen dabei allerdings erstaunlich wenig Raum ein ${ }^{80}$. Auch Friedrich Zimmermann blendet in seinen 1991 erschienenen Memoiren die Geschichte der CSU in den fünfziger Jahren und seine eigene Tätigkeit als Generalsekretär weitgehend aus ${ }^{81}$.

Verglichen mit der Situation in den sechziger und siebziger Jahren, als die ersten empirischen Studien über die Entwicklung und Struktur der CSU entstanden, hat sich die Quellenlage in letzter Zeit erheblich verbessert, ohne daß sie jedoch uneingeschränkt als befriedigend oder gar als gut bezeichnet werden kann. Für diese Verbesserung sind vor allem die Abgabe umfangreicher Quellenbestände an verschiedene Archive und die deutlich liberalere Genehmigungspraxis der zuständigen Parteiinstanzen verantwortlich. Das Archiv für Christlich-Soziale Politik der Hanns-Seidel-Stiftung verfügte schon 1989 über rund 1000 laufende Meter an Archivalien, darunter Registraturgut der Parteiorganisation, Materialien der Landtagsfraktion und der Bonner Landesgruppe sowie mehr als 60 Nachlässe bzw. Handakten von Politikern, die der CSU entweder selbst angehörten oder ihr nahestanden ${ }^{82}$. Gemäß seinem Selbstverständnis „als Zentralarchiv der Christlichen Demokratie in Deutschland“ sammelte auch das Archiv für Christlich-Demokratische Politik der Konrad-Adenauer-Stiftung Nachlässe und Teilnachlässe von CSU-Politikern ${ }^{83}$. Die Bestandsübersicht des ACDP von 1992 verzeichnet mehr als 30 solcher Nachlässe, darunter Unterlagen der Bundesminister Siegfried Balke, Wilhelm Niklas und Hans Schuberth.

Die archivalische Basis der vorliegenden Studie ruht gleichsam auf vier Säulen. Zum einen ist das Schriftgut der Parteiorganisation und des Parteiapparats der bayerischen Unionspartei zu nennen, das sich im ACSP befindet. Die dazugehörenden Sitzungsprotokólle des geschäftsführenden Landesvorstands, des Landesvorstands, des Landesausschusses und der Landesversammlungen der CSU wurden nebst allen Anlagen bis 1963 in ihrer Gesamtheit ausgewertet. Die Sitzungen des geschäftsführenden Landesvorstands und des Landesvorstands sind für die Zeit bis 1950 und ab 1954 relativ dicht dokumentiert, für den Zeitraum dazwischen bestehen dagegen große Lücken, die sich auch durch ausgedehnte Recherchen in Nachlässen nicht schließen ließen ${ }^{84}$. Die Über-

${ }^{79}$ Vgl. Hans Ehard, Tatsachen und Zusammenhänge aus meiner elfjährigen Ministerpräsidentschaft, München 1964. Überdies existiert eine Sammlung von Reden des Ministerpräsidenten und CSU-Vorsitzenden: Ehard, Bayerische Politik.

${ }^{80}$ Strauß, Erinnerungen; Strauß geht vor allem im Kapitel „Bayern und die CSU“ auf die Entwicklung seiner Partei ein, wobei die Auseinandersetzungen mit der Bayernpartei und Fragen der Kulturpolitik breiteren Raum einnehmen.

81 Vgl. Zimmermann, Kabinettstücke.

82 Vgl. die Broschüre "ACSP-Informationen“ von 1989.

${ }^{83}$ Die Bestände des Archivs für Christlich-Demokratische Politik der Konrad-Adenauer-Stiftung. Kurzübersicht, Melle 3., veränderte und aktualisierte Auflage 1992, S. VI.

84 Als besonders problematisch hat sich auch die Form der Überlieferung erwiesen. Für die Jahre zwischen 1953 und 1963 liegen ca. 50 Sitzungsprotokolle ausschließlich als teilweise sehr umfangreiche stenographische Aufzeichnungen vor. Vermutlich war der Mangel an Arbeitskräften im Generalsekretariat dafür verantwortlich, daß die Reinschrift der Protokolle zeitweise unterblieb. Für die Jahre 1954, 1956 bis 1959 und 1962 existieren die Protokolle nahezu ausschließlich in der Form stenographischer Aufzeichnungen. Diese Stenogramme, die sich zum Teil in schlechtem Zustand befinden, könnten nur von Fachleuten anhand der Originale transkribiert und damit für die Forschung erschlossen werden. 
lieferung der Protokolle von Landesausschuß und Landesversammlung ist dagegen weit weniger gestört. Wurden Aufzeichnungen über die oftmals mehrtägigen Sitzungen dieser Gremien angefertigt, so haben sich diese in den meisten Fällen auch erhalten, wobei einschränkend zu bemerken ist, daß bestimmte Tagesordnungspunkte, zu denen kontroverse Diskussionen zu erwarten waren, insbesondere in den Jahren 1949 bis 1955 nicht protokolliert wurden.

Demgegenüber scheinen sich bis Mitte der sechziger Jahre nur wenige Akten der Landesgeschäftsstelle und des Generalsekretariats der CSU erhalten zu haben, sieht man von den teilweise umfangreichen Anlagen zu den Sitzungsprotokollen einmal ab, die Unterlagen zu Satzungsfragen, zur politischen Programmatik, zur organisatorischen Entwicklung der Partei oder zu Kandidatenaufstellungen für Land- und Bundestagswahlen enthalten. Die Arbeit der Parteizentrale läßt sich aus diesem Grund ebenso nur unzureichend fassen wie Funktionsweise, Reform und Ausbau des Parteiapparats. $\mathrm{Daß}$ die Registratur der Landesleitung bis in die Ära Strauß hinein als weitgehend verloren angesehen werden muß, ist vielleicht das größte Manko für alle weiteren Studien zur organisatorischen Entwicklung der bayerischen Unionspartei. Erschwerend kommt hinzu, daß sich dieser Quellenbestand nur bedingt rekonstruieren läßt, da das Schriftgut der horizontalen und vertikalen Untergliederungen und Suborganisationen - von Ausnahmen abgesehen - für diese Jahre ebenfalls unergiebig is ${ }^{85}$. Am meisten findet sich noch in den Nachlässen von Josef Müller und Hans Ehard sowie in der Korrespondenz zwischen der Landesleitung und den Geschäftsstellen der Landtagsfraktion und der Landesgruppe.

Der zweite große Quellenbestand, der dieser Studie zugrunde liegt, ist das Schriftgut der CSU-Fraktion im bayerischen Landtag ${ }^{86}$. Diese umfangreichen Materialien für die vier Legislaturperioden (1946 bis 1962) mehrere hundert Aktenordner - waren der Forschung bisher weitgehend verschlossen. Lediglich Peter Jakob Kock konnte für seine Arbeiten über Föderalismus und Föderalismuspolitik in Bayern für die Jahre 1946 bis 1949 auf die Sitzungsprotokolle der Unionsfraktion zurückgreifen. Die Akten der Landtagsfraktion umfassen neben diesen Protokollen, die anders als die Niederschriften über die Sitzungen des Landesvorstands weitgehend lückenlos überliefert sind, die Korrespondenz der Fraktionsvorsitzenden und der Fraktionsgeschäftsstelle, Materialsammlungen zu den einzelnen Abgeordneten sowie zu den wichtigsten Fragen bayerischer und deutscher Politik. Einzelne Problemfelder - z. B. Schulpolitik und Lehrerbildung, Föderalismus, das Verhältnis zur Bayernpartei oder zur SPD sind erstaunlich dicht dokumentiert. Dieses Material ermöglicht es beispielsweise, nach Kontinuitäten und Zäsuren in der Politik der CSU zu fragen. Für die vorliegende Untersuchung ist unter anderem das Verhältnis zwischen Parteiführung und Frak-

${ }^{85}$ Die Quellenbestände Junge Union und Frauen-Union im ACSP erwiesen sich als unergiebig, aus dem Bestand EAK der CSU ließen sich jedoch wichtige Erkenntnisse gewinnen. Die Geschichte der Arbeitsgemeinschaften der CSU ist noch weitgehend unbekannt; zur JU vgl. Jürgen Mittrücker, Junge Union und CSU, dargestellt am Beispiel des Regierungsbezirks Oberfranken bis 1983. Die Junge Union als Arbeitsgemeinschaft der CSU, unveröffentlichte Diplomarbeit, Bamberg 1984.

${ }^{86}$ Vgl. dazu Claus Brügmann, Die Fraktionsakten der Christlich-Sozialen Union (CSU) im Archiv für Christlich-Soziale Politik der Hanns-Seidel-Stiftung, in: Günter Buchstab (Hrsg.), Parteien im Parlament. Fraktionsakten in europäischen Partei- und Parlamentsarchiven. Tagung der Sektion der Archjve und Archivare der Parlamente und politischen Parteien im Internationalen Archivrat. Budapest 17.-19. November 1995, St. Augustin 1997, S. 28-31. 
tionsmehrheit von wesentlicher Bedeutung, das lange Zeit gespannt war. Die Akten der Landtagsfraktion lassen es nicht nur zu, den Dualismus zwischen Partei und Fraktion in seiner ganzen Tragweite zu erfassen und zu beurteilen, sondern liefern darüber hinaus wertvolle Ergänzungen zur lückenhaften Überlieferung der Landesleitung.

Nach den ersten Bundestagswahlen im August 1949 trat mit der Landesgruppe der CSU im Deutschen Bundestag ein Gremium ins Leben, das sich gleichsam als Fraktion innerhalb der gemeinsamen CDU/CSU-Fraktion konstituierte und sich in kurzer Zeit neben den Führungsgremien der Parteiorganisation und der Landtagsfraktion zu einem weiteren Gravitationszentrum politischer Macht entwickelte. Die Protokolle der Landesgruppensitzungen galten bis vor wenigen Jahren als geheime Verschlußsache und wurden noch 1992 von den Abgeordneten in Bonn selbst verwahrt ${ }^{87}$. Sie sind nahezu vollständig überliefert, lediglich für die ersten Jahre bis 1951 bestehen Lücken. Überwiegend handelt es sich um relativ kurze Verlaufs- oder um Ergebnisprotokolle, so daß man in vielen Fällen weder die Diskussion noch die Entscheidungsfindung nachvollziehen kann. Dennoch sind die Protokolle der Landesgruppensitzungen ein Quellenbestand, der für die Geschichte der Bundesrepublik ebenso von Bedeutung ist wie für die Geschichte der CSU. Gut dokumentiert sind darin die Anfänge westdeutscher Außen- und Sicherheitspolitik, die immer wieder problematische Zusammenarbeit mit der CDU sowie die Vorgänge in der bayerischen Unionspartei selbst. Die Protokolle der Landesgruppensitzungen zeigen innerbayerische und innerparteiliche Entwicklungen aus dem Blickwinkel der Bundespolitik und ermöglichen fundierte Aussagen über die Koordination der politischen Arbeit zwischen München und Bonn, über gemeinsame Ziele oder Interessendivergenzen und über die sich verändernde Rolle der Landesgruppe in der CSU. Vervollständigen läßt sich dieses Bild durch weiteres Aktenmaterial der Landesgruppe, insbesondere Korrespondenzen der Landesgruppenvorsitzenden und der Parlamentarischen Geschäftsführer, die im ACSP einzusehen sind.

Eine geradezu ideale Ergänzung zu den Akten der Parteiorganisation, der Landtagsfraktion und der Landesgruppe - und das ist die vierte Säule, auf der die Quellenbasis dieser Studie ruht - bilden Nachlässe wichtiger Persönlichkeiten der bayerischen und deutschen Nachkriegspolitik ${ }^{88}$. Private Aufzeichnungen und Briefwechsel lassen Sach- und Personalentscheidungen, wie sie sich in parteioffiziellem Material widerspiegeln, oftmals in einem anderen Licht erscheinen und geben überdies eher Auskunft über persönliche Beziehungen und Konflikte zwischen führenden Politikern oder über innerparteiliche Koalitionen, als dies die Bestände der Parteiorganisation und der Fraktionen tun. Von besonderer Bedeutung waren für die vorliegende Untersuchung die Nachlässe der Parteivorsitzenden Müller (ACSP) ${ }^{89}$, Ehard (BayHStA) und Seidel (ACSP) ${ }^{90}$. Die Nachlässe von Josef Müller und Hans Ehard enthalten für die

${ }^{87}$ Ergänzend dazu findet sich in der BSB, NL Schwend 18 und 19, eine Reihe von Berichten aus der Dienststelle des bayerischen Bevollmächtigten beim Bund über Sitzungen der Landesgruppe und der CDU/CSU-Bundestagsfraktion für die Jahre 1950 bis 1954.

${ }^{88}$ Für die Genehmigung, die Nachlässe ihrer verstorbenen Angehörigen auswerten zu dürfen, bin ich Frau Dr. Gerda Bracker, Frau Dr. Sieglinde Ehard, Frau Christa Müller und Frau Rosa-Sophie Freifrau von und zu Guttenberg zu großem Dank verpflichtet.

${ }^{89}$ Bei Abschluß der Quellenrecherchen war dieser Nachlaß noch nicht vollständig archiviert, so daß sich Abweichungen bei den Archivsignaturen ergeben können.

90 Neue Erkenntnisse über die Geschichte der CSU läßt der Nachlaß des 1988 verstorbenen Franz Josef 
Jahre 1945 bis 1955 Materialien, die man eigentlich in den Akten der Landesleitung erwarten würde. So finden sich Unterlagen über Aufbau, Organisation und Finanzierung des Parteiapparats oder über Anfänge und Entwicklung der Parteipresse, die im überlieferten Schriftgut der Parteiorganisation anscheinend fehlen und ohne die eine $\mathrm{Ge}-$ schichte der bayerischen Unionspartei nur schwer geschrieben werden könnte. Der Nachlaß von Hans Ehard wird ergänzt durch die Nachlässe seiner Mitarbeiter Anton Pfeiffer (BayHStA) und Karl Schwend (BSB), die den Ministerpräsidenten als leitende Beamte der Staatskanzlei zunächst bei der Formulierung und Durchsetzung seiner Politik, später aber auch bei der Führung der CSU unterstützten.

Als weiterer Quellenbestand, der gleichsam quer zu allen genannten Überlieferungen liegt, konnte die umfangreiche Sammlung von Alf Mintzel ausgewertet werden, die sich seit März 1991 im Archiv des Instituts für Zeitgeschichte befindet. Es handelt sich dabei um 56 Bände, die vornehmlich Kopien von Unterlagen der Landesgeschäftsstelle und verschiedener Bezirksgeschäftsstellen der CSU sowie Druckschriften der Partei, aber auch einige Originaldokumente enthalten. Den Kern der Sammlung bilden Protokolle von Sitzungen wichtiger Parteigremien und die vorwiegend vertraulichen Rechenschaftsberichte der Generalsekretäre und Landesgeschäftsführer. Die Dokumente umfassen den Zeitraum von der Gründung der Partei im Herbst 1945 bis zum Ende der sechziger Jahre; die Druckschriften, z. B. Reden von CSU-Politikern auf Parteitagen, reichen teilweise bis ins Jahr 1976. Wenn die Sammlung Mintzel auch den wohl größten Bestand an Dokumenten zur Geschichte der CSU außerhalb der einschlägigen Archive darstellt, so muß doch der selektive Charakter der Sammlung betont werden, da die Quellenauswahl Mintzels stark von seinen spezifischen Fragestellungen geprägt war. Ein Rückgriff auf die Originalbestände - sofern sie zugänglich sind - ist deshalb unerläßlich.

Strauß erwarten, der derzeit im ACSP archiviert wird. Dieser umfangreiche Bestand ist für die Forschung größtenteils noch nicht zugänglich und konnte auch für die vorliegende Arbeit nicht ausgewertet werden. 


\section{Nachwort}

Die vorliegende Studie ist die überarbeitete und ergänzte Fassung meiner Dissertation, die im Sommersemester 1996 von der Philosophischen Fakultät der Ludwig-Maximilians-Universität München angenommen wurde. Als ich 1991 zusammen mit Barbara Fait und Alf Mintzel an der dreibändigen Dokumentation zur Frühgeschichte der CSU zu arbeiten begann, hätte ich nicht gedacht, daß daraus einmal ein eigenes Buch entstehen würde - und ohne die tatkräftige Hilfe meiner akademischen Lehrer, meiner Kollegen, meiner Freunde und meiner Familie wäre es wohl auch nie entstanden. Besonders zu Dank verpflichtet bin ich Klaus-Dietmar Henke und Hans Woller, die mich ermutigt haben, in ihre Fußstapfen zu treten, ebenso Hans Günter Hockerts, meinem Doktorvater, der stets ein offenes Ohr für alle wissenschaftlichen und persönlichen Anliegen hatte. Dem Direktor des Instituts für Zeitgeschichte, Horst Möller, und seinem Stellvertreter Udo Wengst verdanke ich es, daß ich meine Dissertation in der einzigartigen Atmosphäre dieses Hauses verfassen konnte; auch Georg Maisinger, der Mann, der das Unmögliche möglich macht, hat mich unterstützt, wo immer er konnte. Mein Dank gilt auch der Christlich-Sozialen Union, die mir die Auswertung wichtiger Quellenbestände gestattet und diese Arbeit dadurch erst ermöglicht hat. Bei den Mitarbeiterinnen und Mitarbeitern des Archivs für Christlich-Soziale Politik der Hanns-Seidel-Stiftung möchte ich mich dafür bedanken, daß sie mir stets mit Rat und Tat zur Seite gestanden und meine Ungeduld mit Nachsicht ertragen haben. Ausgezeichnet betreut wurde ich auch im Bayerischen Hauptstaatsarchiv, in der Abteilung $\mathrm{V}$ insbesondere von Michael Stephan und in der Abteilung II von Hermann-Joseph Busley, der zudem so freundlich war, das Zweitgutachten für meine Dissertation zu erstellen. Freunde und Kollegen wie Theresia Bauer, Renate Bihl, Christoph Boyer, Jaromír Dittmann-Balcar, Claus Fackler, Norbert Frei, Karl-Ulrich Gelberg, Katja Klee, Rainer Ostermann, Dieter Pohl sowie Dietmar und Winfried Süß haben mit Anregungen und Kritik nicht gespart, Gott sei Dank auch nicht mit aufmunternden Worten. Am meisten zu verdanken habe ich aber meinem Freund Hans Woller, nicht nur wissenschaftlich, sondern auch menschlich. Er hat meine Arbeit von Anfang an mit Interesse und Engagement begleitet, war auch zu den ungewöhnlichsten Zeiten immer für eine Diskussion zu haben, spornte mich an, wenn ich zögerlich war, und ließ mich an seinem reichen Erfahrungsschatz teilhaben. Widmen möchte ich dieses Buch meiner Frau Regina. Sie hat meine Arbeit durch ihre Fähigkeiten als Historikerin und Germanistin bereichert, war stets die Zuversicht in Person und wußte auch in schwierigen Zeiten immer einen Ausweg. 


\section{Abkürzungsverzeichnis}

\begin{tabular}{ll} 
ACDP & Archiv für Christlich-Demokratische Politik \\
ACSP & Archiv für Christlich-Soziale Politik \\
AG & Adjutant General \\
AG & Aktiengesellschaft \\
Anm. & Anmerkung \\
APuZ & Aus Politik und Zeitgeschichte \\
AsD & Archiv der sozialen Demokratie \\
BAK & Bundesarchiv Koblenz \\
BayHStA & Bayerisches Hauptstaatsarchiv \\
BBB & Bayerischer Bauernbund \\
BBV & Bayerischer Bauernverband \\
BCBV & Bayerischer Christlicher Bauernverein \\
Bd., Bde. & Band, Bände \\
bearb. & bearbeitet \\
BGB & Bayerischer Gewerkschaftsbund \\
BHE & Bund der Heimatvertriebenen und Entrechteten \\
BHKP & Bayerische Heimat- und Königspartei \\
Bl. & Blatt \\
BLB & Bayerischer Landbund \\
BP & Bayernpartei \\
BRD & Bundesrepublik Deutschland \\
BSB & Bayerische Staatsbibliothek \\
BVP & Bayerische Volkspartei \\
CDU & Christlich-Demokratische Union \\
CIC & Counter Intelligence Corps \\
CSU & Christlich-Soziale Union \\
CSVD & Christlich-sozialer Volksdienst \\
DAF & Deutsche Arbeitsfront \\
DBV & Deutscher Bauernverband \\
DDP & Deutsche Demokratische Partei \\
DDR & Deutsche Demokratische Republik \\
DG & Deutsche Gemeinschaft \\
Diss. & Dissertation \\
DM & Deutsche Mark \\
DNVP & Deutsch-Nationale Volkspartei \\
DP & Deutsche Partei \\
DVP & Deutsche Volkspartei \\
EAK & Evangelischer Arbeitskreis \\
eingel. & eingeleitet \\
& \\
\hline
\end{tabular}




$\begin{array}{ll}\text { EJPR } & \text { European Journal of Political Research } \\ \text { EUCOM } & \text { European Command } \\ \text { ev. } & \text { evangelisch } \\ \text { e. V. } & \text { eingetragener Verein } \\ \text { FDP } & \text { Freie Demokratische Partei } \\ \text { frktls. } & \text { fraktionslos } \\ \text { Gestapo } & \text { Geheime Staatspolizei } \\ \text { GiW } & \text { Geschichte im Westen } \\ \text { GmbH } & \text { Gesellschaft mit beschränkter Haftung } \\ \text { GuG } & \text { Geschichte und Gesellschaft } \\ \text { GWU } & \text { Geschichte in Wissenschaft und Unterricht } \\ \text { HICOG } & \text { High Commissioner (U. S.), Germany } \\ \text { HJb } & \text { Historisches Jahrbuch } \\ \text { Hrsg., hrsg. } & \text { Herausgeber, herausgegeben } \\ \text { IfZ } & \text { Institut für Zeitgeschichte } \\ \text { JMH } & \text { The Journal of Modern History } \\ \text { JU } & \text { Junge Union } \\ \text { Kap. } & \text { Kapitel } \\ \text { kath. } & \text { katholisch } \\ \text { KL } & \text { Konzentrationslager } \\ \text { KPD } & \text { Kommunistische Partei Deutschlands } \\ \text { KZG } & \text { Kirchliche Zeitgeschichte } \\ \text { LG } & \text { Landesgruppe } \\ \text { LL } & \text { Landesleitung } \\ \text { LL } & \text { Landesliste } \\ \text { LRA } & \text { Landratsamt } \\ \text { LSG } & \text { Landesschiedsgericht } \\ \text { LTF } & \text { Landtagsfraktion } \\ \text { LTW } & \text { Landtagswahl } \\ \text { MdB } & \text { Mitglied des Bundestags } \\ \text { MdL } & \text { Mitglied des Landtags } \\ \text { MdR } & \text { Mitglied des Reichstags } \\ \text { MdS } & \text { Mitglied des Senats } \\ \text { MdVLV } & \text { Mitglied der Verfassunggebenden Landesversammlung } \\ \text { MdWR } & \text { Mitglied des Wirtschaftsrats } \\ \text { Mfr. } & \text { Mittelfranken } \\ \text { NA } & \text { National Archives } \\ \text { Nachr. } & \text { Nachrücker } \\ \text { Nachw. } & \text { Nachwahl } \\ \text { Ndb. } & \text { Niederbayern } \\ \text { NL } & \text { Nachlaß } \\ \text { NS } & \text { Nationalsozialismus, nationalsozialistisch } \\ \text { NSDAP } & \text { Nationalsozialistische Deutsche Arbeiterpartei } \\ \text { Obb. } & \text { Oberbayern } \\ \text { Ofr. } & \text { Oberfranken } \\ \text { o. J. } & \text { ohne Jahr } \\ \end{array}$




$\begin{array}{ll}\text { OLCB } & \text { Office of the Land Commissioner for Bavaria } \\ \text { OMGBY } & \text { Office of Military Government for Bavaria } \\ \text { OMGUS } & \text { Office of Military Government for Germany, United States } \\ \text { o. O. } & \text { ohne Ort } \\ \text { o. P. } & \text { ohne Paginierung } \\ \text { Opf. } & \text { Oberpfalz } \\ \text { OSS } & \text { Office of Strategic Services } \\ \text { POLAD } & \text { Political Advisor } \\ \text { PVS } & \text { Politische Vierteljahresschrift } \\ \text { RG } & \text { Record Group } \\ \text { RM } & \text { Reichsmark } \\ \text { SA } & \text { Sturmabteilung } \\ \text { SBZ } & \text { Sowjetische Besatzungszone } \\ \text { Schw. } & \text { Schwaben } \\ \text { SED } & \text { Sozialistische Einheitspartei Deutschlands } \\ \text { SMAD } & \text { Sowjetische Militäradministration } \\ \text { Smlg. } & \text { Sammlung } \\ \text { SPD (SOPADE) } & \text { Sozialdemokratische Partei Deutschlands (im Exil) } \\ \text { SS } & \text { Schutzstaffel } \\ \text { StA } & \text { Staatsarchiv } \\ \text { StBKAH } & \text { Stiftung Bundeskanzler-Konrad-Adenauer-Haus } \\ \text { StK } & \text { Staatskanzlei } \\ \text { StP } & \text { Deutsche Staatspartei } \\ \text { SZ } & \text { Süddeutsche Zeitung } \\ \text { UdA/UdV } & \text { Union der Ausgewiesenen bzw. der Vertriebenen } \\ \text { Ufr. } & \text { Unterfranken } \\ \text { USA } & \text { United States of America } \\ \text { Verz. } & \text { Verzicht } \\ \text { VfZ } & \text { Vierteljahrshefte für Zeitgeschichte } \\ \text { WAV } & \text { Wirtschaftliche Aufbau-Vereinigung } \\ \text { ZBSL } & \text { Zeitschrift des Bayerischen Statistischen Landesamts } \\ \text { ZfBLG } & \text { Zeitschrift für bayerische Landesgeschichte } \\ \text { ZfP } & \text { Zeitschrift für Politik } \\ \text { ZfParl } & \text { zitiert für Parlamentsfragen } \\ \text { zit. } & \end{array}$




\section{Quellen- und Literaturverzeichnis}

\section{Archivalien}

Archiv der CSU-Landesgruppe, Bonn

Protokolle der Landesgruppensitzungen

Zeitungsausschnitte und Materialien

Archiv der sozialen Demokratie, Bonn (AsD)

SPD-Landesverband Bayern

Archiv des Bayerischen Rundfunks, München

Aufzeichnung eines Interviews mit Josef Müller anläßlich seines 70. Geburtstags am 27. 3. 1968

Archiv des Erzbistums Bamberg

Repertorium 4/3 - Erzbischöfliches Ordinariat, Generalia

Archiv für Christlich-Demokratische Politik, St. Augustin (ACDP)

I-175 Nachlaß Siegfried Balke

I-369 Nachlaß Hermann Ehlers

IV-001 Evangelischer Arbeitskreis der CDU/CSU

Archiv für Christlich-Soziale Politik, München (ACSP)

Protokolle der Sitzungen des geschäftsführenden Landesvorstands

Protokolle der Sitzungen des Landesvorstands

Protokolle der Sitzungen des Landesausschusses

Protokolle der Landesversammlungen und Parteitage

Protokolle der Sitzungen der Landtagsfraktion

Registraturgut der Geschäftsstelle der Landtagsfraktion

Korrespondenz des Vorsitzenden der CSU-Landesgruppe in Bonn

Korrespondenz des Parlamentarischen Geschäftsführers der CSU-Landesgruppe in Bonn

Bestand Landesschiedsgericht

Evangelischer Arbeitskreis der CSU

Materialien zu Land- und Bundestagswahlen

Druckschriften

Nachlaß Wilhelm Arnold

Nachlaß Franz Elsen

Nachlaß Josef Müller

Nachlaß Hanns Seidel

Bayerisches Hauptstaatsarchiv, München (BayHStA)

Akten der Bayerischen Staatskanzlei

Nachlaß Hans Ehard

Nachlaß Hans Kraus

Nachlaß Josef Panholzer

Nachlaß Anton Pfeiffer

Nachlaß Otto Schedl

Nachlaß Josef Schwalber

Nachlaß Lorenz Sedlmayr

Bayerische Staatsbibliothek, München (BSB)

Ana 308 Nachlaß Karl Schwend 
Bundesarchiv, Koblenz (BAK)

Nachlaß 1018 Jakob Kaiser

Nachlaß 1147 Hans Ritter von Lex

Nachlaß 1168 Fritz Schäffer

Nachlaß 1219 Maria Probst

Nachlaß 1397 Karl Theodor Freiherr von und zu Guttenberg

Institut für Zeitgeschichte, München (IfZ)

ED 92 Nachlaß Josef Müller

ED 120 Nachlaß Wilhelm Hoegner

ED 132 Nachlaß Joseph Baumgartner

ED 145 Nachlaß Dieter Sattler

ED 719 Sammlung Bayernpartei

ED 720 Sammlung Alf Mintzel

Fh 56 Dokumente zur Frühgeschichte der CSU

MA 90 Nachlaß Johannes Semler

MS 343 Sammlung Karl Köhler

Sammlung Klaus-Dietmar Henke

ZS 659 Transkripte von Interviews mit Josef Müller

Record Group 260 OMGUS/OMGBY:

AG 1945/46-1/5

10/125-2/12

$13 / 150-1 / 6$

AG 1945/46-1/6

$10 / 130-3 / 1$

13/150-1/9

AG 1945/46-6/7

$11 / 35-2 / 9$

$13 / 150-1 / 11$

AG 1947/1/2

$12 / 147-2 / 16$

$13 / 150-1 / 13$

AG 1948-27/2

$13 / 100-1 / 10$

$13 / 150-1 / 14$

$7 / 29-1 / 13-16$

$13 / 142-2 / 1$

$10 / 80-1 / 26$

$13 / 142-2 / 3$

$13 / 150-1 / 15$

10/89-3/5

$13 / 143-3 / 4$

$13 / 150-1 / 16$

$10 / 90-1 / 16$

$13 / 147-2 / 16$

$13 / 150-3 / 1$

$10 / 90-1 / 24$

$13 / 147-3 / 3$

$13 / 150-3 / 8$

$10 / 90-1 / 33$

$13 / 149-2 / 1$

$13 / 150-3 / 10$

$10 / 90-3 / 1$

$13 / 149-2 / 3$

$13 / 150-3 / 12$

$10 / 90-3 / 4$

$13 / 149-3 / 3$

$15 / 102-2 / 1$

$10 / 90-3 / 5$

$13 / 150-1 / 1$

$15 / 102-2 / 10$

$15 / 102-2 / 11$

$10 / 90-3 / 8$

$13 / 150-1 / 2$

$15 / 108-2 / 17$

$10 / 90-3 / 9$

$13 / 150-1 / 3$

$15 / 108-2 / 23$

$10 / 91-1 / 1$

$13 / 150-1 / 4$

$17 / 162-1 / 7$

$10 / 91-1 / 4$

$13 / 150-1 / 5$

Record Group 84 POLAD:

$459 / 2$

$747 / 30$

$461 / 16$

$747 / 33$

OMGBY Selected Records:

MA $1420 / 13$

MA $1479 / 9$

Staatsarchiv Bamberg

K3/1981 - Regierung von Oberfranken:

Personalakten oberfränkischer Landräte

Politische Parteien

Staatsarchiv Würzburg

Landratsamt Alzenau

Stadtarchiv Bamberg

Bamberg-Sammlung

Nachlaß Hermann Etzel

Nachlaß Thomas Dehler 
Stadtarchiv Ingolstadt

CSU Ingolstadt-Stadt und -Land

National Archives, Washington (NA)

Record Group 466 HICOG - Office of the Land Commissioner for Bavaria:

Central Files

Field Operations Division

\section{Gedruckte Quellen}

Adenauer. Briefe 1945-1955, bearb. von Hans Peter Mensing, 5 Bde., Berlin 1983-1995.

Adenauer: „Es mußte alles neu gemacht werden.“ Die Protokolle des CDU-Bundesvorstands 1950-1953, bearb. von Günter Buchstab, Düsseldorf 1986.

Adenauer: „Wir haben wirklich etwas geschaffen." Die Protokolle des CDU-Bundesvorstands 1953-1957, bearb. von Günter Buchstab, Düsseldorf 1990.

Adenauer: „... um den Frieden zu gewinnen.“ Die Protokolle des CDU-Bundesvorstands 1957-1961, bearb. von Günter Buchstab, Düsseldorf 1994.

Auftakt zur Ära Adenauer. Koalitionsverhandlungen und Regierungsbildung 1949, bearb. von Udo Wengst, Düsseldorf 1985.

Die CDU/CSU im Parlamentarischen Rat. Sitzungsprotokolle der Unionsfraktion, bearb. von Rainer Salzmann, Stuttgart 1981.

Die CDU/CSU im Frankfurter Wirtschaftsrat. Protokolle der Unionsfraktion 1947-1949, bearb. von Rainer Salzmann, Düsseldorf 1988.

Die CSU-Landtagsfraktion berichtet, in: Politisches Jahrbuch der CSU 1954, S. 96-118.

Die CSU 1945-1948. Protokolle und Materialien zur Frühgeschichte der Christlich-Sozialen Union, hrsg. von Barbara Fait und Alf Mintzel unter Mitarbeit von Thomas Schlemmer, 3 Bde., München 1993.

Dokumente zur Geschichte von Staat und Gesellschaft in Bayern, Abt. III, Bd. 9: Die Regierungen von 1945-1962, bearb. von Fritz Baer, München 1976.

Dokumente zur parteipolitischen Entwicklung in Deutschland seit 1945, hrsg. von Ossip K. Flechtheim, 9 Bde., Berlin 1962-1971.

Walter L. Dorn, Inspektionsreisen in der US-Zone. Notizen, Denkschriften und Erinnerungen aus dem Nachlaß, hrsg. von Lutz Niethammer, Stuttgart 1973.

Entwurf einer bayerischen Verfassung zur Vorlage an die Verfassunggebende Landesversammlung, hrsg. von der Bayerischen Staatskanzlei, München 1946.

Das „Ermächtigungsgesetz“ vom 24. März 1933. Quellen zur Geschichte und Interpretation des "Gesetzes zur Behebung der Not von Volk und Reich“, hrsg. von Rudolf Morsey, Düsseldorf 1992.

Karl-Ulrich Gelberg, Die Protokolle der SPD-Fraktion in der bayerischen Verfassunggebenden Landesversammlung 1946, in: Zeitschrift für bayerische Landesgeschichte 60 (1997), S. 10511093.

Hermann Graml, Zur Frage der Demokratiebereitschaft des deutschen Bürgertums nach dem Ende der NS-Herrschaft. Hermann Maus Bericht über eine Reise nach München im März 1946, in: Wolfgang Benz (Hrsg.), Miscellanea. Festschrift für Helmut Krausnick zum 75. Geburtstag, Stuttgart 1980, S. 149-168.

Otto Gritschneder, Die Akten des Sondergerichts über Stadtpfarrer Dr. Emil Muhler, in: Beiträge zur altbayerischen Kirchengeschichte 29 (1975), S. 125-149.

Im Zeichen des Föderalismus. Programme und Programmatisches der Bayerischen Volkspartei, München 1924.

Lehrjahre der CSU. Eine Nachkriegspartei im Spiegel vertraulicher Berichte an die amerikanische Militärregierung, hrsg. von Klaus-Dietmar Henke und Hans Woller, Stuttgart 1984.

Politische Zeitfragen. Lose Mitteilungen über alle Gebiete des öffentlichen Lebens, hrsg. vom Generalsekretariat der BVP, o. O. 1919. 
Die Protokolle des Bayerischen Ministerrats 1945-1954: Das Kabinett Schäffer - 28. Mai bis 28. September 1945, bearb. von Karl-Ulrich Gelberg, München 1995.

Die Protokolle des Bayerischen Ministerrats 1945-1954: Das Kabinett Hoegner I - 28. September 1945 bis 21. Dezember 1946, bearb. von Karl-Ulrich Gelberg, München 1996.

Sammlung der vom Alliierten Kontrollrat und der amerikanischen Militärregierung erlassenen Proklamationen, Gesetze, Verordnungen, Befehle, hrsg. von Ruth Hemken, 3 Bde., Stuttgart o. J.

Stenographische Berichte über die Verhandlungen des Bayerischen Landtags, 1919-1933, München o. J.

Stenographische Berichte über die Verhandlungen des Bayerischen Landtags, 1946-1955, München o. J.

Stenographische Berichte über die Verhandlungen der Bayerischen Verfassunggebenden Landesversammlung, München 1946.

Stenographische Berichte über die Verhandlungen des Verfassungsausschusses der Verfassunggebenden Landesversammlung Bayerns, München 1946.

Um den Bestand Bayerns! Bayerische Reichsprovinz? - nein, Staat Bayern! Gedanken und Materialien zu dem Verfassungskampf zwischen Einheitsstaat und Bundesstaat in Deutschland, hrsg. vom Generalsekretariat der BVP, München 1929.

Die Unionsparteien 1946-1950. Protokolle der Arbeitsgemeinschaft der CDU/CSU Deutschlands und der Konferenzen der Landesvorsitzenden, bearb. von Brigitte Kaff, Düsseldorf 1991.

Verhandlungen des Bayerischen Landtags, 1919-1933, Beilagenbände, München o. J.

Was ist und was will die Bayerische Volkspartei? München 1929.

Otto Weinkamm - Politiker der ersten Stunde. Aufbau und Konsolidierung eines demokratischen Europas. Berichte eines Zeitzeugen, hrsg. von Peter Eisenmann, Frankfurt am Main 1993.

Zwischen Befreiung und Besatzung. Analysen des US-Geheimdienstes über Positionen und Strukturen deutscher Politik 1945, hrsg. von Ulrich Borsdorf und Lutz Niethammer, Wuppertal 1976.

\section{Autobiographien, Memoiren und Tagebücher}

Hans Ehard, Tatsachen und Zusammenhänge aus meiner elfjährigen Ministerpräsidentschaft, München 1964 (Historisch-Politische Schriftenreihe des Neuen Presseclubs, München: Die Bayerischen Ministerpräsidenten der Nachkriegszeit 3).

Hans Ehard, Der Wiederbeginn des Bayerischen Landtags nach dem Zweiten Weltkrieg, in: Heinz Rosenbauer, Volkmar Gabert (Hrsg.), Parlamentarismus und Föderalismus. Festschrift für Rudolf Hanauer aus Anlaß seines 70. Geburtstages, München 1978, S. 45-48.

Erinnerungsinterview mit Werner Dollinger, in: Geschichte einer Volkspartei. 50 Jahre CSU 1945-1995, Grünwald 1995, S. 525-540.

Erinnerungsinterview mit Franz Heubl, in: Geschichte einer Volkspartei. 50 Jahre CSU 1945-1995, Grünwald 1995, S. 541-561.

Erinnerungsinterview mit Richard Jaeger, in: Geschichte einer Volkspartei. 50 Jahre CSU 1945-1995, Grünwald 1995, S. 563-580.

Erinnerungsinterview mit Richard Stücklen, in: Geschichte einer Volkspartei. 50 Jahre CSU 1945-1995, Grünwald 1995, S. 581-603.

Erinnerungsinterview mit Hans Weiß, in: Geschichte einer Volkspartei. 50 Jahre CSU 1945-1995, Grünwald 1995, S. 605-617.

Erinnerungsinterview mit Friedrich Zimmermann, in: Geschichte einer Volkspartei. 50 Jahre CSU 1945-1995, Grünwald 1995, S. 619-632.

Franz Haas, Regierungsbildung mit klammen Fingern, in: Michael Schröder, Bayern 1945: Demokratischer Neubeginn. Interviews mit Augenzeugen, München 1985, S. 163-174.

„Harte Knochenarbeit statt Amt und Würden“. Die ersten Jahre des CSU-Kreisverbands aus der Sicht von Freiherr Otto von Feury, in: 50 Jahre CSU im Landkreis Ebersberg, hrsg. vom CSU-Kreisverband Ebersberg, o. O. o. J., S. 19-25.

Ulrich von Hassell, Vom andern Deutschland. Aus den nachgelassenen Tagebüchern 1938-1944, Zürich, Freiburg 1946. 
August Haußleiter, Der Sturz des „Ochsensepp“, in: Michael Schröder, Bayern 1945: Demokratischer Neubeginn. Interviews mit Augenzeugen, München 1985, S. 89-104.

Franz Heubl, Jugend und Demokratie. Erfahrungen nach dem Zusammenbruch, in: Christoph Böhr (Hrsg.), Jugend bewegt Politik. Die Junge Union Deutschlands 1947 bis 1987, Krefeld 1988, S. 69-80.

Wilhelm Hoegner, Der schwierige Außenseiter. Erinnerungen eines Abgeordneten, Emigranten und Ministerpräsidenten, München 1959.

Alois Hundhammer, Mein Beitrag zur bayerischen Politik 1945-1965, München 1965 (HistorischPolitische Schriftenreihe des Neuen Presseclubs, München: Bayerische Profile 1).

Im Zentrum der Macht. Das Tagebuch von Staatssekretär Lenz 1951-1953, bearb. von Klaus Gotto, Hans-Otto Kleinmann, Reinhard Schreiner, Düsseldorf 1989.

Hugo Karpf, Erinnerungen, in: Abgeordnete des Deutschen Bundestages. Aufzeichnungen und Erinnerungen, Bd. 3, Boppard am Rhein 1985, S. 88-139.

Franziska Kimpfler, Erinnerungen an Adam Stegerwald, in: Politische Studien 39 (1988), S. 208-221.

Karl Köhler, Der Mittwochskreis beim „Ochsensepp“. Die Union wird geboren, in: Michael Schröder, Bayern 1945: Demokratischer Neubeginn. Interviews mit Augenzeugen, München 1985, S. 67-88.

Heinrich Krone. Tagebücher, Bd. 1: 1945-1961, bearb. von Hans-Otto Kleinmann, Düsseldorf 1995.

Adolf Miller, Parteiarbeiter aus Verlegenheit, in: Michael Schröder, Bayern 1945: Demokratischer Neubeginn. Interviews mit Augenzeugen, München 1985, S. 111-120.

Josef Müller, Bis zur letzten Konsequenz. Ein Leben für Frieden und Freiheit, München 1975.

Fritz Schäffer, Die Bayerische Volkspartei (BVP), in: Politische Studien 14 (1963), S. 46-63.

Fritz Schäffer, Die Zeit der ersten Ministerpräsidentschaft in Bayern nach dem Zusammenbruch im Jahre 1945, München 1963 (Historisch-Politische Schriftenreihe des Neuen Presseclubs, München: Die Bayerischen Ministerpräsidenten der Nachkriegszeit 1).

Hannes Schinagl, Politische Bildung im „Dienstag-Club“, in: Michael Schröder, Bayern 1945: Demokratischer Neubeginn. Interviews mit Augenzeugen, München 1985, S. 105-110.

Hans Schütz, Die Deutsche Christlichsoziale Volkspartei in der Ersten Tschechoslowakischen Republik, in: Karl Bosl (Hrsg.), Die Erste Tschechoslowakische Republik als multinationaler Parteienstaat, München, Wien 1979, S. 271-290.

Hans Schütz, Die christlichen Gewerkschaften und die Politik, in: Hans Schütz - Helfer und Wegweiser in schwerer Zeit. Gewerkschafter - Sozialpolitiker - Jungaktivist - Vertriebenenpolitiker - Europapolitiker, hrsg. von der Ackermann-Gemeinde, München 1982, S. 115-122.

Wilhelm Seutter von Lötzen, Bayerns Königstreue im Widerstand. Erinnerungen 1933-1964, Feldafing o. J. (1978).

Franz Josef Strauß, Die Erinnerungen, Berlin 1989.

Friedrich Zimmermann, Kabinettstücke. Politik mit Strauß und Kohl 1976-1991, München, Berlin 1991.

\section{Reden und Schriften prominenter Politiker von BVP, CDU und CSU}

Konrad Adenauer. Reden 1917-1967. Eine Auswahl, hrsg. von Hans-Peter Schwarz, Stuttgart 1975. Hans Ehard, Bayerische Politik. Ansprachen und Reden des bayerischen Ministerpräsidenten, ausgewählt und eingeleitet von Karl Schwend, München 1952.

Hans Ehard, Die CSU als Regierungspartei, in: Politisches Jahrbuch der CSU 1954, S. 55-80.

Hermann Ehlers. Präsident des Deutschen Bundestages. Ausgewählte Reden, Aufsätze und Briefe 1950-1954, bearb. von Rüdiger Wenzel, hrsg. und eingel. von Karl Dietrich Erdmann, Boppard am Rhein 1991.

Franz Elsen, Der Wirtschaftsbeirat, in: Politisches Jahrbuch der CSU 1954, S. 126-127.

25 Jahre Christlich-Soziale Union in Bayern, hrsg. von der CSU-Landesleitung, München 1971. 
Fritz Gerathewohl, Die Quellen erfolgreicher Lebensführung, München ${ }^{2} 1934$.

Fritz Gerathewohl, Jederzeit redebereit, hrsg. von der DAF, München o. J.

Georg Haindl, Der Wirtschaftsbeirat der CSU. Mittler zwischen Politik und Wirtschaft, in: Gesellschaftspolitische Kommentare 14 (1967), S. 236-238.

August Haußleiter, Wolfgang Prechtl, Kulturpolitik der Union. Warum Bekenntnisschule? Die Union zur Frage Staat und Kirche, München 1946 (Fragen der Zeit. Schriftenreihe der Christlich-Sozialen Union Bayerns 2).

Roman Herzog, Die geistigen Grundlagen der freiheitlichen Gesellschaftsordnung. Zugleich: zu den Aufgaben des Evangelischen Arbeitskreises der CDU/CSU in Politik und Kirche, in: Hermann Kunst, Helmut Kohl, Peter Egen (Hrsg.), Dem Staate verpflichtet. Festgabe für Gerhard Schröder, Stuttgart, Berlin 1980, S. 157-169.

Alois Hundhammer, Staatsbürgerliche Vorträge, Regensburg ${ }^{2} 1931$.

In Verantwortung für Bayern. 50 Jahre CSU-Fraktion im Bayerischen Landtag 1946-1996, hrsg. von der CSU-Landtagsfraktion, München 1996.

Richard Keßler, 30 Jahre Landtags-Fraktion der CSU, in: Festschrift zum 30 jährigen Bestehen der Landtagsfraktion der CSU , München 1976, S. 4-9 (Sondernummer der CSU-Correspondenz).

Walter Künneth, Die Stellung des evangelischen Christen zur Politik, in: Hanns Seidel, Weltanschauung und Politik, München ${ }^{2} 1961$, S. 59-71.

Hermann Leeb, Die Regierungsfraktion im Bayerischen Parlament, in: Auftrag, Bewährung, Ausblick. 40 Jahre Bayerische Verfassung 1946-1986, München 1986, S. 45-51.

Josef Müller, Maximen der Unionspolitik, in: Unsere soziale Revolution, München 1948, S. 3-7 (Fragen der Zeit. Schriftenreihe der Christlich-Sozialen Union Bayerns 5).

Josef Müller, Festansprache, in: 10 Jahre Christlich-Soziale Union in Bayern, hrsg. vom Generalsekretariat der Christlich-Sozialen Union in Bayern aus Anlaß des Landesparteitages am 23. Oktober 1955 in München, München 1955, S. 37-50.

Emil Muhler, Die ideologischen Grundlagen der CSU, in: Politisches Jahrbuch der CSU 1954, S. 13-32.

Anton Pfeiffer, Wie Bayern wieder ein Staat wurde, in: Unser Bayern. Politik, Wirtschaft, Kultur, hrsg. von der Bayerischen Staatskanzlei, München 1950, S. 7-10.

Eugen Rindt, Der Weg zur staatsbürgerlichen Selbsthilfe, in: Unsere soziale Revolution, München 1948, S. 11-16 (Fragen der Zeit. Schriftenreihe der Christlich-Sozialen Union Bayerns 5).

Franz Sackmann, Die Junge Union Bayerns, in: Politisches Jahrbuch der CSU 1954, S. 179-184.

Fritz Schäffer, Ein bayerischer Staatspräsident. Kritische Betrachtungen und Vorschläge zur Bayerischen Verfassung vom 14.8. 1919, München 1922 (Politische Zeitfragen. Monatsschrift über alle Gebiete des öffentlichen Lebens 4 (1922) H. 1).

Fritz Schäffer, Der Föderalismus in Deutschland. Die Lage Ende Dezember 1927 vor Beginn der "Länderkonferenz" in Berlin, o. O. 1928.

Fritz Schäffer, Die Aushöhlungs- und Aushungerungspolitik des Reiches gegenüber den Ländern. Nach einer Rede in der großen politischen Aussprache im bayerischen Landtag am 27. November 1928, München 1929.

Franz August Schmitt (Hrsg.), Zehn Jahre Wirtschaftsbeirat der Bayerischen Volkspartei. Ein Beitrag zur regionalen Wirtschaftspflege, München 1930.

Karl Schubert, Die Heimatvertriebenen und die Christlich-Soziale Union, in: Politisches Jahrbuch der CSU 1954, S. 155-175.

Lorenz Sedlmayr, Die soziale Neuordnung, in: Unsere soziale Revolution, München 1948, S. 8-10 (Fragen der Zeit. Schriftenreihe der Christlich-Sozialen Union Bayerns 5).

Johannes Semler, Wirtschaftslage und Wirtschaftsgestaltung, München 1946 (Fragen der Zeit. Schriftenreihe der Christlich-Sozialen Union Bayerns 1).

Adam Stegerwald, Von deutscher Zukunft, Würzburg 1946.

Adam Stegerwald, Wo stehen wir?, Würzburg 1946.

Adam Stegerwald, Wohin gehen wir?, Würzburg 1946.

Franz Josef Strauß, Die politische Arbeit der CSU im Bundestag, in: Politisches Jahrbuch der CSU 1954, S. 81-95.

Franz Josef Strauß, An der Wiege der CSU. Der Gewerkschaftsführer und Politiker Adam Stegerwald, in: Politische Studien Sonderheft 3/1981, S. 41-45. 
Franz Josef Strauß, Ein Glücksfall deutscher Geschichte. Die CSU feiert Geburtstag - 40 Jahre Leistung und Erfolg für Bayern, Deutschland und Europa, in: Bayern-Kurier vom 30.11. 1985, S. 17-23.

Gerold Tandler (Hrsg.), 40 Jahre Landtagsfraktion der CSU, Würzburg 1986 (Schriftenreihe der CSU-Fraktion XIX).

40 Jahre Junge Union Bayern. 1947-1987, hrsg. von der Jungen Union Bayern, München 1987.

Theo Waigel, Die Rolle der CSU-Landesgruppe im Spannungsfeld von Partei, Regierung und Fraktion, in: Politische Studien Sonderheft 1/1989, S. 106-112.

\section{Interviews}

Franz Sachmann am 3.4. 1998 in Roding

Friedrich Zimmermann am 2.6. 1992 in München

\section{Zeitungen und Zeitschriften}

\author{
Abendzeitung (München) \\ Bayerische Landeszeitung \\ Bayerische Rundschau \\ Bayerischer Kurier \\ Bayern-Kurier \\ CSU-Correspondenz \\ Echo der Woche \\ Fränkische Volksstimme \\ Fränkischer Tag (Bamberg) \\ Frankfurter Allgemeine Zeitung \\ Frankenpost (Hof) \\ Der Gerade Weg \\ Isar Post (Landshut) \\ Kurier (Berlin) \\ Main-Echo (Aschaffenburg) \\ Main-Post (Würzburg) \\ Mitteilungen der Christlich-Sozialen Union \\ Mittelbayerische Zeitung (Regensburg) \\ Münchner Merkur
}

\author{
Neue Zeitung \\ Neue Zürcher Zeitung \\ Oberbayerisches Volksblatt (Rosenheim) \\ Die Politische Information \\ Passauer Neue Presse \\ Regensburger Post \\ Schwäbische Landeszeitung (Augsburg) \\ Sopade-Informationsdienst \\ Der Spiegel \\ Stuttgarter Nachrichten \\ Stuttgarter Zeitung \\ Süddeutsche Zeitung (München) \\ Südost-Kurier (Bad Reichenhall) \\ Tagespost (Augsburg) \\ Tagesspiegel \\ Telegraf \\ Union-Dienst \\ Die Zeit
}

\section{Bibliographien und Nachschlagewerke}

Die Bestände des Archivs für Christlich-Demokratische Politik der Konrad-Adenauer-Stiftung.

Kurzübersicht, Melle 3., veränderte und aktualisierte Auflage 1992.

Bibliographie zur Geschichte der CDU und CSU 1945-1980, bearb. von Gerhard Hahn, Stuttgart 1982.

Bibliograhie zur Geschichte der CDU und CSU 1981-1986. Mit Nachträgen 1945-1980, bearb. von Brigitte Krahe und Michaela Seibel, Düsseldorf 1990.

Bibliograhie zur Geschichte der CDU und CSU 1987-1990, bearb. von Thomas Schaarschmidt und Hildegard Krengel, Düsseldorf 1994.

Die Bundestagswahl von A bis Z. 11. Bundestagswahl in Bayern am 25. Januar 1987, hrsg. vom Bayerischen Landesamt für Statistik und Datenverarbeitung und der Bayerischen Landeszentrale für politische Bildungsarbeit, München 1987.

Die erste Bundestagswahl in Bayern am 14. August 1949, hrsg. vom Bayerischen Statistischen Landesamt, München 1950. 
Handbuch politischer Institutionen und Organisationen 1945-1949, bearb. von Heinrich Potthoff in Zusammenarbeit mit Rüdiger Wenzel, Düsseldorf 1983.

Handbücher des Bayerischen Landtags, hrsg. vom Landtagsamt, München 1948-1991.

Handbücher des Deutschen Bundestags, hrsg. vom Deutschen Bundestag, Bonn 1950-1991.

Peter Jakob Kock, Der Bayerische Landtag 1946-1986, Bd. 1: Chronik, Bd. 2: Protokolle, Bamberg 1986.

Die Landtagswahl von A bis Z. 12. Landtagswahl in Bayern am 14. Oktober 1990, hrsg. vom Bayerischen Landesamt für Statistik und Datenverarbeitung und der Bayerischen Landeszentrale für politische Bildungsarbeit, München 1990.

Gerhard A. Ritter, Merith Niehuss, Wahlen in Deutschland 1946-1991. Ein Handbuch, München 1991.

Martin Schumacher (Hrsg.), M. d. R. Die Reichstagsabgeordneten der Weimarer Republik in der Zeit des Nationalsozialismus. Politische Verfolgung, Emigration und Ausbürgerung 19331945. Eine biographische Dokumentation, Düsseldorf 3., erheblich erweiterte und überarbeitete Auflage 1994.

Martin Schumacher (Hrsg.), Das Ende der Parlamente 1933 und die Abgeordneten der Landtage und Bürgerschaften der Weimarer Republik in der Zeit des Nationalsozialismus. Politische Verfolgung, Emigration und Ausbürgerung 1933-1945. Ein biographischer Index, Düsseldorf 1995.

Statistisches Jahrbuch für Bayern für 1947, hrsg. vom Bayerischen Statistischen Landesamt, München o. J. (1948).

Wer ist Wer? Das deutsche Who's Who, Bd. XI-XVI, Berlin 1951-1970.

Zweite Bundestagswahl in Bayern am 6. September 1953, hrsg. vom Bayerischen Statistischen Landesamt, München 1954.

\section{Literatur}

Dieter Albrecht, Von der Reichsgründung bis zum Ende des Ersten Weltkrieges (1871-1918), in: Max Spindler (Hrsg.), Handbuch der bayerischen Geschichte, Bd. IV/1: Das Neue Bayern 1800-1970, München 1974, S. 283-386.

Dieter Albrecht, Hans Ehard (1887-1980), in: Jürgen Aretz, Rudolf Morsey, Anton Rauscher (Hrsg.), Zeitgeschichte in Lebensbildern. Aus dem deutschen Katholizismus des 19. und 20. Jahrhunderts, Bd. 5, Mainz 1982, S. 266-280.

Otto Altendorfer, Fritz Schäffer. Politik in schwierigen Zeiten. Eine Studie zum 100. Geburtstag (1888-1988), in: Politische Studien 39 (1988), S. 305-322.

Otto Altendorfer, Fritz Schäffer als Politiker der Bayerischen Volkspartei (1888-1945), 2 Bde., München 1993.

Helmut Anzeneder, Willi Götz, 1946-1996. 50 Jahre CSU in Erlangen, Erlangen 1995.

Helmut Anzeneder, Die Anfänge der CSU, in: Jürgen Sandweg, Gertraud Lehmann (Hrsg.), Hinter unzerstörten Fassaden - Erlangen 1945-1955, Erlangen 1996, S. 232-276.

Fritz Baer, Die Ministerpräsidenten Bayerns 1945-1962. Dokumentation und Analyse, München 1971.

Winfried Becker, Historische Grundlagen der christlich-demokratischen Parteibildung nach 1945, in: Günter Buchstab, Klaus Gotto (Hrsg.), Die Gründung der Union. Traditionen, Entstehung und Repräsentanten, München, Wien 1981, S. 7-33.

Winfried Becker, Die CDU im demokratischen Neubeginn 1945/1946 - Motive der Gründung und parteipolitischer Standort, in: Günther Rüther (Hrsg.), Geschichte der Christlich-Demokratischen und Christlich-Sozialen Bewegungen in Deutschland. Grundlagen, Unterrichtsmodelle, Quellen und Arbeitshilfen für die politische Bildung, Bonn ${ }^{2} 1987$, S. 333-360.

Winfried Becker, CDU und CSU 1945-1950. Vorläufer, Gründung und regionale Entwicklung bis zum Entstehen der CDU-Bundespartei, Mainz 1987.

Winfried Becker, Fritz Schäffer und der Föderalismus, in: Wolfgang J. Mückl (Hrsg.), Föderalismus und Finanzpolitik. Gedenkschrift für Fritz Schäffer, Paderborn u. a. 1990, S. 9-36. 
Winfried Becker, Franz Josef Strauß (1915-1988), in: Jürgen Aretz, Rudolf Morsey, Anton Rauscher (Hrsg.), Zeitgeschichte in Lebensbildern. Aus dem deutschen Katholizismus des 19. und 20. Jahrhunderts, Bd. 7, Mainz 1994, S. 227-244.

Winfried Becker, Gründung und Wurzeln der Christlich-Sozialen Union, in: Geschichte einer Volkspartei. 50 Jahre CSU 1945-1995, Grünwald 1995, S. 69-107.

Wolfgang Behr, Sozialdemokratie und Konservatismus. Ein empirischer und theoretischer Beitrag zur regionalen Parteianalyse am Beispiel der Geschichte und Nachkriegsentwicklung Bayerns, Hannover 1969.

Wolfgang Benz, Föderalistische Politik in der CDU/CSU. Die Verfassungsdiskussion im „Ellwanger Kreis“ 1947/48, in: Vierteljahrshefte für Zeitgeschichte 25 (1977), S. 776-820.

Wolfgang Benz, Der politische Neubeginn in Bayern - Hanns Seidel und die CSU, in: Hanns Seidel - „Ein Leben für Bayern“. Symposion der Hanns-Seidel-Stiftung am 18. und 19. Juli 1986 in Wildbad Kreuth, o. O. 1987, S. 38-49.

Wolfgang Benz, Parteigründungen und erste Wahlen. Der Wiederbeginn des politischen Lebens, in: ders. (Hrsg.), Neuanfang in Bayern 1945-1949. Politik und Gesellschaft in der Nachkriegszeit, München 1988, S. 9-35.

Walter Berberich, Die CSU als neue interkonfessionell-christliche und föderalistische Mehrheitspartei. Ein Beitrag zur Geschichte der Christlich-Sozialen Union in Bayern, in: Politisches Jahrbuch der CSU 1954, S. 33-53.

Walter Berberich, 10 Jahre Christlich-Soziale Union in Bayern. Arbeit, Kampf, Verantwortung und Erfolge, in: 10 Jahre Christlich-Soziale Union in Bayern, hrsg. vom Generalsekretariat der Christlich-Sozialen Union in Bayern aus Anlaß des Landesparteitages am 23. Oktober 1955 in München, München 1955, S. 5-36.

Walter Berberich, Die historische Entwicklung der Christlich-Sozialen Union in Bayern bis zum Eintritt in die Bundespolitik, Diss., Würzburg 1965.

Helmut Berding, Staatliche Identität, nationale Integration und politischer Regionalismus, in: ders., Aufklären durch Geschichte. Ausgewählte Aufsätze, Göttingen 1990, S. 284-309.

Hannsjörg Bergmann, Der Bayerische Bauernbund und der Bayerische Christliche Bauernverein 1919-1928, München 1986.

Gerhard Besier, „Christliche Parteipolitik“ und Konfession. Zur Entstehung des Evangelischen Arbeitskreises der CDU/CSU, in: Kirchliche Zeitgeschichte 3 (1990/1991), S 166-187.

Jutta Beyer, Demokratie als Lernprozeß. Politische Kultur und lokale Politik nach 1945 am Beispiel der Städte Forchheim und Schwabach, Nürnberg 1989.

Klaus von Beyme, Die politischen Theorien der Gegenwart. Eine Einführung, München, Zürich 6., überarbeitete und ergänzte Auflage 1986.

Andreas Biefang, Die Wiederentstehung politischer Parteien in Deutschland nach 1945, in: Aus Politik und Zeitgeschichte 18-19/95, S. 34-46.

Adolf M. Birke, Die Bundesrepublik Deutschland. Verfassung, Parlament und Parteien, München 1997.

Günter Bischof, Die Instrumentalisierung der Moskauer Erklärung nach dem 2. Weltkrieg, in: Zeitgeschichte 20 (1993), S. 345-366.

Detlef Bischoff, Franz Josef Strauß, die CSU und die Außenpolitik. Konzeption und Realität am Beispiel der Großen Koalition, Meisenheim am Glan 1973.

Werner K. Blessing, Georg Meixner (1887-1960), in: Fränkische Lebensbilder 16 (1996), S. 213 240.

Rebecca Boehling, German Municipal Self-Government and the Personnel Policies of the Local U.S. Military Government in Three Major Cities of the Zone of Occupation: Frankfurt, Munich and Stuttgart, in: Archiv für Sozialgeschichte 25 (1985), S. 333-383.

Lothar Bossle, Nachruf auf Wilhelm Arnold, in: Politische Studien 35 (1984), S. 3-4.

Heike Bretschneider, Die Bildung der Viererkoalition. Die parteipolitische Konstellation in Bayern in der ersten Hälfte der fünfziger Jahre, in: Zeitschrift für bayerische Landesgeschichte 41 (1978), S. 999-1038.

Fritz Brickwedde, Josef Müller, in: Günter Buchstab, Klaus Gotto (Hrsg.), Die Gründung der Union. Traditionen, Entstehung und Repräsentanten, München, Wien 1981, S. 222-233.

Claus Brügmann, Die Fraktionsakten der Christlich-Sozialen Union (CSU) im Archiv für Christlich-Soziale Politik der Hanns-Seidel-Stiftung, in: Günter Buchstab (Hrsg.), Parteien im Parla- 
ment. Fraktionsakten in europäischen Partei- und Parlamentsarchiven. Tagung der Sektion der Archive und Archivare der Parlamente und politischen Parteien im Internationalen Archivrat. Budapest 17.-19. November 1995, St. Augustin 1997, S. 28-31.

Hans Buchheim, Die Lebensbedingungen unter totalitärer Herrschaft, in: Karl Forster (Hrsg.), Möglichkeiten und Grenzen für die Bewältigung historischer und politischer Schuld in Strafprozessen, Würzburg 1962, S. 89-106.

Hubert Buchinger, Volksschule und Lehrerbildung im Spannungsfeld politischer Entscheidungen 1945-1970, München 1975.

Günter Buchstab, Brigitte Kaff, Hans-Otto Kleinmann (Hrsg.), Verfolgung und Widerstand 1933-1945. Christliche Demokraten gegen Hitler, Düsseldorf 1986.

Günter Buchstab, Der Ellwanger Freundeskreis der CDU/CSU, in: Winfried Becker, Werner Chrobak (Hrsg.), Staat, Kultur, Politik. Beiträge zur Geschichte Bayerns und des Katholizismus. Festschrift zum 65. Geburtstag von Dieter Albrecht, Kallmünz 1992, S. 431-441.

Werner Burger, Die CDU in Baden-Württemberg und die CSU in Bayern. Eine vergleichende Analyse, Freiburg 1984.

Heinz Burghart, Das Ende der „Provinz“, in: Georg Jenal (Hrsg.), Gegenwart in Vergangenheit. Beiträge zur Kultur und Geschichte der neueren und neuesten Zeit. Festschrift für Friedrich Prinz zum 65. Geburtstag, München 1993, S. 391-417.

Carol Carl-Sime, Bavaria, the CSU and the West German Party System, in: West European Politics 2 (1979), S. 89-107.

Noel D. Cary, Political Catholicism and the reform of the German party system 1900-1957, Diss., Ann Arbor/Mich. 1988.

Christlich-Soziale Union (CSU), in: Die westdeutschen Parteien 1945-1965. Ein Handbuch, hrsg. vom Deutschen Institut für Zeitgeschichte, Berlin (Ost) 1966, S. 184-219.

Bernhard Claußen, Was ist und wie erforscht man politische Sozialisation?, in: ders., Klaus Wasmund (Hrsg.), Handbuch der politischen Sozialisation, Braunschweig 1982, S. 1-22.

Bernhard Claußen, Historische Sozialisationsmuster in Deutschland, in: Dirk Berg-Schlosser, Jakob Schissler (Hrsg.), Politische Kultur in Deutschland. Bilanz und Perspektiven der Forschung, Opladen 1987, S. 155-165.

Clay Clemens, The CSU and West German Foreign Policy. The Strauß Era and beyond, in: Politics and Society in Germany, Austria and Switzerland 2 (1990), S. 16-38.

Werner Conze, Jakob Kaiser, Bd. 3: Politiker zwischen Ost und West 1945-1949, Stuttgart u. a. 1969.

Hans-Ulrich Derlien, Continuity and change in the West German federal elite 1949-1984, in: European Journal of Political Research 18 (1990), S. 349-372.

Ernst Deuerlein, CDU/CSU 1945-1957. Beiträge zur Zeitgeschichte, Köln 1957.

Ernst Deuerlein, Wolf D. Gruner, Die politische Entwicklung Bayerns 1945-1972, in: Max Spindler (Hrsg.), Handbuch der bayerischen Geschichte, Bd. IV/1: Das Neue Bayern 1800-1970, München 1974, S. 538-644.

Wolfgang F. Dexheimer, Die CSU-Landesgruppe. Ihre organisatorische Stellung in der CDU/ CSU-Fraktion, in: Zeitschrift für Parlamentsfragen 3 (1972), S. 307-313.

Wolfgang F. Dexheimer, Koalitionsverhandlungen in Bonn 1961, 1965, 1969. Zur Willensbildung in Parteien und Fraktionen, Bonn 1973.

Jürgen Domes, Mehrheitsfraktion und Bundesregierung. Aspekte des Verhältnisses der Fraktion der CDU/CSU im 2. und 3. Deutschen Bundestag zum Kabinett Adenauer, Köln 1964.

James Donohoe, Hitler's conservative opponents in Bavaria 1930-1945. A study of Catholic, monarchist and separatist anti-Nazi activities, Leiden 1961.

D. R. Dorondo, Bavaria and German Federalism. Reich to Republic. 1918-33, 1945-49, New York 1992.

Ulrich Dübber, Parteifinanzierung in Deutschland. Eine Untersuchung über das Problem der Rechtslegung in einem künftigen Parteiengesetz, Köln, Opladen 1962.

Dieter Düding, Bayern und der Bund. Bayerische „Opposition“ während der Grundgesetzberatungen im Parlamentarischen Rat (1948/49), in: Der Staat 29 (1990), S. 355-370.

Hansjörg Dürr, Soziale Strukturen des Bayerischen Landtags. Aspekte der Soziologie parlamentarischer Mandatsträger, in: Reinhold Bocklet (Hrsg.), Das Regierungssystem des Freistaates Bayern, Bd. 1: Beiträge, München 1977, S. 211-393. 
Wolfgang Eckart, Amerikanische Reformpolitik und deutsche Tradition. Nürnberg 1945-1949. Nachkriegspolitik im Spannungsfeld zwischen Neuordnungsvorstellungen, Notlage und pragmatischer Krisenbewältigung, Nürnberg 1988.

Peter Egen, Die Entstehung des Evangelischen Arbeitskreises der CDU/CSU, Diss., Bochum 1971. Alois Egger, Die Landtagswahl am 24. April 1932, in: Zeitschrift des Bayerischen Statistischen Landesamts 64 (1932), S. 357-424.

Andreas Eichmüller, Landwirtschaft und bäuerliche Bevölkerung in Bayern. Ökonomischer und sozialer Wandel 1945-1970. Eine vergleichende Untersuchung der Landkreise Erding, Kötzting und Obernburg, München 1997.

Erich Eisner, Das europäische Konzept von Franz Josef Strauß. Die gesamteuropäischen Ordnungsvorstellungen der CSU, Meisenheim am Glan 1975.

Günter Endruweit, Elitebegriffe in den Sozialwissenschaften, in: Zeitschrift für Politik 26 (1979), S. 31-46.

Sylvia Epp, Die Anfänge der CSU in Augsburg 1945-1950, in: Peter Fassl, Wilhelm Liebhart, Wolfgang Wüst (Hrsg.), Aus Schwaben und Altbayern. Festschrift für Pankraz Fried zum 60. Geburtstag, Sigmaringen 1991, S. 11-20.

Paul Erker, Keine Sehnsucht nach der Ruhr. Grundzüge der Industrialisierung in Bayern 1900-1970, in: Geschichte und Gesellschaft 17 (1991), S. 480-511.

Paul Erker, Der lange Abschied vom Agrarland. Zur Sozialgeschichte der Bauern im Industrialisierungsprozeß, in: Matthias Frese, Michael Prinz (Hrsg.), Politische Zäsuren und gesellschaftlicher Wandel im 20. Jahrhundert. Regionale und vergleichende Perspektiven, Paderborn 1996, S. 327-360.

Konrad Maria Färber, Bayern wieder ein Königreich? Die monarchistische Bewegung in Bayern nach dem Zweiten Weltkrieg, in: Wolfgang Benz (Hrsg.), Neuanfang in Bayern 1945-1949. Politik und Gesellschaft in der Nachkriegszeit, München 1988, S. 163-182.

Barbara Fait, „In einer Atmosphäre der Freiheit“. Die Rolle der Amerikaner bei der Verfassunggebung in den Ländern der US-Zone 1946, in: Vierteljahrshefte für Zeitgeschichte 33 (1985), S. $420-455$.

Barbara Fait, Auf Befehl der Besatzungsmacht? Der Weg zur Bayerischen Verfassung, in: Wolfgang Benz (Hrsg.), Neuanfang in Bayern 1945-1949. Politik und Gesellschaft in der Nachkriegszeit, München 1988, S. 36-63.

Barbara Fait, Die Anfänge der CSU 1945-1948. Der holprige Weg zur Erfolgspartei, München 1995.

Jürgen W. Falter, Bayerns Uhren gehen wirklich anders. Politische Verhaltens- und Einstellungsunterschiede zwischen Bayern und dem Rest der Bundesrepublik, in: Zeitschrift für Parlamentsfragen 13 (1982), S. 504-521.

Jürgen W. Falter, Wie gehen sie nun wirklich, die bayerischen Uhren?, in: Zeitschrift für Parlamentsfragen 19 (1988), S. 113-114.

Heinz-Dietrich Fischer, Parteien und Presse in Deutschland seit 1945, Bremen 1971.

Franz Focke, Sozialismus aus christlicher Verantwortung. Die Idee eines christlichen Sozialismus in der katholisch-sozialen Bewegung und in der CDU, Wuppertal ${ }^{2} 1981$.

Marie Elise Foelz-Schroeter, Föderalistische Politik und nationale Repräsentation 1945-1947. Westdeutsche Länderregierungen, zonale Bürokratien und politische Parteien im Widerstreit, Stuttgart 1974.

Christina M. Förster, Der Harnier-Kreis. Widerstand gegen den Nationalsozialismus in Bayern, Paderborn u. a. 1996.

Helmut Fogt, Politische Generationen. Empirische Bedeutung und theoretisches Modell, Opladen 1982.

Norbert Frei, Nationalsozialistische Eroberung der Provinzpresse. Gleichschaltung, Selbstanpassung und Resistenz in Bayern, Stuttgart 1980.

Norbert Frei, Amerikanische Lizenzpolitik und deutsche Pressetradition. Die Geschichte der Nachkriegszeitung Südost-Kurier, München 1986.

Volkmar Gabert, Die Bedeutung der Viererkoalition und des Spielbankenuntersuchungsausschusses für die Entwicklung der politischen Verhältnisse in Bayern, in: Hans Jochen Vogel, Helmut Simon, Adalbert Podlech (Hrsg.), Die Freiheit des Anderen. Festschrift für Martin Hirsch, Baden-Baden 1981, S. 187-206. 
Karl Gabriel, Die Katholiken in den 50er Jahren: Restauration, Modernisierung und beginnende Auflösung eines konfessionellen Milieus, in: Axel Schildt, Arnold Sywottek (Hrsg.), Modernisierung im Wiederaufbau. Die westdeutsche Gesellschaft der 50er Jahre, Bonn 1993, S. 418430.

Thomas M. Gauly, Katholiken. Machtanspruch und Machtverlust, Bonn 1991.

Thomas M. Gauly, Konfessionalismus und politische Kultur in Deutschland, in: Aus Politik und Zeitgeschichte 20/91, S. 45-53.

Karl-Ulrich Gelberg, Hans Ehard. Die föderalistische Politik des bayerischen Ministerpräsidenten 1946-1954, Düsseldorf 1992.

Karl-Ulrich Gelberg, Hans Ehard und Karl Arnold. Stationen eines wechselvollen Verhältnisses 1948-1952, in: Zeitschrift für bayerische Landesgeschichte 55 (1992), S. 625-646.

Karl-Ulrich Gelberg, Bayerischer Landtag und Föderalismus in Deutschland nach 1945, in: Walter Ziegler (Hrsg.), Der Bayerische Landtag vom Spätmittelalter bis zur Gegenwart. Probleme und Desiderate historischer Forschung. Kolloquium des Instituts für Bayerische Geschichte am 20. Januar 1995 im Maximilianeum in München, München 1995, S. 185-204.

Karl-Ulrich Gelberg, Josef Müller (1898-1979), in: Jürgen Aretz, Rudolf Morsey, Anton Rauscher (Hrsg.), Zeitgeschichte in Lebensbildern. Aus dem deutschen Katholizismus des 19. und 20. Jahrhunderts, Bd. 8, Mainz 1997, S. 155-172.

Günther Gerstenberg, Der Wiederaufbau der Münchner Gewerkschaftsbewegung und der Bayerische Gewerkschaftsbund 1945 bis 1949, unveröffentlichte Magisterarbeit, München 1984.

Constantin Goschler, Der Fall Philipp Auerbach. Wiedergutmachung in Bayern, in: Ludolf Herbst, Constantin Goschler (Hrsg.), Wiedergutmachung in der Bundesrepublik Deutschland, München 1989, S. 77-98.

Klaus Gotto, Die deutschen Katholiken und die Wahlen in der Adenauer-Ära, in: Albrecht Langner (Hrsg.), Katholizismus im politischen System der Bundesrepublik 1949-1963, Paderborn 1978, S. 7-32.

Hans-Jürgen Grabbe, Unionsparteien, Sozialdemokratie und Vereinigte Staaten von Amerika 1945-1966, Düsseldorf 1983.

Hans Ferdinand Groß, Hanns Seidel 1901-1961. Eine politische Biographie, München 1992.

Dieter Grosser, Die Rolle Fritz Schäffers als Finanzminister in den ersten beiden Kabinetten Konrad Adenauers, in: Wolfgang J. Mückl (Hrsg.), Föderalismus und Finanzpolitik. Gedenkschrift für Fritz Schäffer, Paderborn u. a. 1990, S. 67-80.

Thomas Grossmann, Zwischen Kirche und Gesellschaft. Das Zentralkomitee der deutschen Katholiken 1945-1970, Mainz 1991.

Wolf D. Gruner, Fritz Schäffer und der Neubeginn in Bayern nach 1945, in: Wolfgang J. Mückl (Hrsg.), Föderalismus und Finanzpolitik. Gedenkschrift für Fritz Schäffer, Paderborn u. a. 1990, S. 37-66.

Dietmar Grypa, Studien zu Kriegsende und Neuanfang im Landkreis Altötting, Burghausen 1991.

Georg Güttler, Die Entwicklung des CSU-Kreisverbands Bamberg-Stadt (1945-1975), unveröffentlichte Zulassungsarbeit, Bamberg 1976.

Arcadius R. L. Gurland, Die CDU/CSU. Ursprünge und Entwicklung bis 1953, Frankfurt am Main 1980.

Peter Gutjahr-Löser, CSU: Porträt einer Partei, München 1979.

Christian Hacke, Die Ost- und Deutschlandpolitik der CDU/CSU. Wege und Irrwege der Opposition seit 1969, Köln 1975.

M. Hagmann, Volksentscheid und Landtagswahl 1946, in: Bayern in Zahlen. Monatshefte des Bayerischen Statistischen Landesamts 1 (1947), S. 118-123.

M. Hagmann, Die Land- und Stadtkreiswahlen in Bayern am 25. April und am 30. Mai 1948. Sonderheft der Reihe Bayern in Zahlen. Monatshefte des Bayerischen Statistischen Landesamts, München 1948.

Manfred Hanisch, Für Fürst und Vaterland. Legitimitätsstiftung in Bayern zwischen Revolution 1848 und deutscher Einheit, München 1991.

Bernhard Hanssler, Der Pluralisierungsprozeß im deutschen Katholizismus und seine gesellschaftlichen Auswirkungen, in: Albrecht Langner (Hrsg.), Katholizismus im politischen System der Bundesrepublik 1949-1963, Paderborn 1978, S. 103-121. 
Peter Claus Hartmann, Fritz Schäffer - ein bedeutender Politiker in schwierigen Zeiten (1888-1967), in: ders., Otto Altendorfer (Hrsg.), 100 Jahre Fritz Schäffer. Politik in schwierigen Zeiten. Katalog der Ausstellung im Museum Kloster Asbach 12. Mai-15. August 1988, Passau 1988, S. 15-28.

Peter Claus Hartmann, Bayerns Weg in die Gegenwart. Vom Stammesherzogtum zum Freistaat heute, Regensburg 1989.

Heinz Haushofer, Der Bayerische Bauer und sein Verband 1945-1970, München u. a. 1970.

Horstwalter Heitzer, Die CDU in der britischen Zone 1945-1949. Gründung, Organisation, Programm und Politik, Düsseldorf 1988.

Klaus-Dietmar Henke, Die amerikanische Besetzung Deutschlands, München 1995.

Christoph Henzler, Fritz Schäffer 1945-1967. Eine biographische Studie zum ersten bayerischen Nachkriegs-Ministerpräsidenten und ersten Finanzminister der Bundesrepublik Deutschland, München 1994.

Christoph Henzler, Die Christlich-Soziale Union in den ersten Nachkriegsjahren, in: Geschichte einer Volkspartei. 50 Jahre CSU 1945-1995, Grünwald 1995, S. 109-161.

Peter Herde, Unionsparteien zwischen Tradition und Neubeginn: Adam Stegerwald, in: Winfried Becker (Hrsg.), Die Kapitulation von 1945 und der Neubeginn in Deutschland, Köln, Wien 1987, S. 245-295.

Friedrich Hermann Hettler, Josef Müller („Ochsensepp“). Mann des Widerstandes und erster CSU-Vorsitzender, München 1991.

Reinhard Heydenreuter, Office of Military Government for Bavaria, in: Christoph Weisz (Hrsg.), OMGUS-Handbuch. Die amerikanische Militärregierung in Deutschland 1945-1949, München 1994, S. 143-315.

Helmut Hoffmann, Bayern. Handbuch zur staatspolitischen Landeskunde der Gegenwart, München 7., völlig überarbeitete Auflage 1981.

Peter Hubert, Uniformierter Reichstag. Die Geschichte der Pseudo-Volksvertretung 1933-1945, Düsseldorf 1992.

Isa Huelsz, Schulpolitik in Bayern zwischen Demokratisierung und Restauration in den Jahren 1945-1950, Hamburg 1970.

Paul Hussarek, Hundhammer. Weg des Menschen und Staatsmannes, München 1951.

Ernst-Ulrich Huster u. a., Determinanten der westdeutschen Restauration 1945-1949, Frankfurt am Main 1972.

Detlev Ipsen, Thomas Fuchs, Die Modernisierung des Raumes - Blockierung und Öffnung. Raumbilder als historische Bedingung regionaler Entwicklung in Nordhessen und Oberbayern, in: 19996 (1991) H.1, S. 13-33.

Wolfgang Ismayr, Gerhard Kral, Bayern, in: Falk Esche, Jürgen Hartmann (Hrsg.), Handbuch der deutschen Bundesländer, Frankfurt am Main, New York 1990, S. 91-131.

Hans Jaeger, Generationen in der Geschichte. Überlegungen zu einer umstrittenen Konzeption, in: Geschichte und Gesellschaft 3 (1977), S. 429-452.

Larry Eugene Jones, Adam Stegerwald und die Krise des deutschen Parteiensystems, in: Vierteljahrshefte für Zeitgeschichte 27 (1979), S. 1-29.

Heino Kaack, Die soziale Zusammensetzung des Deutschen Bundestages, in: Uwe Thaysen, Roger H. Davidson, Robert G. Livingston (Hrsg.), US-Kongreß und Deutscher Bundestag. Bestandsaufnahmen im Vergleich, Opladen 1988, S. 128-151.

Brigitte Kaff, Eine Volkspartei entsteht. Zirkel und Zentren der Unionsgründung, in: Günter Buchstab, Klaus Gotto (Hrsg.), Die Gründung der Union. Traditionen, Entstehung und Repräsentanten, München, Wien 1981, S. 70-101.

Josef Kirchmann, Die Bedeutung christlicher Werte in Programm und Praxis der CSU, Diss., St. Ottilien 1985.

Gerhard Kleinhenz, Wirtschafts- und Sozialpolitik - Die Verwirklichung einer Sozialen Marktwirtschaft durch die Landespolitik der CSU, in: Geschichte einer Volkspartei. 50 Jahre CSU 1945-1995, Grünwald 1995, S. 253-289.

Hans-Otto Kleinmann, Geschichte der CDU 1945-1982, Stuttgart 1993.

Christoph Kleßmann, Kontinuitäten und Veränderungen im protestantischen Milieu, in: Axel Schildt, Arnold Sywottek (Hrsg.), Modernisierung im Wiederaufbau. Die westdeutsche Gesellschaft der 50er Jahre, Bonn 1993, S. 403-417. 
Georg Knauss, Kulturhoheit der Länder - Chance oder Hypothek?, in: Rainer A. Roth, Freistaat Bayern. Die politische Wirklichkeit eines Landes der Bundesrepublik Deutschland, München 3., überarbeitete Auflage 1982, S. 161-174.

Peter Jakob Kock, Bayern und Deutschland. Föderalismus als Anspruch und Wirklichkeit, in: Wolfgang Benz (Hrsg.), Neuanfang in Bayern 1945-1949. Politik und Gesellschaft in der Nachkriegszeit, München 1988, S. 183-204.

Peter Jakob Kock, Bayerns Weg in die Bundesrepublik, München ${ }^{2} 1988$.

Peter Jakob Kock, Warum im Senat so viele Landwirte wie Gewerkschafter sitzen. Protokoll beweist: Der CSU-Wirtschaftsflügel wurde ausgebootet, in: Maximilianeum 4 (1992) Nr. 3, S. 36.

Peter Jakob Kock, Bayern nach dem Zweiten Weltkrieg, in: Manfred Treml, Geschichte des modernen Bayern. Königreich und Freistaat, München 1994, S. 375-498.

Henning Köhler, Adenauer. Eine politische Biographie, Frankfurt am Main, Berlin 1994.

Daniel Koerfer, Schwierige Geburten: Regierungsbildungen 1961, 1962, 1963 und 1965, in: Wolfgang Mischnick (Hrsg.), Verantwortung für die Freiheit. 40 Jahre F. D. P., Stuttgart 1989, S. 156-162.

Ferdinand Kramer, Der Neuanfang des U. S.-Generalkonsulates in München nach 1945, in: Egon Johannes Greipl, Alois Schmid, Walter Ziegler (Hrsg.), Aus Bayerns Geschichte. Forschungen als Festgabe zum 70. Geburtstag von Andreas Kraus, St. Ottilien 1992, S. 465-496.

Dorit-Maria Krenn, Die christliche Arbeiterbewegung in Bayern vom Ersten Weltkrieg bis 1933, Mainz 1991.

Wolfgang Krieger, Franz Josef Strauß. Der barocke Demokrat aus Bayern, Göttingen, Zürich 1995.

Wolfgang Krieger, Franz Josef Strauß und die zweite Epoche in der Geschichte der CSU, in: Geschichte einer Volkspartei. 50 Jahre CSU 1945-1995, Grünwald 1995, S. 163-193.

Peter Kritzer, Wilhelm Hoegner. Politische Biographie eines bayerischen Sozialdemokraten, München 1979.

Peter Kritzer, Wilhelm Hoegner und seine Verfassungspolitik, in: Hartmut Mehringer (Hrsg.), Von der Klassenbewegung zur Volkspartei. Wegmarken der bayerischen Sozialdemokratie 1892-1992, München u. a. 1992, S. 228-235.

Erich Kuby u. a., Franz Josef Strauß. Ein Typus unserer Zeit, Wien u. a. 1963.

Franz Kühnel, Die CSU und der fränkische Protestantismus 1945-1953, unveröffentlichte Magisterarbeit, Erlangen 1983.

Aline M. Kuntz, Conservatives in Crisis: The Bavarian Christian-Social Union and the Ideology of Antimodernism, Diss., Ann Arbor/Mich. 1987.

Rainer Kunz, Richard Stücklen, in: Walther L. Bernecker, Volker Dotterweich (Hrsg.), Persönlichkeit und Geschichte in der BRD. Politische Porträts, Bd. 2, Göttingen 1982, S. 209-217.

Christiane Landfried, Parteifinanzen und politische Macht. Eine vergleichende Studie zur Bundesrepublik Deutschland, zu Italien und den USA, Baden-Baden 1990.

Claudia Lanig-Heese, Gewerkschaften in Bayern 1945 bis 1949, Marburg 1991.

Maximilian Lanzinner, Zwischen Sternenbanner und Bundesadler. Bayern im Wiederaufbau 1945-1958, Regensburg 1996.

Heinz Laufer, Bayern und die Bundesrepublik. Der Freistaat Bayern im föderativen System der Bundesrepublik Deutschland, in: Reinhold Bocklet (Hrsg.), Das Regierungssystem des Freistaates Bayern, Bd. 2: Beiträge, München 1979, S. 109-165.

Werner Lederer, Die Einflußnahme der kleinen Koalitionsparteien auf die Regierungspolitik des Bundeskanzlers in den Jahren 1949-1957, Diss., Kiel 1967.

Bernhard Lehmann, Katholische Kirche und Besatzungsmacht in Bayern 1945-1949 im Spiegel der OMGUS-Akten, München 1994.

Kurt Lenk, „Elite“ - Begriff oder Phänomen?, in: Aus Politik und Zeitgeschichte 42/82, S. 2737.

Leonhard Lenk, Zur Geschichte der bayerischen Volksvertretung. Grundlinien - Wahlrecht - Parteien - Parlamentsarbeit, in: Reinhold Bocklet (Hrsg.), Das Regierungssystem des Freistaates Bayern, Bd. 2: Beiträge, München 1979, S. 19-77.

M. Rainer Lepsius, Generationen, in: Martin Greiffenhagen, Sylvia Greiffenhagen, Rainer Prätorius (Hrsg.), Handwörterbuch der Politischen Kultur der Bundesrepublik Deutschland, Opladen 1981, S. 172-176. 
Bernd Lerch, Klaus Stephan, Josef Walter König, Eine Stadt und ihre Christlich-Soziale Union. Donauwörth 1945-1995, Donauwörth 1995.

Richard Ley, Föderalismusdiskussion innerhalb der CDU/CSU von der Parteigründung bis zur Verabschiedung des Grundgesetzes, Mainz 1978.

Johannes Ludwig, Boykott, Enteignung, Mord. Die „Entjudung“ der deutschen Wirtschaft, Hamburg, München 1989.

Josef Ludwig Lypp, Die Entstehungsgeschichte der Christlich-Sozialen Union in Bamberg, unveröffentlichte Diplomarbeit, Bamberg 1983.

Ursula Männle, Mit Mütterlichkeit verbundene Energie: Maria Probst (1902-1967), in: Renate Hellwig (Hrsg.), Unterwegs zur Partnerschaft. Die Christdemokratinnen, Stuttgart 1984, S. 194-203.

Ursula Männle, Maria Probst (1902-1967), in: Jürgen Aretz, Rudolf Morsey, Anton Rauscher (Hrsg.), Zeitgeschichte in Lebensbildern. Aus dem deutschen Katholizismus des 19. und 20. Jahrhunderts, Bd. 7, Mainz 1994, S. 113-127.

Christian Maga, Prälat Johann Leicht (1868-1940). Konservativer Demokrat in der Krise der Zwischenkriegszeit, Diss., Würzburg 1990.

Karl Mannheim, Das Problem der Generationen, in: Martin Kohli (Hrsg.), Soziologie des Lebenslaufs, Darmstadt, Neuwied 1978, S. 38-53.

Berthold Mauch, Die bayerische FDP. Portrait einer Landespartei 1945-1949, München 1981.

Klaus-Jürgen Matz, Reinhold Maier (1889-1971). Eine politische Biographie, Düsseldorf 1989.

Josef H. Mauerer, Aus dem Leben und politischen Wirken des Dr. Josef Müller (Ochsensepp) 1945-1965, München 1967 (Historisch-Politische Schriftenreihe des Neuen Presseclubs, München: Bayerische Profile 4).

Hartmut Mehringer, Waldemar von Knoeringen. Eine politische Biographie. Der Weg vom revolutionären Sozialismus zur sozialen Demokratie, München u. a. 1989.

Hartmut Mehringer, Die bayerische SPD zwischen Verbot und Wiederaufbau, in: ders. (Hrsg.), Von der Klassenbewegung zur Volkspartei. Wegmarken der bayerischen Sozialdemokratie 1892-1992, München u. a. 1992, S. 195-211.

Franz Menges, Fritz Schäffer (1888-1967), in: Jürgen Aretz, Rudolf Morsey, Anton Rauscher (Hrsg.), Zeitgeschichte in Lebensbildern. Aus dem deutschen Katholizismus des 19. und 20. Jahrhunderts, Bd. 6, Mainz 1984, S. 139-152.

Alf Mintzel, Die CSU in Bayern: Phasen ihrer organisationspolitischen Entwicklung, in: Politische Vierteljahresschrift 13 (1972), S. 205-243.

Alf Mintzel, Die CSU. Anatomie einer konservativen Partei 1945-1972, Opladen 1975.

Alf Mintzel, 21 Thesen zur Entwicklung der CSU. Ergebnisse einer parteiensoziologischen Analyse, in: Zeitschrift für Parlamentsfragen 6 (1975), S. 218-233.

Alf Mintzel, Bayern und die CSU, in: Revue d'Allemagne 9 (1977), S. 433-460.

Alf Mintzel, Geschichte der CSU. Ein Überblick, Opladen 1977.

Alf Mintzel, Gesellschaft, Staat und Parteiorganisation. Ein analytisches Stenogramm der Entwicklung Bayerns und der CSU, in: Wolf-Dieter Narr (Hrsg.), Auf dem Weg zum Einparteienstaat, Opladen 1977, S. 173-212.

Alf Mintzel, The Christian-Social Union in Bavaria. Analytical notes on its development, role and political success, in: Max Kaase, Klaus von Beyme (Hrsg.), Elections and Parties, London 1978, S. 191-225.

Alf Mintzel, Die Bayerische Landtagswahl vom 27. Oktober 1974. Triumph einer konservativen Partei: Ein wahlsoziologischer Sonderfall?, in: Reinhold Bocklet (Hrsg.), Das Regierungssystem des Freistaates Bayern, Bd. 2: Beiträge, München 1979, S. 259-278.

Alf Mintzel, Franz Josef Strauß und die CSU-Landesgruppe im Deutschen Bundestag, in: Friedrich Zimmermann (Hrsg.), Anspruch und Leistung. Widmungen für Franz Josef Strauß, Stuttgart 1980, S. 281-307.

Alf Mintzel, Franz Josef Strauß, in: Walther L. Bernecker, Volker Dotterweich (Hrsg.), Persönlichkeit und Politik in der Bundesrepublik Deutschland. Politische Porträts, Bd. 2, Göttingen 1982, S. 196-208.

Alf Mintzel, Die Bayernpartei, in: Richard Stöss (Hrsg.), Parteien-Handbuch. Die Parteien der Bundesrepublik Deutschland 1945-1980, Bd. 1: AUD-CDU, Opladen 1986, S. 395-489. 
Alf Mintzel, Die Christlich-Soziale Union in Bayern e. V., in: Richard Stöss (Hrsg.), ParteienHandbuch. Die Parteien der Bundesrepublik Deutschland 1945-1980, Bd. 2: CSU bis DSU, Opladen 1986, S. 661-718.

Alf Mintzel, Besonderheiten der politischen Kultur Bayerns. Facetten und Etappen einer politisch-kulturellen Homogenisierung, in: Dirk Berg-Schlosser, Jakob Schissler (Hrsg.), Politische Kultur in Deutschland. Bilanz und Perspektiven der Forschung, Opladen 1987, S. 295308.

Alf Mintzel, Die Christlich-Soziale Union: Bollwerk Bayern, in: Peter Haungs, Eckhard Jesse (Hrsg.), Parteien in der Krise? In- und ausländische Perspektiven, Köln 1987, S. 109-114.

Alf Mintzel, Gehen Bayerns Uhren wirklich anders?, in: Zeitschrift für Parlamentsfragen 18 (1987), S. 77-93.

Alf Mintzel, Die Rolle der CSU-Landesgruppe im politischen Kräftespiel der Bundesrepublik Deutschland, in: Politische Studien Sonderheft 1/1989, S. 113-134.

Alf Mintzel, Die Christlich-Soziale Union in Bayern, in: ders., Heinrich Oberreuter (Hrsg.), Parteien in der Bundesrepublik Deutschland, Bonn 1990, S. 199-236.

Alf Mintzel, Political and Socio-Economic Developments in the Post-War Era: The Case of Bavaria 1945-1989, in: Karl Rohe (Hrsg.), Elections, Parties and Political Traditions. Social Foundations of German Parties and Party Systems 1867-1987, New York u. a. 1990, S. 145178.

Alf Mintzel, Regionale politische Traditionen und CSU-Hegemonie in Bayern, in: Dieter Oberndörfer, Karl Schmitt (Hrsg.), Parteien und regionale Traditionen in der Bundesrepublik Deutschland, Berlin 1991, S. 125-180.

Alf Mintzel, Die CSU in Bayern als Forschungsobjekt - Entwicklung, Stand, Defizite und Perspektiven der CSU-Forschung, in: Oskar Niedermayer, Richard Stöss (Hrsg.), Stand und Perspektiven der Parteienforschung in Deutschland, Opladen 1993, S. 81-118.

Alf Mintzel, Bayern und die CSU - Regionale politische Traditionen und Aufstieg zur dominierenden Kraft, in: Geschichte einer Volkspartei. 50 Jahre CSU 1945-1995, Grünwald 1995, S. 195-252.

Maria Mitchell, Materialism and Secularism: CDU Politicians and National Socialism 1945-1949, in: The Journal of Modern History 67 (1995), S. 278-308.

Jürgen Mittrücker, Junge Union und CSU, dargestellt am Beispiel des Regierungsbezirks Oberfranken bis 1983. Die Junge Union als Arbeitsgemeinschaft der CSU, unveröffentlichte Diplomarbeit, Bamberg 1984.

Karl Möckl, Die Struktur der Christlich-Sozialen Union in Bayern in den ersten Jahren ihrer Gründung, in: Zeitschrift für bayerische Landesgeschichte 36 (1973), S. 719-753.

Karl Möckl, Hanns Seidel in seiner Zeit. Die politisch-historische Entwicklung Bayerns (19461961), in: Hanns Seidel - „Ein Leben für Bayern“. Symposion der Hanns-Seidel-Stiftung am 18. und 19. Juli 1986 in Wildbad Kreuth, o. O. 1987, S. 50-60.

Horst Möller, Franz Josef Strauß 1915-1988, in: Lothar Gall (Hrsg.), Die großen Deutschen unserer Epoche, Berlin 1995, S. 535-553.

Hans Mommsen, Preußentum und Nationalsozialismus, in: Wolfgang Benz, Hans Buchheim, Hans Mommsen (Hrsg.), Der Nationalsozialismus. Studien zur Ideologie und Herrschaft, Frankfurt am Main 1993, S. 29-41.

Rudolf Morsey, Die Bildung der ersten Regierungskoalition 1949. Adenauers Entscheidung von Frankfurt und Rhöndorf am 20. und 21. August 1949, in: Historisches Jahrbuch 97/98 (1978), S. 418-438.

Rudolf Morsey, Katholizismus und Unionsparteien in der Ära Adenauer, in: Albrecht Langner (Hrsg.), Katholizismus im politischen System der Bundesrepublik 1949-1963, Paderborn 1978, S. 33-59.

Rudolf Morsey, Die Rhöndorfer Weichenstellung am 21. August 1949. Neue Quellen zur Vorgeschichte der Koalitions- und Regierungsbildung nach der Wahl zum ersten Deutschen Bundestag, in: Vierteljahrshefte für Zeitgeschichte 28 (1980), S. 508-542.

Rudolf Morsey, Zwischen Bayern und der Bundesrepublik. Die politische Rolle des bayerischen Ministerpräsidenten Hans Ehard 1946-1949, in: Juristenzeitung 36 (1981), S. 361-370.

Rudolf Morsey, Die Bundesrepublik Deutschland. Entstehung und Entwicklung bis 1969, München 1987. 
Rudolf Morsey, Die Bundesrepublik Deutschland. Entstehung und Entwicklung bis 1969, München 3., überarbeitete und erweiterte Auflage 1995.

Rudolf Morsey, Hans Ehard (1887-1980), in: Dr. Hans Ehard 1887-1980. Eine Ausstellung des Bayerischen Hauptstaatsarchivs aus dem Nachlaß des Bayerischen Ministerpräsidenten anläßlich seines 100. Geburtstags, München 1987, S. 7-23.

Rudolf Morsey, Hans Ehard (1887-1980), in: Geschichte im Westen 2 (1987), S. 71-89.

Rudolf Morsey, Föderalismus im Bundesstaat. Die Rolle des bayerischen Ministerpräsidenten Hans Ehard in der Vor- und Frühgeschichte der Bundesrepublik Deutschland, in: Historisches Jahrbuch 108 (1988), S. 430-447.

Rudolf Morsey, Prälaten auf der politischen Bühne. Zur Rolle geistlicher Parlamentarier im 19. und 20. Jahrhundert, in: Winfried Becker, Werner Chrobak (Hrsg.), Staat, Kultur, Politik. Beiträge zur Geschichte Bayerns und des Katholizismus. Festschrift zum 65. Geburtstag von Dieter Albrecht, Kallmünz 1992, S. 313-323.

Rudolf Morsey, Das föderalistische Konzept Hans Ehards. Ansprache anläßlich der Präsentation des Buches von Karl-Ulrich Gelberg über den bayerischen Ministerpräsidenten, in: Zeitschrift für bayerische Landesgeschichte 56 (1993), S. 769-775.

Günter Müchler, Zum frühen Verhältnis von CDU und CSU, in: Politische Studien 23 (1972), S. 595-613.

Günter Müchler, CDU/CSU. Das schwierige Bündnis, München 1976.

Winfried Müller, Schulpolitik in Bayern im Spannungsfeld von Kultusbürokratie und Besatzungsmacht 1945-1949, München 1995.

Franz Neumann, Der Block der Heimatvertriebenen und Entrechteten 1950-1960. Ein Beitrag zur Geschichte und Struktur einer politischen Interessenpartei, Meisenheim am Glan 1968.

Rainer Nick, Schwesterparteien. CDU, CSU und Österreichische Volkspartei. Ein Vergleich, Innsbruck 1984.

Oskar Niedermayer, Hermann Schmitt, Sozialstruktur, Partizipation und politischer Status in Parteiorganisationen, in: Politische Vierteljahresschrift 24 (1983), S. 293-310.

Lutz Niethammer, Die amerikanische Besatzungsmacht zwischen Verwaltungstradition und politischen Parteien in Bayern 1945, in: Vierteljahrshefte für Zeitgeschichte 15 (1967), S. 153210.

Lutz Niethammer, Dic Mitläuferfabrik. Die Entnazifizierung am Beispiel Bayerns, Berlin, Bonn 1982.

Lutz Niethammer, Problematik der Entnazifizierung in der BRD, in: Sebastian Meissl, KlausDieter Mulley, Oliver Rathkolb (Hrsg.), Verdrängte Schuld, verfehlte Sühne. Entnazifizierung in Österreich 1945-1955, München 1986, S. 15-27.

Thomas Nipperdey, Christliche Parteien, in: ders., Nachdenken über die deutsche Geschichte. Essays, München 1986, S. 126-139.

Heinrich Oberreuter, Konkurrierende Kooperation - Die CSU in der Bundespolitik, in: Geschichte einer Volkspartei. 50 Jahre CSU 1945-1995, Grünwald 1995, S. 319-332.

Günter Opitz, Der Christlich-soziale Volksdienst. Versuch einer protestantischen Partei in der Weimarer Republik, Düsseldorf 1969.

Wolfgang Pauly, Christliche Demokraten und Christlich-Soziale. Untersuchungen zum innerparteilichen Bündnisverhalten von CDU und CSU 1969-1979, Diss., Trier 1981.

Detlef Peukert, Die Weimarer Republik. Krisenjahre der Klassischen Moderne, Frankfurt am Main 1987.

Hans Pflaumer, Hanns Seidel, in: Christliche Demokraten der ersten Stunde, hrsg. von der Konrad-Adenauer-Stiftung, Bonn 1966, S. 331-361.

Jürgen Plöhn, Untersuchungsausschüsse der Landesparlamente als Instrumente der Politik, Opladen 1991.

Johann Pörnbacher, Ein Pfarrer im Widerstand in München. Vor 100 Jahren wurde Emil Muhler in München geboren, in: Unser Bayern vom Oktober 1992, S. 78-80.

Geoffrey Pridham, Christian Democracy in Western Germany. The CDU/CSU in Government and Opposition 1945-1976, London 1977.

Michael Renner, Nachkriegsprotestantismus in Bayern. Untersuchungen zur politischen und sozialen Orientierung der Evangelisch-Lutherischen Kirche Bayerns und ihres Landesbischofs Hans Mciser in den Jahren 1945-1955, München 1991. 
Konrad Repgen, Über die Anfänge des CSU-Programms von 1945, in: Andreas Kraus (Hrsg.), Land und Reich, Stamm und Nation. Probleme und Perspektiven bayerischer Geschichte. Festgabe für Max Spindler zum 90. Geburtstag, Bd. 3: Vom Vormärz bis zur Gegenwart, München 1984, S. 459-471.

Christiane Reuter, „Graue Eminenz der bayerischen Politik“. Eine politische Biographie Anton Pfeiffers (1888-1957), München 1987.

Hans-Günter Richardi, Klaus Schumann, Geheimakte Gerlich/Bell. Röhms Pläne für ein Reich ohne Hitler, München 1993.

Jana Richter, Eine Schule für Bayern. Die schulpolitischen Auseinandersetzungen um die Einführung der Christlichen Gemeinschaftsschule in Bayern nach 1945, München 1997.

Michaela Riebel, CSU im Werden. Gründung und Entwicklung der Christlich-Sozialen Union in Regensburg von 1945 bis zu den Wahlen zum Ersten Deutschen Bundestag, Regensburg 1985.

Herbert Riehl-Heyse, CSU. Die Partei, die das schöne Bayern erfunden hat, München 1979.

Gerhard A. Ritter, Wilhelm Hoegner (1887-1980), in: Ferdinand Seibt (Hrsg.), Gesellschaftsgeschichte. Festschrift für Karl Bosl zum 80. Geburtstag, Bd. 2, München 1988, S. 337-360.

Karl Rohe, Vom Revier zum Ruhrgebiet. Wahlen, Parteien, politische Kultur, Essen 1986.

Hans-Georg Roth, Entstehungsgeschichte des Bayerischen Senats. Tradition und Kontinuität des Bayerischen Zweikammersystems, in: Zeitschrift für bayerische Landesgeschichte 40 (1977), S. 231-244.

Rainer Roth, Zentralgewalt und Eigenstaatlichkeit. Das Ringen um die Mitgestaltung der Bundespolitik, in: Rainer A. Roth, Freistaat Bayern. Die politische Wirklichkeit eines Landes der Bundesrepublik Deutschland, München 3., überarbeitete Auflage 1982, S. 143-160.

Günther Rüther, Der Weg zur Gründung der Union. Eine Einführung, in: ders. (Hrsg.), Geschichte der Christlich-Demokratischen und Christlich-Sozialen Bewegungen in Deutschland. Grundlagen, Unterrichtsmodelle, Quellen und Arbeitshilfen für die politische Bildung, Bonn ${ }^{2} 1987$, S. 11-26.

Karsten Ruppert, Im Dienst am Staat von Weimar. Das Zentrum als regierende Partei in der Weimarer Demokratie 1923-1930, Düsseldorf 1992.

Walter Siegel, Bayerns Staatwerdung und Verfassungsentstehung 1945/1946. Ein Beitrag zur politischen und rechtlichen Problematik bei der Entstehung der Verfassung des Freistaates Bayern von 1946, Bamberg 1978.

Richard Schachtner, Die Wahlen in den Gemeinden und Kreisen Bayerns 1946 und 1948, München 1949.

Richard Schachtner, Die Wahl zum ersten Bundestag. Vorläufiges Ergebnis der Wahl vom 14. August 1949, in: Bayern in Zahlen. Monatshefte des Bayerischen Statistischen Landesamts 3 (1949), S. 189-195.

Axel Schildt, Arnold Sywottek, „Wiederaufbau“ und „Modernisierung“. Zur westdeutschen Gesellschaftsgeschichte in den fünfziger Jahren, in: Aus Politik und Zeitgeschichte 6-7/89, S. 1832.

Thomas Schlemmer, Die Amerikaner in Bayern. Militärregierung und Demokratisierung nach 1945, in: Heinrich Oberreuter, Jürgen Weber (Hrsg.), Freundliche Feinde? Die Alliierten und die Demokratiegründung in Deutschland, München 1996, S. 67-99.

Thomas Schlemmer, Auf dem Weg zur Demokratie. Parteigründungen und erste Wahlen in Regensburg 1945/46, in: Regensburger Almanach 29 (1996), S. 59-72.

Thomas Schlemmer, Gesellschaft und Politik in Bayern 1949-1973. Ein neues Projekt des Instituts für Zeitgeschichte, in: Maximilian Lanzinner, Michael Henker (Hrsg.), Landesgeschichte und Zeitgeschichte. Forschungsperspektiven zur Geschichte Bayerns nach 1945, Augsburg 1997, S. 103-109.

Eduard Schmidt, Staatsgründung und Verfassungsgebung in Bayern. Die Entstehung der Bayerischen Verfassung vom 8. Dezember 1946, 2 Bde., München 1997.

Ute Schmidt, Zentrum oder CDU. Politischer Katholizismus zwischen Tradition und Anpassung, Opladen 1987.

Karl Schmitt, Religious Cleavages in the West German Party System: Persistence and Change 1949-1987, in: Karl Rohe (Hrsg.), Elections, Parties and Political Traditions. Social Foundations of German Parties and Party Systems 1867-1987, New York u. a. 1990, S. 179-201. 
Horst W. Schmollinger, Die Deutsche Partei, in: Richard Stöss (Hrsg.), Parteien-Handbuch. Die Parteien der Bundesrepublik Deutschland 1945-1980, Bd. 2: CSU-DSU, Opladen 1986, S. $1025-1111$.

Wulf Schönbohm, Die CDU wird moderne Volkspartei. Selbstverständnis, Mitglieder, Organisation und Apparat 1950-1980, Stuttgart 1985.

Klaus Schönhoven, Die Bayerische Volkspartei 1924-1932, Düsseldorf 1972.

Klaus Schönhoven, Der politische Katholizismus in Bayern unter der NS-Herrschaft 1933-1945, in: Martin Broszat, Hartmut Mehringer (Hrsg.), Bayern in der NS-Zeit, Bd. 5: Die Parteien KPD, SPD, BVP in Verfolgung und Widerstand, München, Wien 1983, S. 541-646.

Helmut J. Schorr, Adam Stegerwald. Gewerkschaftler und Politiker der ersten deutschen Republik. Ein Beitrag zur Geschichte der christlich-sozialen Bewegung in Deutschland, Recklinghausen 1966.

Helmut J. Schorr, Adam Stegerwald. Skizze eines mutigen Lebens, in: Christliche Demokraten der ersten Stunde, hrsg. von der Konrad-Adenauer-Stiftung, Bonn 1966, S. 363-382.

Herbert Schott, Die Amerikaner als Besatzungsmacht in Würzburg 1945-1949, Würzburg 1985.

Hilde Schrepfer, Beiträge zur Frühgeschichte der CSU in Bayern, unveröffentlichte Zulassungsarbeit, Bamberg 1965.

Klaus Schreyer, Bayern - ein Industriestaat. Die importierte Industrialisierung. Das wirtschaftliche Wachstum nach 1945 als Ordnungs- und Strukturproblem, München, Wien 1969.

Michael Schröder, Die Parteien-Lizenzierungspolitik der amerikanischen Militärregierung in Bayern nach 1945, in: ders., Bayern 1945: Demokratischer Neubeginn. Interviews mit Augenzeugen, München 1985, S. 9-14.

Wilhelm Heinz Schröder, Lebenslaufforschung zwischen biographischer Lexikographik und kollektiver Biographik. Überlegungen zu einem „Biographischen Handbuch der Parlamentarier in den deutschen Reichs- und Landtagen bis 1933“ (BIOPARL), in: Historical Social Research 31 (1984), S. 38-62.

Wilhelm Heinz Schröder, Kollektive Biographien in der historischen Sozialforschung: Eine Einführung, in: ders. (Hrsg.), Lebenslauf und Gesellschaft. Zum Einsatz von kollektiven Biographien in der historischen Sozialforschung, Stuttgart 1985, S. 7-17.

Gerhard Schulz, Die CDU - Merkmale ihres Aufbaus, in: Max Gustav Lange u. a., Parteien in der Bundesrepublik. Studien zur Entwicklung der deutschen Parteien bis zur Bundestagswahl 1953, Stuttgart, Düsseldorf 1955, S. 3-153.

Hagen Schulze, Die Biographie in der „Krise der Geschichtswissenschaft“, in: Geschichte in Wissenschaft und Unterricht 29 (1978), S. 508-518.

Hans-Peter Schwarz, Modernisierung oder Restauration? Einige Vorfragen zur künftigen Sozialgeschichtsforschung über die Ära Adenauer, in: Rheinland-Westfalen im Industriezeitalter, Bd. 3: Vom Ende der Weimarer Republik bis zum Land Nordrhein-Westfalen, hrsg. von Kurt Düwell und Wolfgang Köllmann, Wuppertal 1984, S. 278-293.

Hans-Peter Schwarz, Die Fünfziger Jahre als Epochenzäsur, in: Jürgen Heideking, Gerhard Hufnagel, Franz Knipping (Hrsg.), Wege in die Zeitgeschichte. Festschrift zum 65. Geburtstag von Gerhard Schulz, Berlin, New York 1989, S. 473-496.

Hans-Peter Schwarz, Adenauer. Der Aufstieg: 1876-1952, Stuttgart ${ }^{2} 1986$.

Hans-Peter Schwarz, Adenauer. Der Staatsmann: 1952-1967, Stuttgart 1991.

Karl Schwend, Bayern zwischen Monarchie und Diktatur. Beiträge zur Bayerischen Frage in der Zeit von 1918-1933, München 1954.

Karl Schwend, Die Bayerische Volkspartei, in: Erich Matthias, Rudolf Morsey (Hrsg.), Das Ende der Parteien 1933, Düsseldorf 1960, S. 457-519.

Leo Schwering, Vorgeschichte und Entstehung der CDU, Köln ${ }^{2} 1952$.

Joachim Selzam, Monarchistische Strömungen in der Bundesrepublik Deutschland 1945-1989, Diss., Erlangen 1994.

Heinrich Senfft, Glück ist machbar. Der bayerische Spielbankenprozeß, die CSU und der unaufhaltsame Aufstieg des Doktor Friedrich Zimmermann. Ein politisches Lehrstück, Köln 1988.

Franz Sonnenberger, Die Rekonfessionalisierung der bayerischen Volksschule 1945-1950, in: Zeitschrift für bayerische Landesgeschichte 45 (1982), S. 87-155.

Max Spindler, Die Grundlagen der Kulturentwicklung in Bayern. Vortrag im Herbst 1946, gehalten vor dem Bayerischen Landesverein für Heimatpflege, in: ders., Erbe und Verpflichtung. 
Aufsätze und Vorträge zur bayerischen Geschichte, hrsg. von Andreas Kraus, München 1966, S. 4-23.

Frederic Spotts, Kirchen und Politik in Deutschland, Stuttgart 1976.

Georg Stadtmüller, Hanns Seidel. Lebensweg, Weltbild, Persönlichkeit, München 1964 (Historisch-politische Schriftenreihe des Neuen Presseclubs, München: Die bayerischen Ministerpräsidenten der Nachkriegszeit 4).

Otto Stammer, Das Elitenproblem in der Demokratie, in: Wilfried Röhrich (Hrsg.), „Demokratische" Elitenherrschaft. Traditionsbestände eines sozialwissenschaftlichen Problems, Darmstadt 1975, S. 192-224.

Walter Stelzle, Föderalismus und Eigenstaatlichkeit. Aspekte der bayerischen Innen- und Außenpolitik 1945-1947. Ein Beitrag zur Staatsideologie, Diss., München 1980.

Richard Stöss, Vom Nationalismus zum Umweltschutz. Die Deutsche Gemeinschaft/Aktionsgemeinschaft Unabhängiger Deutscher im Parteiensystem der Bundesrepublik, Opladen 1980.

Richard Stöss, Die Deutsch-Soziale Union, in: ders. (Hrsg.), Parteien-Handbuch. Die Parteien der Bundesrepublik Deutschland 1945-1980, Bd. 2: CSU-DSU, Opladen 1986, S. 1243-1278.

Richard Stöss, Der Gesamtdeutsche Block/BHE, in: ders. (Hrsg.), Parteien-Handbuch. Die Parteien der Bundesrepublik Deutschland 1945-1980, Bd. 3: EAP-KSP, Opladen 1986, S. 1424 1477.

Richard Stöss, Struktur und Entwicklung des Parteiensystems der Bundesrepublik. Eine Theorie, in: ders. (Hrsg.), Parteien-Handbuch. Die Parteien der Bundesrepublik Deutschland 19451980, Bd. 1: AUD-CDU, Opladen 1986, S. 17-309.

Lawrence Stone, Prosopographie - englische Erfahrungen, in: Konrad Jarausch (Hrsg.), Quantifizierung in der Geschichtswissenschaft, Düsseldorf 1976, S. 64-97.

Heinz-Werner Stuiber, Die CSU in Nürnberg-Fürth. Zur Geschichte des Bezirksverbandes 1945-1983, Nürnberg 1983.

Arnold Sywottek, Wege in die 50er Jahre, in: Axel Schildt, Arnold Sywottek (Hrsg.), Modernisierung im Wiederaufbau. Die westdeutsche Gesellschaft der 50er Jahre, Bonn 1993, S. 13-39.

Klaus Tenfelde, Bayerische Wirtschaft und Gesellschaft im 19. und frühen 20. Jahrhundert, in: Hartmut Mehringer (Hrsg.), Von der Klassenbewegung zur Volkspartei. Wegmarken der bayerischen Sozialdemokratie 1892-1992, München u. a. 1992, S. 9-19.

Dietrich Thränhardt, Wahlen und politische Strukturen in Bayern 1848-1953. Historisch-soziologische Untersuchungen zum Entstehen und zur Ncuerrichtung eines Parteiensystems, Düsseldorf 1973.

Norbert Trippen, Interkonfessionelle Irritationen in den ersten Jahren der Bundesrepublik Deutschland, in: Karl Dietrich Bracher u. a. (Hrsg.), Staat und Parteien. Festschrift für Rudolf Morsey zum 65. Geburtstag, Berlin 1992, S. 345-377.

Günter J. Trittel, Hans Schlange-Schöningen. Ein vergessener Politiker der „Ersten Stunde“, in: Vierteljahrshefte für Zeitgeschichte 35 (1987), S. 25-63.

Günter J. Trittel, Hunger und Politik. Die Ernährungskrise in der Bizone 1945-1949, Frankfurt am Main, New York 1990.

Rudolf Uertz, Christentum und Sozialismus in der frühen CDU. Grundlagen und Wirkungen der christlich-sozialen Ideen in der Union 1945-1949, Stuttgart 1981.

Ilse Unger, Die Bayerische Bewegung. Politische Strömungen in Bayern nach 1945, unveröffentlichte Magisterarbeit, Erlangen 1969.

Ilse Unger, Die Bayernpartei. Geschichte und Struktur 1945-1957, Stuttgart 1979.

Hildegard Vieregg, Wächst Gras darüber? München: Hochburg des Nationalsozialismus und Zentrum des Widerstands, München 1993.

Adolf Voelcker, Die Verteilung der katholischen und evangelischen Bevölkerung in Bayern 1933 und 1946, in: Zeitschrift des Bayerischen Statistischen Landesamts 81 (1949), S. 37-44.

Clemens Vollnhals, Die Evangelische Landeskirche in der Nachkriegspolitik. Die Bewältigung der nationalsozialistischen Vergangenheit, in: Wolfgang Benz (Hrsg.), Neuanfang in Bayern 1945-1949. Politik und Gesellschaft in der Nachkriegszeit, München 1988, S. 143-162.

Clemens Vollnhals, Evangelische Kirche und Entnazifizierung 1945-1949. Die Last der nationalsozialistischen Vergangenheit, München 1989.

Clemens Vollnhals, Die Hypothek des Nationalprotestantismus. Entnazifizierung und Strafverfolgung von NS-Verbrechen nach 1945, in: Geschichte und Gesellschaft 18 (1992), S. 51-69. 
Vor den Landtagswahlen. Bericht über die Bevölkerungsumfragen in Hessen und Bayern, durchgeführt vom Institut für Demoskopie, Allensbach 1954.

Voraussetzungen der Landtagswahlen 1954 in Bayern. Eine Spezialstudie im Auftrage der Landesgeschäftsführung der CSU Bayern, durchgeführt vom Emnid-Institut für Meinungsforschung, Bielefeld 1954.

Regina Vossen, „Föderalistisch leben oder asiatisch sterben“. Joseph Baumgartner und die bayerische Politik 1945-1953, unveröffentlichte Zulassungsarbeit, München 1993.

Max Weber, Wirtschaft und Gesellschaft. Grundriß der verstehenden Soziologie, bearb. von Johannes Winckelmann, Tübingen 5., überarbeitete Auflage 1980.

Hans-Ulrich Wehler, Zum Verhältnis von Geschichtswissenschaft und Psychoanalyse, in: ders. (Hrsg.), Geschichte und Psychoanalyse, Köln 1971, S. 9-30.

Paul-Ludwig Weinacht, Der Weg in den Südweststaat, in: Der Weg zum Südweststaat, hrsg. von der Landeszentrale für politische Bildung Baden-Württemberg, Karlsruhe 1991, S. 310-323.

Udo Wengst, Die CDU/CSU im Bundestagswahlkampf 1949, in: Vierteljahrshefte für Zeitgeschichte 34 (1986), S. 1-52.

Udo Wengst, Deutsche Parteien nach 1945 und ihre Geschichte. Anmerkungen zu Quellen und Ergebnissen historischer Parteienforschung in der Bundesrepublik Deutschland, in: Jürgen Heideking, Gerhard Hufnagel, Franz Knipping (Hrsg.), Wege in die Zeitgeschichte. Festschrift zum 65. Geburtstag von Gerhard Schulz, Berlin, New York 1989, S. 165-181.

Emil Werner, Die SPD in Regierung und Opposition, in: Hartmut Mehringer (Hrsg.), Von der Klassenbewegung zur Volkspartei. Wegmarken der bayerischen Sozialdemokratie 1892-1992, München u. a. 1992, S. 279-294.

Karl Jörg Wohlhüter, Die CSU. Der linke Flügel lahmt, in: Peter Josef Bock u. a. (Hrsg.), Im Prinzip sozial. Die großen Parteien und die Arbeitnehmer, Hannover 1976, S. 87-105.

Konstanze Wolf, CSU und Bayernpartei. Ein besonderes Konkurrenzverhältnis, 1948-1960, Köln ${ }^{2} 1984$.

Hans Woller, Die Loritz-Partei. Geschichte, Struktur und Politik der Wirtschaftlichen AufbauVereinigung (WAV) 1945-1955, Stuttgart 1982.

Hans Woller, Gesellschaft und Politik in der amerikanischen Besatzungszone. Die Region Ansbach und Fürth, München 1986.

Zehn Jahre Bayerischer Bauernverband, München 1955.

Ulrich Zelinsky, Bedingungen und Probleme der Neubildung von Führungsgruppen in Deutschland 1945-1949, in: Josef Becker, Theo Stammen, Peter Waldmann (Hrsg.), Vorgeschichte der Bundesrepublik Deutschland. Zwischen Kapitulation und Grundgesetz, München 2., überarbeitete Auflage 1987, S. 223-239.

Annette Zimmer, Demokratiegründung und Verfassungsgebung in Bayern. Die Entstehung der Verfassung des Freistaates Bayern von 1946, Frankfurt am Main u. a. 1987.

Bernhard Zittel, Alois Hundhammer (1900-1974), in: Jürgen Aretz, Rudolf Morsey, Anton Rauscher (Hrsg.), Zeitgeschichte in Lebensbildern. Aus dem deutschen Katholizismus des 19. und 20. Jahrhunderts, Bd. 5, Mainz 1982, S. 253-265.

Wolfgang Zorn, Bayerns Geschichte im 20. Jahrhundert. Von der Monarchie zum Bundesland, München 1986. 


\title{
Abbildungsverzeichnis
}

\author{
Photos, Plakate, Karikaturen
}

Abb. 1: Ankündigung der CSU in Wolfratshausen für eine öffentliche Versammlung im Februar 1946; ACSP, Plakatsammlung - 3818

Abb. 2: Josef Müller (April 1951); Stadtarchiv München, Photosammlung - Josef Müller

Abb. 3: Plakate für die Kommunalwahlen in München am 26. Mai 1946; Stadtarchiv München, Photosammlung - Kommunalwahl 1946

Abb. 4: Michael Horlacher (Dezember 1951); Stadtarchiv München, Photosammlung - Michael Horlacher

Abb. 5: Alois Hundhammer (ca. 1947); Stadtarchiv München, Photosammlung - Alois Hundhammer

Abb. 6: Mitglieder der CSU-Fraktion im bayerischen Landtag (1947); ACSP, NL Hundhammer - Photos

Abb. 7: Josef Müller und Franz Josef Strauß auf der Landesversammlung der CSU vom 27. bis zum 29. Mai 1949 in Straubing; ACSP, NL Strauß - Photos

Abb. 8: Franz Josef Strauß, Josef Müller und Fritz Schäffer (1963); ACSP, Photosammlung

Abb. 9: Die CSU im Wahlkampf, vermutlich 1953; ACSP, NL Strauß - Parteiveranstaltungen 1945-1951

Abb. 10: Wahlkampfveranstaltung der CSU mit Konrad Adenauer, vermutlich 1953; ACSP, NL Strauß - Photos

Abb. 11: Mitglieder der bayerischen Staatsregierung bei der Fronleichnamsprozession 1949 in München; Stadtarchiv München, Photosammlung - Kirchen

Abb. 12: „Nun spielen sie wieder... Hansi: ,Da geht ja nie eine Mannschaft z'samm! “; Karikatur von Ernst Maria Lang in der SZ vom 18./19.11. 1950

Abb. 13: „Der Entscheidung entgegen“. Plakat für die Landtagswahlen 1950; ACSP, Plakatsammlung -2814

Abb. 14: „Deine Stimme Dr. Josef Müller“. Plakat für die Landtagswahlen 1950; ACSP, Plakatsammlung -2813

Abb. 15: „Wir können nicht zaubern“. Plakat für die Landtagswahlen 1950; ACSP, Plakatsammlung -340

Abb. 16: „Wer christlich denkt, sozial handelt und bayerisch fühlt, wählt CSU“. Plakat für die Landtagswahlen 1954; ACSP, Plakatsammlung - 1114

Abb. 17: Plakate für die Landtagswahlen 1954; Stadtarchiv München, Photosammlung - Landtagswahl 1954

Abb. 18: „Die Gegenkoalition? ,Der Starke ist am schwächlichsten allein ...““; Karikatur von Ernst Maria Lang in der SZ vom 2. 12. 1954

Abb. 19: Zehn Jahre Christlich-Soziale Union 1955; ACSP, Photosammlung

Abb. 20: Tagung des Landesausschusses der CSU am 7./8. Juni 1958 in Hof, ACSP, NL StraußPhotos 


\section{Karten und Schaubilder}

Christlich-Soziale Union in den Stadt- und Landkreisen 1948; Richard Schachtner, Die Wahlen in den Gemeinden und Kreisen Bayerns 1946 und 1948, München 1949.

Bayernpartei in den Stadt- und Landkreisen 1948; Richard Schachtner, Die Wahlen in den Gemeinden und Kreisen Bayerns 1946 und 1948, München 1949.

Sozialdemokratische Partei in den Stadt- und Landkreisen 1948; Richard Schachtner, Die Wahlen in den Gemeinden und Kreisen Bayerns 1946 und 1948, München 1949.

Flüchtlingsgruppen in den Stadt- und Landkreisen 1948; Richard Schachtner, Die Wahlen in den Gemeinden und Kreisen Bayerns 1946 und 1948, München 1949.

Unionsmitglieder; Anlage zu: BayHStA, NL Ehard 131, Rundschreiben Richard Schachtners „Unions-Finanzen“ vom 23. 5. 1949.

Durchschnittliche Erträge und Aufwendungen pro Monat und ihre Gliederung; Anlage zu: BayHStA, NL Ehard 131, Rundschreiben Richard Schachtners „Unions-Finanzen“ vom 23. 5. 1949.

Vom Beitragsanteil in Höhe von 50 Pf bzw. 45 Pf und 20 Pf wurden tatsächlich an die Landesgeschäftsstelle bezahlt; Anlage zu: BayHStA, NL Ehard 131, Rundschreiben Richard Schachtners „Unions-Finanzen“" vom 23. 5. 1949.

Nichtbezahite Beitragsanteile der Kreisverbände in den Bezirken; Anlage zu: BayHStA, NL Ehard 131, Rundschreiben Richard Schachtners „Unions-Finanzen“ vom 23. 5. 1949.

Bezahlte Gehälter und Aufwandsentschädigungen; Anlage zu: BayHStA, NL Ehard 131, Rundschreiben Richard Schachtners „Unions-Finanzen“ vom 23. 5. 1949.

Die erste Bundestagswahl in Bayern am 14. August 1949; Bayerisches Statistisches Landesamt

Stimmenanteile der Parteien an der Gesamtzahl der gültigen Stimmen in den Bundeswahlkreisen am 14. 8. 1949; Bayerisches Statistisches Landesamt

Die zweite Bundestagswahl in Bayern am 9. September 1953; Bayerisches Statistisches Landesamt 


\section{Register}

\section{Personenregister}

Adenauer, Konrad 2, 25, 53, 97f., 197, 205, 223, 241, 311f., 328, 342 ff., 369f., 372, 380, $384,386 f$., 389 ff., 393 f., 404, 425, 429 f., 434, 511

Aigner, Heinrich 333

Albert, Hilde 482

Albert, Martin 197

Allwein, Max 155, 229, 489

Amberger, Johann 83

Ammann, Erwin 489

Ammann, Franz 447, $449 \mathrm{f}$.

Anetseder, Josef 489,491

Ankermüller, Willi $90,186,193,217,489$

Anzenhofer, Karl 318, 339

Aretin, Anton von 21, 229

Arnold, Karl $385 \mathrm{f}$.

Auerbach, Philipp 286, 408, 472

Aumer, Hermann 370

Bachmann, Georg 146, 372, $488 \mathrm{f}$.

Bachmann, Wilhelm 489

Balke, Siegfried 473, 511

Banzer, Georg 44

Bartel, Hans 256, 349

Barth, Georg $23,37,42,76,288,290,410,488$

Bauer, Hermann 135, 145

Bauer, Josef 494

Bauereisen, Friedrich $350,421,427,494$

Baumeister $57 \mathrm{f}$.

Baumeister, Leonhard 489

Baumgartner, Joseph $26,32,52 \mathrm{f}$., 62, 80, 82, $84,87,91$ ff., $105 f$., 122, 125, 134, 146, 152, $163,194,205 f ., 215,220,229 f ., 276,287$, $298,309,318$ f., 332, 370, 372-376, 379, 479, 489,503

Baur, Leonhard 489

Becker, Winfried 30, $90 \mathrm{f}$., 501

Bengl, Hans 244

Berberich, Walter $52 \mathrm{f} ., 67,321,498$

Berger, Ludwig 489

Berger, Rupert 33, 153, 489

Berlinghoff (CSU-Landesgeschäftsstelle) 244

Bernhard, Alfons $323 \mathrm{f}$.

Besold, Anton 333, 383

Bickleder, Karl 489
Birkl, Rudolf 158

Bismarck, Otto von 22, 79, 128

Blank, Theodor 343

Blaser, Kurt 76, 85

Blum, Ludwig 83

Bodensteiner, Hans 388, 494

Böck, Toni 99f., 295, 339, 344

Boeckl, Karl 416

Bogendörfer, Otto $291 \mathrm{f}$.

Bracker, Gerda 513

Brand, Ludwig 289

Brandner, Johann 337, 489

Braun, Alois 322

Braun, Josef 489

Brentano, Heinrich von $343,389,391$

Brüning, Heinrich 324

Brumberger, Josef 489

Brunner, Josef $322,366,433,436 f ., 457,459$, 471, 487

Bühner, Eustach 489,493

Burges, Bernhard 37

Burns, Paul 110, 173, 178, 217

Butterhof, Franz Xaver 307f., 336, 347

Canaris, Wilhelm 95, 98, 171

Centmayer, Hans 202, 489

Chapeaurouge, Paul de 394

Churchill, Winston 188

Clay, Lucius D. 171 ff., 175, 177

Dahm, Else 76

Deggendorfer, Emanuel 14, 488

Dehler, Thomas 144, 176, 182, 186, 345

Deku, Maria 34, 126, 145 ff., 202, 489, 492

Demmelmeier, Hans $489,491,494$

Dengler, Fritz 290f., 348, 488

Derlien, Hans-Ulrich 79

Deuerlein, Ernst $\quad 435,497$

Dietlein, Johann 489

Dittrich, Stefan 494

Döpfner, Julius 425

Dörpinghaus, Bruno 342

Dötsch, Berta 34

Dollinger, Werner 402, 422, 479, $493 \mathrm{f}$., 508

Donat, Karl 389 
Donderer, Karl 377

Donhauser, Anton 87, 227, 229, 370, 494

Donohoe, James 34

Donsberger, Josef $\quad 14,83,155 f$., 208, 488, 490

Dürr, Kaspar 40, 42, 488

Eberhard, Rudolf $86,396,398,430,483$, $487 \mathrm{f}$., 490

Eberl, Joseph 160

Ebert, Friedrich 324

Eder, Hans 490

Egen, Peter 421

Egger (CSU-Landesgeschäftsstelle) 244

Egger, Alois 490

Ehard, Hans $3 f$., 6, 26f., 53, 75, 80, 82, 96, 106, 114, $118 f$., 121 f., 132 f., 141, 146, 150 , $160,167 \mathrm{ff} ., 177 \mathrm{ff}$., 181-196, $198 \mathrm{f}$., $202 \mathrm{f}$., 206, 211, 213-220, 223, $226 \mathrm{ff}$., $240 \mathrm{f}$., 258, 281 ff., 288 f., 292, 296, 298, 302f., 305-314, $316 \mathrm{ff}$., 320-329, 331-339, 341-350, 354, 362, $364-374,376-381,383-388,390,392$, 394-400, 402f., 405 ff., 409f., 412, 414-418, $424,426 \mathrm{f}$., 429-435, 437-446, $448 \mathrm{ff}$., $455 \mathrm{f}$., $458 \mathrm{ff} ., 463,466 \mathrm{ff}$., 470-473, 475, 477-483, $487,490,500,507$ f., 510-514

Ehard, Sieglinde 513

Ehlers, Hermann $375,420,424,426,430$

Eichelbrönner, Gottfried 490

Eichhorn, Wilhelm 55, 61, 76, 95, 103, 158

Eicken, Hans Hermann von $57,75,105,109$, 117, 201, 214, 281

Eisenhower, Dwight D. 53

Elhardt, Heinrich 83

Elsen, Franz $355,434,467,472,487,490$

Emmert, Heinrich $197,208,292,345,469,490$

Engelhardt, Alois 466

Englert, Rudolf 490

Erhard, Ludwig 343

Etzel, Hermann 343

Euerl, Alfred 76, 189, 315, 335, $337 \mathrm{f}$., $364 \mathrm{f}$., $374,414,469,488,490$

Fackler, Franz Xaver 31, 33 f., 57, 132, 318, 446

Fait, Barbara $17,58,501$

Falkner, Ernst 87,370

Faltermeier, Josef 490

Faulhaber, Michael von 137, 185, 349

Feilner, Hildegunde 410

Fendt, Franz 143

Feury, Otto Freiherr von $371,487,490$

Fischer, Heinz $314,319,405$

Fischer, Josef 228, 315, 324, 436, 444, 472, 488,490

Fischer, Karl 490

Fischer, Walter 244
Flechtheim, Ossip K. 510

Fleischmann, Charlotte 259, 322, 339ff., 345, 350

Flörl, Fritz 350,355

Fogt, Helmut 77

Franckenstein, Georg Freiherr von und zu 490

Frank, Hans 170

Franz, Ludwig 494

Freundl, Otto 490

Friedrich II., König von Preußen 22

Frings, Josef $413 \mathrm{f}$.

Fromm, Kurt-Wilhelm 355

Fuchs, Gustav 494

Fürstenberg, Elimar von 398

Fugger von Glött, Fürst Josef Ernst $\quad 391,494$

Funk, Friedrich Jakob 350, 354, 420, $493 \mathrm{f}$.

Gaab, Karl $169,295 \mathrm{f}$.

Gabler, Karl 417, 421, 430

Gamperl, Georg 33f., 90, 149, 158, 189, 260, 291, 410, 488

Gandhi, Mahatma 221

Gaßner, Alfons 87, 105

Gaßner, Wilhelm 490

Gehring, Georg 490

Geiger, Hugo 186, 193, 305, 310, 487 f., 490, 492, 494

Geiselberger, Hans 34, 150

Geisendörfer, Ingeborg 494

Gelberg, Karl-Ulrich 91, 95, 130, 384, 390 , 504, $507 f$.

Gennerwein, Agnes 350

Gensert, Hans-Hubert 271, 274, 277

Gentner, Hans 143, 145

Georgiew, Leonid 97

Gerathewohl, Fritz $37 \mathrm{ff} ., 41,73,85,149$

Gerlich, Fritz 272

Gerstenmaier, Eugen 420

Gerstl, Max 53, 55, 263, 451 f., 456

Gleissner, Franz 494

Goebbels, Joseph 195

Göttler, Wilhelm 490, 493

Goetzendorff, Günter 361, 363

Goldschagg, Edmund 169, 230, 240

Goppel, Alfons 86

Graf, Benno 428, 494

Graf, Otto 354, 405

Grasmann, Max 54ff., 158f., 244, 487

Greib, Karl 290, 297, 312, 314f., 350, 352, $354,488,490$

Gröber, Franziska $\quad 275,488,490$

Gromer, Georg 162, 490

Gronwald, Karl 37, 73, 85, 127

Groß, Hans Ferdinand 508

Grosser, Dieter 396 
Grotewohl, Otto 36

Gumrum, Otto 428, 494

Gurland, Arcadius R.L. 497

Guttenberg, Rosa-Sophie Freifrau von und zu 513

Haaf, Karl 490

Haas, Franz 181

Hagmann, Michael 163

Hagn, Hans 83, 411, $490 \mathrm{f}$.

Hahn, Elisabeth $34,43,158$

Haindl, Georg 505

Haisch, Andreas 490

Hall, Josef 276, 279

Hammerschmidt, Helmut 271, 274, 277

Haniel-Niethammer, Fritz von $376 \mathrm{ff} ., 398$, 472, 488, 490

Harnier, Adolf Freiherr von 21, 33 f., 37

Hartmann, Alfred 343

Hassel, Hans 416, 488

Hassell, Ulrich von 20

Hauck, Georg 298, 490

Haugg, Pius 37, 490

Haunhorst, Hanswolf $85,90,139 f ., 149,176$, 244f., 254, 258, 289, 338

Haußleiter, August 25, 28, 73, 75f., 90, 98, $103,108,113 \mathrm{ff} ., 124-127,131,134 \mathrm{f} ., 140 \mathrm{f}$., $146,153-157,159,161,170,175,186$, 189-195, 199-203, 211 f., 214 f., 218, 225, 232, 241, 251, 262f., 269, 272, 287 ff., 299, 302, $304 f ., 311,314,317,319,321,324,335$, $337 \mathrm{ff} ., 344,354,364,374,411 \mathrm{f} ., 414,417$, $487 \mathrm{f}, 490$

Heggenreiner, Heinz 254-257

Heigl, Ludwig 490

Heim, Georg 91, 394

Heizmann, Kurt Heinrich 42, 52, 501

Held, Heinrich $16,95,128,169,380,437$

Held, Josef $16,51,379$

Held, Philipp 86

Held, Walter 490

Helmerich, Michael $82 \mathrm{f} ., 122,146,490$

Henckel von Donnersmarck, Graf Georg 494

Henke, Klaus-Dietmar 97, 501, 509

Henzler, Christoph 58, 104, 380, 507

Herde, Peter 54

Hergenröder, Anton 288, 290, 302f., 305, $311,443 \mathrm{f} ., 468,488$

Herrmann, Hans 472, 488

Hettler, Friedrich Hermann 95, 137, 159, 293, 321, 408, 507

Hettrich, Philipp 491

Heubl, Franz 79f., 99 f., 109, 158, 339, 351, 407, 488, 491, 508

Heydte, Friedrich Freiherr von der 322

Hille, Arnold 184
Hindenburg und Beneckendorff, Paul von 111,324

Hipp, Otto 51

Hirschenauer, Benedikt 491

Hirschfeld, Richard 295

Hitler, Adolf 31, 35f., 80, 91, 107, 169, 176, 181

Höcherl, Hermann $388,427,493,495$

Hoegner, Wilhelm 4, 21, 31, 50f., 53, 59, 92, 96, 108, $121 \mathrm{f} ., 131 \mathrm{ff} ., 137,141 \mathrm{ff} ., 150,173$, $176,179 f$., 184 f., 188 f., 203, 215, 230, 346, $371,376,410,481 \mathrm{f} ., 485$

Höhenberger, Fritz 350, 488

Hofmann, Engelbert 491

Hofmann, Siegfried 421

Horlacher, Michael 25f., 52, 58, 61, 63, 72, $80,84,91 \mathrm{ff}$., 95, $101 \mathrm{f} ., 105 \mathrm{f} ., 108-112,123$, $125 \mathrm{f} ., 132 \mathrm{f} ., 135 \mathrm{f} ., 138,140,142 \mathrm{f} ., 145$, $150-159,163,167 \mathrm{f} ., 172,175 \mathrm{ff} ., 179,181 \mathrm{ff}$. , $187 \mathrm{f} ., 190,194,196,200,204,206,208 f$, $212 \mathrm{f} ., 215 \mathrm{ff} ., 224,277,283,287,291,299$, $305,314-317,319,322-326,329,350,352 \mathrm{ff}$., 369, 382, 389f., 402, 487, 490f., 493, 495

Hort, Sepp 220, 244

Huber (Delegierter) 6, 432, 480

Huber, Ludwig 310, 316, 322, 338

Huber, Sebastian 93, 491

Hundhammer, Alois 2f., 27, $31 \mathrm{ff} ., 36 \mathrm{f}$., $42 \mathrm{f}$., $61,69,72,75,79 f ., 84,91 \mathrm{ff} ., 95,98,100 \mathrm{f}$., 103, 105-108, 110, $114 \mathrm{ff} ., 121 \mathrm{f} ., 124-127$, $131 \mathrm{f} ., 134,137,139,143 \mathrm{f} ., 146,148,150 \mathrm{ff} .$, 154-157, 159, 165, 167f., 170ff., 175-192, 195-203, 206, 208-213, 215-221, 223, 225, $227 \mathrm{ff} ., 242,256,259,271,273-276,281,283$, 285, 287f., 292-301, 303-308, 310-313, 315f., 318-322, 325-329, 332, 334-339, $344 \mathrm{f} ., 347 \mathrm{f}$., $350,354 \mathrm{f} ., 367-370,372-381,399-402$, 404413, 415f., 422, 425, 434, 440, 443, 449 f., 454, $456,469,476-483,487 \mathrm{ff} ., 491,504,507,510$

Huth, Fritz 146, 167, 491

Imhoff, Sebastian 244

Imler, Hans 126, 143

Jaeger, Hans 78

Jaeger, Richard 22, 24, 30, 36f., $44 \mathrm{ff}$., $48 \mathrm{f}$., $65,80 f ., 100,131,239,352,356,390,392$, $396,402,479,494 \mathrm{f}$.

Jaumann, Anton $483 \mathrm{f}$.

Jörg, Josef 124

Jüngling, Max Josef 491

Junker, Heinrich $372,433,489,491$

Kaack, Heino $81 \mathrm{f}$.

Kahn, Karl 278, 347f., 495

Kahr, Gustav Ritter von 130 
Kaifer, Albert $32 \mathrm{ff} ., 109,155,178,488,491$

Kaiser, Fritz 82

Kaiser, Jakob 97, 116f., 173, 189, 241, 343

Kalbskopf, Otto 297, 305

Karl, Hans 491

Karpf, Hugo $32 \mathrm{f}$., 72, 83, 146, 152, 353, 355, 382, 386, 495

Keating, Frank A. 173

Kemmer, Emil 13, 352, 402, 463, $495 \mathrm{f}$.

Kerber, Ferdinand 491

Keynes, John M. 47

Kienitz, Erwin von $56 \mathrm{f}$.

Kihn, Karl Alfred 388, 495

Kimpfler, Franziska 54

Kirchheimer, Otto 500

Klausner, Wolfgang 495

Kleindinst, Josef Ferdinand 355, 495

Kleinmann, Hans-Otto 10, 116

Klenk, Wilhelm 86

Klughammer, Alois 444

Knilling, Eugen von 133

Knoeringen, Waldemar von $215,374,376,481$

Koch, Heinrich 422

Kock, Peter Jakob 503, 512

Köhler, Karl 43, 51, 181, 210f., 281, 315-318, 328,410

Koenig, Joseph 194

Konrad, Adolf $14,83,150,191,350,353$

Konstantin, Prinz von Bayern 496

Kramel, Angelo 495

Krapp, Lorenz 13, 126, 132

Kraus, Engelbert 377, 491

Kraus, Hans 122, 157, 298

Krehle, Heinrich $32,52 \mathrm{f} ., 55,57,82 \mathrm{f} ., 122$, $125 \mathrm{f} ., 146,152,168,179,189,220,377 \mathrm{f}$., $487 f ., 491$

Krempl, Josef $\quad 34,124,272,299,491$

Kreußel, Alfons $417,421 \mathrm{f}$., 425 f., $429 f$., 487

Kroll, Gerhard 12f., 36, 45-48, 90, 103, 115 ff., 127, 164, 188-192, 194, 196, 207, 213, $219,289,293,302,328$ f., 413, 488, 491

Krone, Heinrich $115,385,393 \mathrm{f}$.

Kronthaler, Josef $188 \mathrm{f}$.

Kroth, Karl August 178, 491

Kuchtner, Edeltraud 495

Kübler, Konrad $73,76,89,126,189,217,240$, 275, 298, 305, 442, 488, 491

Kühnel, Franz 421

Küßwetter, Hans 421, 423, 430, 488

Kunze, Anton 251

Kurz, Andreas 340, 372, 489, 491

Lacherbauer, Carl $152,171,194,196,208$, 213,491

Laforet (Sohn von Wilhelm Laforet) 178

Laforet, Wilhelm $354 \mathrm{f}$., 491, 495
Lang, Andreas 156, 489, 491

Lang, Georg 495

Lang-Brumann, Thusnelda 471

Lange, Max Gustav 497

Lau, Johannes 491

Lechmann, Heinz 487

Lehmer, Max 491

Lehr, Robert 383, 390

Lenz, Karl 472, 491

Lermer, Josef 495

Leukert, Edmund 495

Lex, Hans Ritter von 38, 43, 137, 387, 482

Liedig, Franz $31,34,37,85,149,172,192$, $242,244-247,253,260$ ff., 269, 289, 410, 487

Linnert, Fritz 144, $182 \mathrm{f}$.

Litchfield, Edward 181

Loibl, Martin 495

Loritz, Alfred 169, 184ff., 188f., 211, 230 , $361 \mathrm{ff}$.

Ludwig II., König von Bayern 22

Lücker, Hans August 495

Lutz, Hermann 491

Maag, Johann 143

Mack, Georg 86, 409, 491

Maderer, Andreas 95, 491

Maier, Anton 126, 382, 388, 491

Maier, Eduard 373

Maier, Reinhold $199 \mathrm{f}$.

Mannheim, Karl 77

Manteuffel-Szoege, Baron Georg von 349, 351 f., 417, 420, 495

Marx, Wilhelm 111, 324

Mau, Hermann 509

Mauerer, Josef 270

Mayer, Gabriel 491

Mayr, Karl Sigmund $76,90,146,158,189$, 254, 289, 306f., 309, 312, 321 f., 335, 350, $354 \mathrm{f} ., 364,366,383,406,412,414,416 \mathrm{f}$., $420 \mathrm{f}$, 424, 426, 429f., 470, 472, $487 \mathrm{f}$.

McNarney, Joseph T. 175

Mehringer, Hartmut 137, 185, 214

Meinzolt, Hans 122

Meiser, Hans 76, $414 f$ f, $419 f$., 425

Meixner, Georg 13, 28, 162, 228, 274, 300f., $376,401 \mathrm{ff} ., 407,409,412,424,437,463$, 480-483, 487, 489, 491, 504, 507

Melchner, August 491

Menzel, Hans 180

Messmer, Josef E. 33, 97, 184

Meyer, Philipp $495 \mathrm{f}$.

Meyer-Gmunden (CSU-Landesgeschäftsstelle) 244

Meyer-Spreckels, Elisabeth $76,146,152$, $158 \mathrm{f}$., 202, 335, 345, 350, 355, $411 \mathrm{f}$., $414 \mathrm{f}$., 431,487 
Michel, Franz 489, 491

Miller, Adolf 99, 231, 236, 240, 286f., 340

Miller, Anton 495

Miller, Walther von 52,61

Mintzel, Alf $66,69,74,83,91,94,104,110$, $115,158 \mathrm{f} ., 250,408,453 \mathrm{f} ., 456,466 \mathrm{f}$, 497-501, 504, 506, 509, 514

Möckl, Karl 483, 498

Morsey, Rudolf 497, 507

Müchler, Günter 342, 382, 502

Müller, Christa 513

Müller, Gebhard 369

Müller, Hans 122

Müller, Josef $2 \mathrm{ff} ., 6,12,16,24-28,30 \mathrm{ff}$., $34,36 \mathrm{f}$., 40-45, 50-55, 57-63, 66, 69f., $72-75,77,79 f ., 85,87-107,109-127$, 131 f., 135-141, 146-155, 158-161, 163, 165-188, 190-193, 195-201, 203-221, $223 \mathrm{ff}$., 227-231, 233, 235, 237ff., 241-244, 246, 251, 255, 257, 259-263, 269-293, 295-317, 319-329, 333-339, 341, 345 ff., 350f., 354, $362,364 f ., 367,369,373,375,377$ f., $380 f$., 388, 394, 399, 403-412, 414, 431 f., 437, 439 f., 442-447, 450, 452, 455, 460, 472, 476-483, $487 \mathrm{f}$., 491, $498 \mathrm{f}$., 501, 507, 509f., $512 \mathrm{f}$.

Muhler, Emil 31, 52f., 85, 153, 156-159, 162, $210,345,349,366,431 \mathrm{f} ., 487$

Muller, Walter J. $171 \mathrm{f}$.

Murphy, Robert D. 98, 173

Nagengast, Wilhelm 491

Napoleon I., Kaiser der Franzosen 18

Narr, Wolf-Dieter 500

Nawiasky, Hans 133,141

Nentwig, Georg 37, 244

Nerreter, Paul 37f., 46, 188, 308, 314, $377 \mathrm{f}$., 415, 421 f., 430

Neumann, Ferdinand 337,491

Neumann, Robert G. 102

Neumann, Sigmund 499

Nickl, Christ of 495

Niederalt, Alois 495

Niekisch, Ernst 36

Nientimp, Hans 31

Niklas, Wilhelm 122, 387, 495, 511

Nirschl, Josef 491

Nuber, Willy 341

Nüssel, Adam 145, 492

Oesterle, Josef $353,494 \mathrm{f}$.

Ohrenstein, Aaron 408

Op den Orth, Franz $144 \mathrm{f}$.

Ortloph, Klement 488,492

Oster, Hans 95

Ostwald, Bernhard 302
Ott, Anton 81

Ott, Franz 363

Panholzer, Josef 99

Papen, Franz von 204

Papstmann, Hans 492

Pfeiffer, Anton 24, 27, 32, 45, 51, 53-58, 60, $71 \mathrm{f} ., 80,82,91,110,120 \mathrm{ff} ., 125 \mathrm{f}$., 133,146 , $152,166,168,172,176,178 \mathrm{ff} ., 184 \mathrm{ff} ., 203$, 206 ff., 212 f., 220, 223, 225 f., 310, 344, 349, 353 ff., $381,383,437,492,507,514$

Pferdmenges, Robert 434

Pfeuffer, Adolf 138

Pflaum, Richard 75, 246

Pfleger, Franz $125 \mathrm{f}$.

Pflüger, Hans 33

Pflüger, Heinrich 33,158

Piechl, Josef 73, 84, 153, 217, 228, 492

Pirkl, Fritz 438

Pittroff, Claus 189

Pix, Georg 102, 105

Plöhn, Jürgen 180

Plonner, Josef 101, 158

Pösl, Johann 492

Prechtl, Wolfgang 85, 162, 492

Prittwitz und Gaffron, Friedrich Wilhelm von $34,43,52,73,134,146,203,208,307,354$, 372 f., 407, 412, 489, 492, 510

Probst, Alfred 34

Probst, Maria $33 \mathrm{f}$., 153, $155 \mathrm{ff} ., 192,196,244$, 350, 354, 489f., 492, 495

Proebst, Hermann 240

Prüschenk, Josef 37, 492

Rätsch, Birgit 36

Ramelsberger, Ludwig 492

Rattenhuber, Ernst 300, 355

Reese, Robert A. $50 \mathrm{f}$.

Reitinger, Josef 275

Renner, Michael 421

Repgen, Konrad 24

Reuter, Christiane 53, 178, 384, 507

Riedel, Georg $143,146,422$

Riederer von Paar zu Schönau, Max Freiherr 495

Rief, Max 125

Riehl-Heyse, Herbert 1

Rindt, Eugen 45, 90, $114 \mathrm{f} ., 143,147$, 153-157, 179, 182f., 190-193, $196 \mathrm{ff} ., 289$, $322,410,412,488$ f., 492

Ringelmann, Richard 377 f., 387

Rinke, Walter $164,211,349,495$

Riß, Josef 492

Röhrl, Wilhelm 340

Roßhaupter, Albert $143 \mathrm{f}$.

Rothermel, Fridolin 26, 72, 84 
Rucker, Eugen 488

Rupprecht, bayerischer Kronprinz 318

Sackmann, Franz 3, 316, 403, 438f., 465, 474

Salzmann, Rainer 503

Sauer, Franz Ludwig 84, 151, 155, 189, 290 , 488,492

Schachtner, Richard 243 f., 249 f., $252 \mathrm{f}$., $256 \mathrm{ff} ., 269,345,467,469,487$

Schäfer, Franz 83, 220, 492

Schäfer, Karl $\quad 416,423,488$

Schäffer, Fritz 3,11, 39 ff., $49 \mathrm{ff} ., 54-62,69$, $71 \mathrm{f}$., 75, 79f., 91, 93, 95, 97 f., 101-106, 108, $110,112,118,121,130,172,219-223$, 225-228, 230, 240, 281, 283f., 288, 290 , $293 \mathrm{f} ., 300,307,310,313,316,319,332,344$, $347,353,355$ f., 368 ff., 372 f., 376f., 380-388, 390, 393 f., 396-400, 427, 434, 437-441, 455, 462 f., 471,477 ff., 482, 488, 494 f., 498, 507, 510

Scharf, Josef 492

Scharnagl, Karl 41, 52 ff., 56 ff., 71 f., 112, 117, $121,131,134$ ff., 142,170

Schatz, Josef 386,495

Schedl, Otto $3,16,37,44,80,86,90,244$, $247,255,260,347 \mathrm{f}$., 371,492

Schefbeck, Otto $133,135,492$

Schieder, Julius 426

Schießl, Rudolf $441 \mathrm{f}$.

Schilling, Heinrich 83

Schlange-Schöningen, Hans 206, 230, $286 \mathrm{f}$.

Schleip, Eva 350, 487

Schleip, Josef 350

Schlögl, Alois 26, 31, 55, 57, 72, 80, 84, $91 \mathrm{ff}$., $106,121,123,125,151 \mathrm{f} ., 157,163,170 \mathrm{f}$., $182,194,200,204,206 f ., 213,218,283,287$, $315,322,377 \mathrm{f} ., 398,425,492$

Schlör, Kaspar 322

Schmid, Andreas 492

Schmid, Karl 155 f., 228, 313, 489, 492

Schmidramsl, Hanns Martin 492

Schmidt, August Wilhelm 37, 42, 44, 85, 473, 487

Schmidt, Eduard 123

Schmitt, Franz August 207

Schnurr, Max 57, $146 \mathrm{f}$.

Schöner, Franz 291, 492

Schönhoven, Klaus 128

Schönwiese, Alexander 255, 443

Schraml, Josef 492

Schrepfer, Hilde 498

Schubert, Karl 492

Schuberth, Hans $387,429,495,511$

Schütz, Hans 164, 349, 355, 474, $494 \mathrm{f}$.

Schumacher, Kurt 96, 346

Schuman, Robert 432
Schuster, Georg 492

Schwägerl, Hans $345,405,472,492$

Schwalber, Josef $86,155,160,307,318 f$., $377 f$., 412, 469, 492

Schwarz, Hans-Peter 485

Schwarzer, Rudolf 58

Schweiger, Andreas 84

Schwend, Karl 2, 317, 392, 418f., 424, 435, $437 f$., 514

Schwering, Leo 10

Schwingenstein, August 92f., 176, $492 \mathrm{f}$.

Schwink (CSU-Landesgeschäftsstelle) 244

Schwinn, Wilhelm Martin 425

Sedlmayr, Lorenz $32,83,114,125$ f., 135 , 152 f., 158 f., 163, 186, 193, 295 f., 487

Seeling, Otto 473

Seidel, Hanns $\quad 6,90,115,134,208,210,217$, $292,307,310,322,324,329,349,353 \mathrm{f}$. $377 \mathrm{f} ., 409,438 \mathrm{f} ., 455,482 \mathrm{ff}$., $492,508,511$, 513

Seidl, Franz 495

Seifried, Josef 143

Seiler, Heinrich $349 \mathrm{f} ., 353$

Semler, Johannes $57,76,115,121,127,146$, 158, 192, 205 f., 307, 350, 355, 412, 415, 420, 496

Senfft, Heinrich 503

Sevenich, Maria 98

Solleder, Max 383, 386f., 389f., 494, 496

Spies, Josef 496

Spörl, Max 496

Spreti, Karl Graf 349,496

Stadelmayer, Franz Xaver 53

Stammer, Otto 5, 499

Stang, Georg $168,179,437,449,490,492$

Staudinger, Karl 16

Steber, Franz 31 f., 158

Steffan (Direktor) 472

Stegerer, Wilhelm 492

Stegerwald, Adam 10-13, $45 \mathrm{f}$., 50, $52 \mathrm{ff}$., $59 \mathrm{f}$., $116,290,381,492$

Stegerwald, Wilhelm 492

Sterzer, Michael 492

Stiller, Georg 423, 496

Stinglwagner, Alois 492

Storch, Anton 343

Strathmann, Hermann 73, 75f., 85, $161 \mathrm{f}$., $178,187,200$ ff., 412 f., 430,492

Strauß, Franz Josef $1 \mathrm{ff} ., 27,52,80 \mathrm{f}$., 90 , $103,107,153,158$ f., 165-168, 179, 184, 199, $204,250,263,277,292,312,315,322,328$, $341 \mathrm{f}$., $344 \mathrm{f}$., 350 , $352 \mathrm{f}$., $355 \mathrm{f}$., $366,369 \mathrm{f}$., $373,377,381$ f., 384-396, 399, 401-404, 407, $409,427,433,438$ f., $444 f$., 459,462 f., 469 , 471 f., 479, 482 f., 487, 494, 496, 501, 508, $511 \mathrm{f},, 514$ 
Streibl, Max 1

Streimer 57

Strenkert, Paul 83, 492

Strobel, Fritz 493

Stücklen, Georg 143, 182, 493

Stücklen, Richard 80,351 f., 427, 480, 494, 496

Stürmann, Josef $33,276,280 f$ f, 337 f., 366, 493

Sturm, Joseph 353

Sühler, Adam $84,126,145,155 \mathrm{ff} ., 192,415$, 489, 493

Sylvester, Papst 107

Thaler, Rupert 167, 493

Thanbichler, Johann 493

Thierfelder, Franz 146

Thoma, Ludwig 317

Thränhardt, Dietrich 499

Tillmanns, Robert 420

Tilly, Johann Tserclaes Graf von 52

Tjulpanow, Sergej 97

Tremmel, Andreas $37 \mathrm{f}$.

Trepte, Hans 493

Trettenbach, Martin 493

Unertl, Franz Xaver $\quad 402,496$

Vidal, Konstantin 493

Vogt, Karl-Heinz 297

Voretzsch, Ernst-Arthur 79

Vorhees, Melvin B. 40

Vossen, Regina 503

Wacher, Gerhard $349-352,402,435,479,494$, 496

Waldburg zu Zeil, Fürst Erich $272 \mathrm{f}$.

Weber, Arnold 467

Weber, Max 3

Wehler, Hans-Ulrich 506
Weigel, Wenzel $371 \mathrm{f} ., 489,493$

Weiglein, Otto 493

Weinkamm, Otto 189, 448-451, 493

Weinzierl, Alois 161,493

Weinzierl, Georg 83, 493

Weismantel, Leo 210

Weiß, Hans 3, 80

Weixler, Franz Peter 318

Wengst, Udo 343

Wiedemann, Ernst 277

Wilhelm II., deutscher Kaiser 79

Wilkinson, James R. 184

Winkler, Martin 493

Winter, Friedrich 496

Wittmann, Franz 496

Wittmann, Franziska 39

Wittmann, Julian 143, 491, 493

Witzgall, Gottfried 294

Witzlinger, Michael 493

Wölfel, Gustav 493

Wösner, Hermann 463

Wohlmuth, Georg 437

Woller, Hans $\quad 64,86,97,169,501,505,509$

Wutzlhofer, Hans 202, 416, 442, 493

Zarusky, Jürgen 96

Zehner, Zita 372, 489, 493

Zeiß, Carl 47

Zeisslein, Anton 490, 493

Ziebell, Jürgen 180

Ziegler, Franz 491, 493

Zillibiller, Max 157, 373, 489, 493

Zimmermann, Friedrich 3, 6, 403, 408, 439, $455,461,465,483,508,511$

Zirkelbach, Julius 412,420

Zitzler, Georg 493

Zorn, Rudolf 195

Zott, Josef 21, $33 \mathrm{f}$., 37

Zwicknagl, Max 125, 146, 177, 193, 208, 493 


\section{Ortsregister}

Aachen 40

Abensberg 458

Aichach 457

Altötting 21, 45, 47, 234, 359, 457, 494

Alzenau 71, 464

Amberg 359, 386, 459, $494 \mathrm{f}$.

Amöneburg 290

Ansbach 18, 86, 235, 349f., 356, 359, $420 \mathrm{ff}$., 463, 494

Aschaffenburg 33, 290, 353, 359, 464, 495

Aschau 373

Augsburg 39, 45, 82, 89, 126, 147, 153, 157, $183,188,190-193,204,243,275,278,280$, $315,353,359,411,436,448,450,456,460$, $462,464,465,468,488,495$

Bad Aibling 94, 234, 457

Bad Brückenau 461, 464

Bad Kissingen 314, 359, 464, 494

Bad Neustadt 464

Bad Reichenhall 94, 368, 397, 457

Bad Tölz 457

Bamberg 9f., 12f., 16, 22, 46, 89, 94, 97, 104, $112,162,235,243,274,288,300,302,328$,

356, 359, 401, 421, 443, 460, 462f., 495, 507

Bayreuth 18, 67, 153, 356, 359, 416, 460

Beilngries 459

Berchtesgaden 94, 457

Berlin 12, 16, 25, 52f., 55, 113, $115 f ., 134$, 172f., 175, 209, 318, 359, 362, 421, 437

Bogen 458

Bonn 5f., 255, 289, 294f., 306, 318, $320 \mathrm{ff}$., 325 f., 346, 348, 352, 354f., 363, 366-369, 372 f., 381-384, 387 ff., 391 ff., 395 f., $398-401,403$ f., 412, 417, 424, 435 ff., 449 , 470 f., 474, 479, 484, 500, 502, 510f., 513

Bremen 359, 362

Brennberg 427

Breslau 12, 164

Burglengenfeld $348,359,459,495$

Cham 359, 459, 495

Coburg 67f., 356, 359, 460

Dachau 31, 33, 234, 272, 318, 433, 457

Deggendorf 235, 359, 458, 494

Dillingen $359,462,495$

Dingolfing $278,378,458$

Dinkelsbühl 256, 314, 417, 421, 458, 463

Donauwörth $359,462,495$

Düsseldorf 147, $341 \mathrm{ff}$., 383

\author{
Ebermannstadt 460 \\ Ebern 464 \\ Ebersberg 234, 371, 457 \\ Eggenfelden 458 \\ Ehingen 421 \\ Eichstätt 177, 188, 204f., 210f., 215, 229, 438, \\ 463
}

Erding 234, 457

Erlangen 75, 85, 178, $201 \mathrm{f} ., 275,350,353$, $356,359,416 f ., 434,463,494$

Eschenbach 291, 459

Eßlingen 363

Feuchtwangen 463

Forchheim 82, 255, 258, 280, 289, 292, 356, $359,460,495$

Frankfurt am Main 12, 59, 116, 199, $205 \mathrm{ff}$., 209, 214 f., 217, 227, 230, 232, 263, 283, 286, 288, 290f., 322, 342, 355, 381 f., 394, 503, 509

Freising 251, 457

Friedberg 462

Fürstenfeldbruck 234, 359, 457, 495

Fürth 76, 86, 146, 150, $210 \mathrm{ff} ., 224 \mathrm{f}$., 243, 315, 349,355 f., 411,414 f., 423,460 f., 463 ff., 468 , $488,494,496$

Füssen 462

Garmisch-Partenkirchen 94, 225, 234, 457

Gauting $315 \mathrm{ff}$., 319, 328, 410

Gemünden 464

Gerolzhofen 350, 464

Grafenau 458

Griesbach 458

Günzburg 462

Gunzenhausen 146,463

Hamburg $164,206,359,362,371$

Hammelburg 124, 350, 464

Hannover 214, 346

Haßfurt 464

Heidelberg 343

Hersbruck 67, 463

Hilpoltstein 250, 463

Hindelang 373

Höchstadt an der Aisch 460

Hof 22, 45, 47, 67f., 85, 153, 349f., 352, 356, 359,460 f., 496

Hofheim 461, 464

Hohenheim 350 
Illertissen 462

Ingolstadt $72,303,359,457,461,494$

Kapfing $\quad 349$

Karlshorst 97, 227

Karlstadt 359, 464, 495

Kaufbeuren 359, 462, $495 \mathrm{f}$.

Kelheim 458

Kemnath 459

Kempten $83,349,359,365 f$., 368, 387, 449, 462,496

Kirchheim 391 f., 396

Kitzingen 461, 464

Koblenz 283

Köln 10, 12, 116, 377, 413

Königshofen im Grabfeld 464

Königstein 196

Königswinter 290

Kötzting 458

Kristiania 79

Kronach 460

Krumbach 250, 462

Kulmbach $356,359,412,460 f ., 496$

Landau $\quad 275,458$

Landsberg $457,494 \mathrm{ff}$.

Landshut $31,33,102,359,402,430,433,458$, 495

Lauf 67,463

Laufen 457

Leipzig 417

Lichtenfels 460

Lindau 462

Lissabon 79

Lohr am Main 464

London 240

Magdeburg $\quad 148$
Mainburg 458
Mallersdorf $\quad 458$

Marktheidenfeld 29, 45, 464

Marktoberdorf 462

Marktredwitz 219, 224, 296, 405, 449, 460

Mellrichstadt 464

Memmingen 359, 462, 472, $494 \mathrm{f}$.

Metten 472

Miesbach $359,457,494$

Miltenberg 464

Mindelheim 280, 462

Moorenweis 14

Moskau 20

Mühldorf 234, 457

Münchberg 67, 460

München $5 \mathrm{f}$., 10, $16 \mathrm{f}$., 21, $23 \mathrm{f}$., 27, $31 \mathrm{f}$., 34 , $38,40 f ., 45$ f., 49 f., 52 ff., $56,58-65,70,75 f$., $79,83,85,93,95,98$ f., 102, 104 ff., 109, 111,
$121 \mathrm{f} ., 124,132,149,151,162,167,181,183$, $189,199,203,210,214,216,220,223$, 229-232, 234 f., 241, 243, 246, 255 f., 259, 263 , 274, 277, 280, 282, 287, 293, $295 \mathrm{ff}$., 299, 303, 305, 310, $313 \mathrm{f} ., 319,324,326,339 \mathrm{f} ., 344$, 350 f., 353, 355 f., 359, 369, 371, 373, 380, $382 \mathrm{f} ., 389,394 \mathrm{ff} ., 398,402,407 \mathrm{f}$., 413, 417 , $421,432 \mathrm{ff} ., 437,440,445 \mathrm{f}$., $456 \mathrm{ff}$., $464 \mathrm{f}$., 468 , $470,472,479,484,488,494$ ff., 500, 508, 513

Nabburg 291, 459

Naila 67,460

Neuburg an der Donau 462

Neu-Ulm 250, 462

Neumarkt 459

Neunburg vorm Wald 459

Neuses am Sand 350

Neustadt bei Coburg 460

Neustadt an der Aisch 67f., 422, 463

Neustadt an der Waldnaab 459

Nördlingen $422,461 \mathrm{f}$.

Nürnberg 9f., 13-16, 22, 38, 45, 47f., 76, 150, 210, 224f., 235, 243, 279, 306f., 315, 336, 338,349 f., 356, 359, 415, 417f., 423, 426, 460 f., $463 \mathrm{ff}$., $468,470,488,496$

Obernburg 297, 464

Oberviechtach 459

Ochsenfurt 424 ff., 429,464

Paris 108

Parsberg 459

Passau 195, 347, 353, 359, 368, 377, 458, $462 \mathrm{f} ., 495 \mathrm{f} ., 507$

Pegnitz 67f., 460

Penzberg 343

Peißenberg 343

Pfaffenhofen 234, 457

Pfarrkirchen $359,458,495$

Potsdam 50

Prag 349, 371

Prien am Chiemsee 373

Regen 458

Regensburg 9f., $15 \mathrm{ff} ., 21,33,135,166,225$, 243,290 f., $359,379,383,386,417$ f., 427 , $432,439,448,452,458 f$., 466, 472, $495 \mathrm{f}$.

Rehau 67, 302, 460

Rhöndorf 197, 369

Riedenburg 459, 465

Roding 459

Rosenheim 41, 101, 234, 359, 457, 494

Roth 496

Rothenburg ob der Tauber 52, 209, 463

Rottenburg an der Laaber $21,29,45,85,162$, 458 
Scheinfeld $67 \mathrm{f} ., 463$

Schierling 383

Schongau 90, 94, 165, 234, 250, 263, 389, 457, $462 \mathrm{f}$.

Schrobenhausen 457

Schwabach $350,356,359,463,495$

Schwabmünchen 462

Schwandorf 34, 272, 299, 459

Schweinfurt $350,354,359,464,494$

Selb 67,460

Sonthofen 373, 462

Stadtsteinach 460

Staffelstein 460

Starnberg 234, 435, 457

Steinhöring 371

Straubing 6, 37, 243, 286, 309, 311f., 321, $328,331 \mathrm{f}$., 334-338, 359, 364, 379, $404 \mathrm{ff}$., $411,440,445,447$ f., 450, 458, 463, 478, 495

Sulzbach-Rosenberg 459,465

Tirschenreuth $359,388,459,494$

Tokio 79

Traunstein 33, 234 f., 359, 457, 495

Tschentschitz 371

Tuntenhausen 399

Tunzenberg 377

Uffenheim $\quad 67 \mathrm{f}$., 86,463
Viechtach $40,42,458$

Vilsbiburg 277, 458

Vilshofen $359,416,458,496$

Vohenstrauß 459

Waldmünchen 459

Washington 184

Wasserburg 146, 234, 457

Wegscheid 292, 363, 458

Weiden 125, 291, 459

Weilheim 352, 359, 457, 496

Weimar 2, 9, 11 ff., 16, 20, 36, 48, 51, 55, 67, $72,79 f ., 82,92,96,100,103 \mathrm{f} ., 111,128$, 132 f., 137,160 f., $274,323,351,400,418$, 476

Weißenburg 351, 356, 359, 463, 496

Wenzenbach 16

Wertheim 434

Wertingen 462

Westheim 146

Wien $18,108,349$

Wolfratshausen 234, 457

Wolfstein 458

Würzburg 9-13, 16, 32, 40, 42, 45f., 48, 53, 116,203 f., 243, 290, 323, 359, 405, 425, 464, 472, 495

Wunsiedel 460 